KLEBER IGUCHI

DESENVOLVIMENTO DE UM ALGORITMO HÍBRIDO DE FOTOMETRIA ESTELAR A PARTIR DE IMAGENS DO ESPAÇO 
KLEBER IGUCHI

\section{DESENVOLVIMENTO DE UM ALGORITMO HÍBRIDO DE FOTOMETRIA ESTELAR A PARTIR DE IMAGENS DO ESPAÇO}

Dissertação apresentada à Escola Politécnica da Universidade de São Paulo para obtenção do título de Mestre em Engenharia.

Área de Concentração:

Engenharia Eletrônica - Sistemas Eletrônicos

Orientador:

Prof. Dr. Hae Yong Kim 
Este exemplar foi revisado e alterado em relação à versão original, sob responsabilidade única do autor e com a anuência de seu orientador.

São Paulo, 20 de dezembro de 2010.

Assinatura do autor

Assinatura do orientador

\section{FICHA CATALOGRÁFICA}

Iguchi, Kleber

Desenvolvimento de um algoritmo híbrido de fotometria estelar a partir de imagens do espaço / K. Iguchi. -- ed.rev. --São Paulo, 2010.

$123 \mathrm{p}$.

Dissertação (Mestrado) - Escola Politécnica da Universidade de São Paulo. Departamento de Engenharia de Sistemas Eletrônicos.

1. Astronomia 2. Processamento digital de imagens 3. Telescópios I.Universidade de São Paulo. Escola Politécnica. Deparamento de Engenharia de Sistemas Eletrônicos II. t. 
A Hazime e Yoshiro Tanaka, e a Namie e Yoshimi Iguchi, meu avós - cujos valores e ensinamentos foram transmitidos a meus pais e são a base estrutural de minha família.

(in memoriam) 


\section{AGRADECIMENTOS}

Agradeço à minha mãe, Izolina, e ao meu pai, Eduardo, pela criação e pela educação que me deram, pela liberdade de escolha que me ofereceram, pela confiança em mim depositada e por estarem sempre ativamente presentes em todas as etapas de minha vida.

Agradeço aos amigos mais próximos, e especialmente aos meus irmãos, Daniel e Larissa, e à minha namorada, Luana, pelos momentos de descontração, por sua amizade e enorme paciência, e por acreditarem na minha capacidade de seguir adiante.

Agradeço, particularmente, ao Prof. Dr. Hae Yong Kim da Escola Politécnica da USP (EP-USP) pelo constante incentivo e pela orientação, sem os quais este trabalho não existiria. Agradeço também ao Prof. Dr. Eduardo Janot-Pacheco do Instituto de Astronomia, Geofísica e Ciências Atmosféricas da USP (IAG-USP), presidente do Comitê CoRoT-Brasil, quem em parceria com o Prof. Dr. Hae Yong Kim formalizou e concedeu esta grande oportunidade de pesquisa na área de imageamento espacial.

Agradeço, também, ao Prof. Dr. Vanderlei Cunha Parro, ao Dr. Leonardo Pinheiro da Silva e ao Dr. Fabio Fialho, por suas enriquecedoras contribuições e por suas sugestões e opiniões importantíssimas para o andamento deste projeto.

Agradeço, finalmente, à Fundação de Amparo à Pesquisa do Estado de São Paulo (FAPESP) pela concessão parcial de bolsa de mestrado para a realização deste trabalho. 
felix qui potuit rerum cognoscere causas.

("Feliz aquele que pode perscrutar as causas das coisas")

Virgílio (Geórgicas, II, 489) 


\section{RESUMO}

CoRoT (Convection, Rotation and planetary Transits) é uma missão espacial liderada pela Agência Espacial Francesa (CNES) em associação com diversos parceiros internacionais, entre eles o Brasil. Seus objetivos principais são o estudo da sismologia estelar e a procura por planetas extra-solares (exoplanetas). Ambos os programas científicos baseiam-se em uma fotometria de altíssima precisão e requerem observações ininterruptas de longa duração, possíveis somente a partir do espaço.

Uma revisão da literatura indica a existência de três técnicas principais para a realização de fotometria estelar a partir de imagens capturadas em CCDs: fotometria por máscara (por abertura), por ajuste de limiar (por threshold), e por ajuste da resposta impulsiva do sistema de aquisição de imagens.

A fotometria por máscara, ou por abertura, apresenta maior precisão para o registro de estrelas brilhantes, em cenários de maior estabilidade de atitude do satélite (situação de baixo jitter), e é a solução adotada a bordo pelo satélite CoRoT, por ser um algoritmo determinístico. A fotometria por ajuste da resposta impulsiva, também chamada de função de espalhamento do ponto (point-spread function, PSF), por sua vez, por levar em conta a resposta do sistema a uma fonte pontual de luz, permite a restauração da imagem original através de processos de deconvolução; apresenta maior precisão para estrelas fracas, ou em um cenário degradado, com perturbações devidas a radiação externa (stray light), ou em que o jitter de atitude do satélite seja elevado. Tal robustez é uma característica desejada no processo de restauração de imagens. Já a fotometria por threshold é aplicada somente em casos de jitter muito elevado e pobre conhecimento da resposta impulsiva do sistema, de modo que não é utilizada no satélite CoRoT.

Este trabalho visa consolidar e potencializar a participação brasileira no projeto CoRoT e contribuir com os esforços associados à redução de dados da missão, através de uma proposta inovadora de fotometria híbrida, que se utilizará dos conhecimentos da PSF modelada do instrumento e da alta relação sinal/ruído alcançada com a fotometria por máscara realizada a bordo, baseada e fundamentada em resultados preliminares que atestam o potencial desta metodologia. Tal algoritmo permite um ganho substancial de precisão fotométrica em relação à técnica de abertura, resultando em uma melhor exploração dos dados disponíveis, dada a sua robustez em caso de degradação dos dados de entrada.

Palavras-chave: CoRoT, super-resolução, fotometria por PSF, fotometria híbrida 


\begin{abstract}
CoRoT (Convection, Rotation and planetary Transits) is a high precision photometry experience dedicated to stellar seismology and the search for extrasolar planets. The mission is led by the French Space Agency (CNES) in association with several French laboratories and international partners in Austria, Belgium, Germany, Spain and Brazil. Both scientific programs require great instrumental stability and long, uninterrupted observation runs, which take place simultaneously on adjacent regions of the sky.

An overview of the literature displays three main techniques to perform stellar photometry from space CCD images: aperture photometry, threshold photometry and PSF-fitting photometry.

Aperture photometry defines a mask which represents the CCD píxels to be summed up in the computation of the collected photon flux for a given star. This method presents very high precision for isolated, bright stars and for stable satellite attitude (low jitter scenarios). It is the data reduction technique implemented on-board, due both to link capacity constraints (given the large number of targets simultaneously observed by the instrument) and to its deterministic algorithm. Fitting photometry allows restoration of degraded stellar images through deconvolution processes, using the point spread function (PSF) of the optical instrument itself. This technique presents better performance for crowded fields and for faint stars; it also presents robustness in the presence of disturbances such as stray light or high satellite attitude jitter. Finally, threshold photometry takes into account only those píxels whose values are above a given pre-computed level. This method is used only in scenarios with excessive satellite depointing due to attitude jitter, or in cases where the instrumental PSF is poorly known. Therefore, it is not used in the CoRoT mission.

This work intends to consolidate and strengthen the Brazilian share in the CoRoT Project, contributing to the efforts associated to the ground-based reduction of scientific data, through an innovative, hybrid photometry technique, which will take advantage of a high-resolution instrumental PSF and of the high signal-to-noise-ratio obtained in the on-board aperture photometry. Studies here described show that this methodology, compared to the Aperture technique, achieves gains in photometric precision and in the operational duty cycle, enabling robust and accurate data exploitation.
\end{abstract}

Keywords: CoRoT, superresolution, PSF-fitting photometry, hybrid photometry 


\section{LISTA DE FIGURAS}

Figura 1. Representação de harmônicas esféricas de oscilação estelar ( $I=0$ a 4 e $\mathrm{m}=1$ a l) (Mosser, 2001).

Figura 2. Espectro de freqüência do Sol observado pela sonda GOLF/SOHO (ESA/NASA).

Figura 3. Efeito do trânsito planetário na curva de luz da estrela-hospedeira (CNES).

Figura 4. Imagem renderizada do instrumento CoRoT (CNES). .32

Figura 5: Imagem renderizada do telescópio afocal. (CNES) 33

Figura 6: Imagem renderizada da unidade óptica do satélite. (CNES) 34

Figura 7: Imagem renderizada da unidade de eletrônica embarcada. (CNES). 35

Figura 8. Diagrama ilustrando o caminho óptico desde a pupila de entrada até o plano focal. (Adaptado de Lapeyrere, 2006)..... 37

Figura 9. Montagem do plano focal do CoRoT. (CNES) 38

Figura 10. Esquema do bloco focal. (Lapeyrere, 2006) 38

Figura 11. Visão esquemática da eletrônica instrumental do CoRoT. (CNES) 39

Figura 12: CCDs E2V Technologies série 4280 posicionados no plano focal do telescópio. (CNES).

Figura 13. Curvas de luz ilustrando a geração de píxels brilhantes logo depois de um impacto de partículas carregadas, refletida na evolução de uma fotometria estelar (em cima) e de fundo de céu (embaixo). (Pinheiro da Silva, 2006).

Figura 14. O cinturão radiação de Van Allen e o ponto da Anomalia do Atlântico Sul (NASA). .48 
Figura 15: Intensidade do campo magnético terrestre no nível do mar (nT). Observase uma assimetria centrada na região do Atlântico Sul, devido ao deslocamento do eixo geomagnético em relação ao eixo de rotação da Terra (International Geomagnetic Reference, IGRF 2005).

Figura 16: Simulação da passagem do telescópio CoRoT sobre a superfície da Terra, ao longo de um período de 24h. (CNES/CLS. Script de rastreio de satélites: Robert Simpson, Cardiff University) 50

Figura 17: Simulação da passagem do telescópio CoRoT sobre a superfície da Terra, ao longo de um período de 24h. (Terrametrics / Google Earth. Script de rastreio de satélites: Robert Simpson, Cardiff University) 50

Figura 18. Uma PSF típica do canal de astrossismologia tal como projetada na superfície do CCD (em cima), capturada e sub-amostrada pelo CCD (no meio), e uma interpolação cúbica dos dados para efeitos de comparação (embaixo). À direita são ilustrados os perfis horizontais para a imagem projetada e interpolada. (Pinheiro da Silva, 2007) 56

Figura 19. Uma série de PSFs sub-amostradas capturadas na presença de jitter de atitude. Os deslocamentos das imagens em relação à matriz de píxels do CCD estão exagerados para melhor visualização. (Pinheiro da Silva, 2007) . 57

Figura 20. Efeito de borramento por movimento como função do tempo total de integração de captura do CCD. (Pinheiro da Silva, 2007).

Figura 21. Processo de aquisição instrumental do CoRoT sob efeito de jitter de atitude.

Figura 22. Distintas medições fotométricas causadas pela sub-amostragem e movimento relativo durante o intervalo de captura da imagem: (em cima) uma PSF contínua e definida gera um sinal fotométrico estável e de fácil interpretação astronômica, enquanto que (embaixo) uma PSF sub-amostrada, borrada, e deslocada gera um sinal fotométrico irregular, de difícil interpretação. (Pinheiro da Silva, 2007) 
Figura 23. Processo de aquisição de imagens por um instrumento genérico: o efeito borramento pode ser modelado pro um filtro linear, enquanto que o ruído associado à captura pode ter propriedades estatísticas conhecidas.

Figura 24. Um filtro gaussiano pode ser usado como aproximação do operador $h(m, n)$

Figura 25. Um filtro passa-baixas pode ser usado como aproximação para um borramento por movimento.

Figura 26. Da esquerda para a direita: PSF capturada pelo CCD, PSF reconstruída com precisão de $1 / 2$ píxel, PSF reconstruída com precisão de 1/4 de píxel e PSF modelada.

Figura 27. Seções vertical e horizontal das PSFs capturada (linha fina) e reconstruída (linha espessa) (1/4 de píxel). 79

Figura 28. Sinais fotométricos resultantes da utilização de distintas PSFs no processo de redução de dados. (Pinheiro da Silva, 2005) 80

Figura 29. O modelo de PSF com precisão de $1 / 4$ de píxel, obtido através de solução de problema inverso, é suficiente para a redução de dados fotométricos do telescópio CoRoT. (Pinheiro da Silva, 2005)

Figura 30. Representação esquemática de um algoritmo não-linear de reconstrução de PSF.

Figura 31. Relação SNR (S/N) plotada em função do raio de abertura da máscara para distintas fontes pontuais de luz. O gráfico mostra que as estrelas deste intervalo de magnitude visual aparente apresentam um máximo de SNR para um raio específico, relativamente pequeno. (Adaptado de Howell, 1989.) 85

Figura 32. Exemplos de imagens degradadas por impactos de partículas carregadas eletricamente durante a passagem do satélite pela região da Anomalia do Atlântico Sul. (Pinheiro da Silva, 2007) 
Figura 33. Comparação entre imagens de dados observados e os correspondentes modelos ajustados de PSF. Dois casos são ilustrados: (acima) sem a incidência de radiação e (abaixo) com a incidência de radiação. (Pinheiro da Silva, 2007) 91

Figura 34. Dez PSFs do campo Astrossismologia. Cada PSF apresenta uma aparência geométrica correspondente a uma posição no CCD e a uma temperatura estelar. 95

Figura 35. Simulação de Imagens Capturadas pelo CoRoT a partir de PSFs Zemax. 96

Figura 36. Simulação de Imagens Capturadas pelo CoRoT. À esq.: a PSF Zemax representa a função espalhamento de fonte pontual, contínua, projetada sobre o CCD do telescópio. Ao centro: a PSF é degradada por sub-amostragem do CCD, impactos de partículas ionizadas e ruídos associados. À dir.: função logarítmica aplicada à imagem central, apenas com caráter ilustrativo do efeito da degradação da PSF. .96

Figura 37. Redução de dados por fotometria por abertura. A partir das imagens simuladas, extrai-se a curva de luz pela somatória dos valores dos píxels internos à mascara ótima previamente calculada. É a metodologia adotada a bordo do CoRoT.

Figura 38. Redução de dados por fotometria por ajuste de PSF. A partir das imagens simuladas, extrai-se a curva de luz por ajuste de uma PSF empírica determinada pelo método de superresolução [24]. É a metodologia adotada pela equipe de solo do CoRoT para aumentar o ciclo de trabalho do satélite. .99

Figura 39. A fotometria híbrida leva em consideração a SNR, a incerteza estatística e os impactos por partículas carregadas. À esq.: imagem original de uma estrela capturada (simulada) pelo CoRoT. Ao centro: PSF empírica relativa a esta estrela. À dir.: imagem composta (híbrida) a partir da qual é extraída a curva de luz. 101

Figura 40. O algoritmo compõe uma seqüência de imagens híbridas, seqHYB, contendo os píxels de alto SNR (azul), baixa incerteza estatística e sem impactos (vermelhos), da qual posteriormente extrairá a curva de luz. 
Figura 41. Redução de dados por fotometria híbrida. A partir das imagens simuladas, extrai-se a curva de luz, unindo-se a precisão da abertura para imagens com alta SNR e a robustez do ajuste de PSF par imagens degradadas. 102

Figura 42. Definição da máscara de abertura ótima: a PSF empírica (esq.) de alta resolução (1/4 de píxel) é reamostrada (centro) para aplicação do algoritmo de extração da máscara ótima (dir.) 103

Figura 43. Topo: Curva de crescimento de SNR em função dos píxels incluídos na máscara. Em baixo: Ordem decrescente de intensidade (ADU) de luz em cada pixel da imagem capturada pelo CCD. Neste exemplo, são incluídos na máscara os 239 píxels com maior intensidade luminosa. 104

Figura 44. Simulação de uma fonte de luz pontual "estática", onde predominam efeitos de jitter de atitude, ruídos de Poisson e de leitura e impactos na zona da SAA. De cima para baixo: curvas de luz extraídas por fotometria por abertura, por ajuste de PSF e pelo algoritmo híbrido. O último painel mostra a comparação visual entre os métodos. 105

Figura 45. Simulação de uma estrela-alvo com atividade fotométrica, em que efeitos de jitter de atitude, ruídos de Poisson e de leitura e impactos na zona da SAA podem comprometer a qualidade da análise científica dos dados. De cima para baixo: curvas de luz extraídas por fotometria por abertura, por ajuste de PSF e pelo algoritmo híbrido. O último painel mostra a comparação visual entre os métodos. 107 


\section{LISTA DE SIGLAS E ABREVIATURAS}

ADU Analog to Digital Unit, unidade de conversão analógico-digital

AS AsteroSeismology, Canal de estudos de Astrossismologia do Telescópio CoRoT

BEP Boîtier d'Életronique de proximité, unidade de eletrônica de préamplificação

BEX Boîtier d'Extraction, unidade de extração de píxels

BCC Boîtier de Control Caméra, unidade de controle de câmera

CCD Coupled-Charge Device, Dispositivo de Carga Acoplada

CNES Centre National d'Études Spatiales, Centro Nacional de Estudos Espaciais da França

CoRoT Convection, Rotation and Planetary Transits

DPU Digital Process Unit, unidade de processamento digital

$e^{-}$Elétron

e-h Par elétron-lacuna

ESA European Space Agency, Agência Espacial Européia

IAG-USP Instituto de Astronomia e Astrofísica da USP

Mauá Instituto Mauá de Tecnologia

MJ Massas de Júpiter, a massa de um planeta em relação à de Júpiter

$M_{T}$ Massas da Terra, a massa de um planeta em relação à terrestre

NASA National Aeronautics and Space Agency, Agência Espacial NorteAmericana

PF Planet Finder, Canal de estudos de Exoplanetas do Telescópio CoRoT

POLI-USP Escola Politécnica da USP

ppm Parte por milhão

PROTEUS Plataforma Reconfigurável para Observação, Telecomunicações e Usos Científicos

PRNU Píxel Response Non-Uniformity, não-uniformidade de resposta de píxel

PSF Point Spread Function, função resposta impulsive

QE Quantic Efficiency, eficiência quântica

$R_{J}$ Raios de Júpiter, o raio de um planeta em relação ao de Júpiter

$R_{T}$ Raios da Terra, o raio de um planeta em relação ao terrestre 
SAA South Atlantic Anomaly, Anomalia Magnética do Atlântico Sul

USP Universidade de São Paulo

\section{LISTA DE SIGLAS E ABREVIATURAS PARA O ALGORITMO HÍBRIDO DE FOTOMETRIA ESTELAR}

seqJTN Seqüência de imagens simuladas de uma estrela, com efeitos de jitter de atitude e de ruídos de leitura e de Poisson.

seqJNI Seqüência de imagens simuladas de uma estrela, com efeitos de jitter de atitude e de ruídos de leitura e de Poisson e de impactos de partículas ionizadas.

seqDOL Seqüência de imagens binárias que acusam quais píxels devem ser considerados como espúrios (outliers).

seqLUP Seqüência de imagens binárias que acusam quais píxels devem ser considerados como de baixa incerteza estatística, mesmo que possuam SNRs individuais baixas.

seqREP Seqüência de imagens binárias que acusam quais píxels devem ser substituídos em cada imagem, para formar uma seqüência de imagens híbridas (seqHYB).

seqFIT Seqüência de imagens artificiais da estrela, ajustadas pela PSF da mesma. Leva em consideração a estrutura física do telescópio em sua formação.

seqHYB Seqüência de imagens híbridas, formadas parte por píxels da seqJNI (originais da imagem da estrela), e parte por píxels da imagem ajustada por PSF, através da seqüência de "máscaras" seqREP.

mskLC Curva de luz extraída da seqüência de imagens através de fotometria por abertura.

fitLC Curva de luz extraída da seqüência de imagens através de fotometria por ajuste de PSF.

thrLC Curva de luz extraída da seqüência de imagens através de fotometria por limiar (threshold).

hybLC Curva de luz extraída da seqüência de imagens através de fotometria híbrida. 


\section{LISTA DE SÍMBOLOS}

$H$ Operador linear contínuo e compacto

$X$ Espaço de objetos

$Y$ Espaço de imagens ruidosas

$Y$ ' Espaço de imagens sem ruído, contido em $Y$

$x$ Elemento pertencente ao espaço de objetos $X$

$y$ Elemento pertencente ao Espaço de Imagens $Y$,

$w$ Ruído associado ao processo de degradação da imagem, $y=H x+w$

$h(m, n)$ Filtro linear em um espaço bidimensional, é uma instanciação prática do operador compacto $H$

$x(m, n)$ Objeto bidimensional pertencente ao espaço de objetos $X$

$z(m, n)$ Imagem resultante da convolução entre $x(m, n)$ e $h(m, n)$, pertencente ao espaço $Y^{\prime}, z(m, n)=x(m, n) * h(m, n)$

$w(m, n)$ Ruído associado ao processo de degradação da imagem bidimensional $y(m, n)=x(m, n) * h(m, n)+w(m, n)$

$\hat{H}, \hat{H}\left(\omega_{1}, \omega_{2}\right)$ Representação no domínio espectral do operador compacto $h(m, n)$

$\hat{x}\left(\omega_{1}, \omega_{2}\right)$ Representação no domínio espectral de $x(m, n)$

$\hat{y}\left(\omega_{1}, \omega_{2}\right)$ Representação no domínio espectral de $y(m, n)$

$\hat{w}\left(\omega_{1}, \omega_{2}\right)$ Representação no domínio espectral de $w(m, n)$

$\hat{H}^{-1}\left(\omega_{1}, \omega_{2}\right) \quad$ Matriz inversa de $\hat{H}\left(\omega_{1}, \omega_{2}\right)$

$\hat{x}$ Solução aproximada do problema inverso $\hat{x}=\hat{H}^{-1} \hat{y}$

$\hat{x}_{0} \quad$ Objeto, ou cena original

$r$ Resíduo, $r=|H x-y|$

$\|r\|^{2} \quad$ Norma do resíduo, ou erro de restauração

$\phi_{d} \quad$ Funcional discrepância, $\phi_{d}=\|H x-y\|^{2}$

$\hat{H}^{\dagger} \quad$ Operador inverso generalizado de $\hat{H}$ (ou pseudo-inverso)

$\hat{x}^{\dagger} \quad$ Solução generalizada de $\hat{x}^{\dagger}=\hat{H}^{\dagger} \hat{y}$ 
$\hat{H}^{*}$ Operador adjunto (transposto conjugado) de $\hat{H}$

$\mu$ Multiplicador de Lagrange, ou Regularizador de Tikhonov

$\mu\|x\|^{2} \quad$ Termo de restrição imposta à solução $x$

$T$ Operador contração, tal que $T x=x$

$\tau$ Parâmetro de relaxação, ou passo de convergência

$x_{j}$ j-ésimo elemento da seqüência $x_{j+1}=T x_{j}$ (ponto fixo de $T$ )

\section{LISTA DE SÍMBOLOS PARA A IMPLEMENTAÇÃO DO ALGORITMO DE SUPERRESOLUÇÃO DE PSF}
$X$ Imagem (de alta resolução) projetada sobre o CCD
$Y_{k}$ k-ésima imagem (de baixa resolução) capturada pelo CCD
$B_{k} \quad$ Matriz de borramento associado ao sistema óptico
$W_{k} \quad$ Matriz de borramento por movimento relativo
$D$ Matriz de sub-amostragem realizada pelo detector CCD
$\eta_{k}$ Ruído intrínseco ao processo de aquisição da imagem $Y_{k}$
$M_{k}^{T} \quad$ Matriz transposta da matriz genérica $M_{k}$
$X_{j}$ j-ésima iteração do Método de Landweber
$\hat{X}_{0} \quad$ Informação a priori da imagem a ser computada $\hat{X}_{0}$ 


\section{SUMÁRIO}

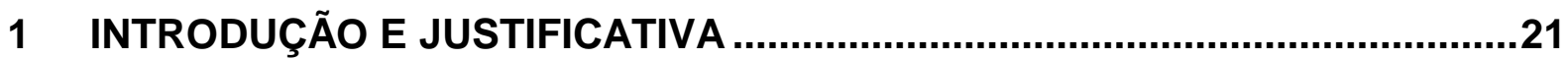

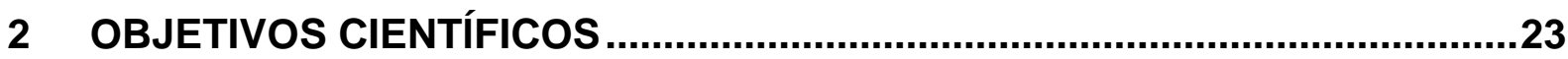

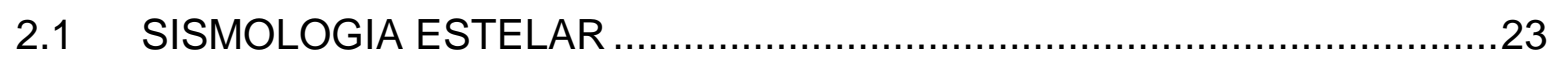

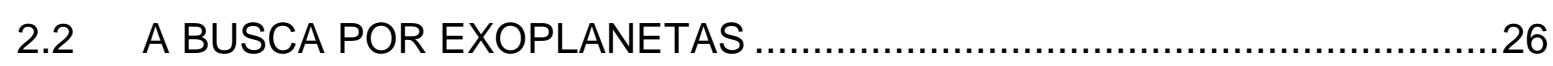

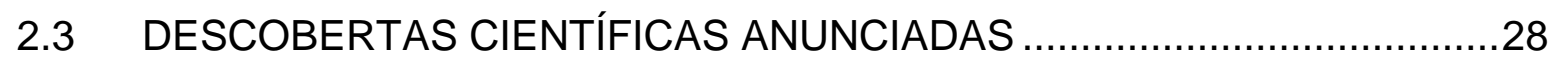

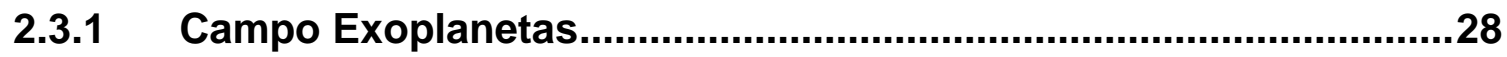

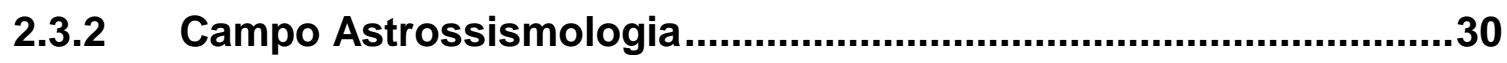

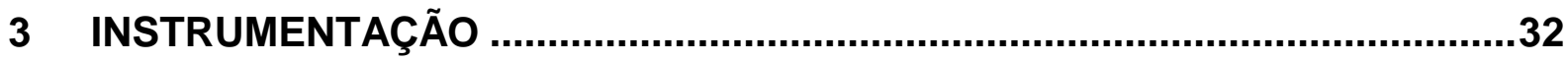

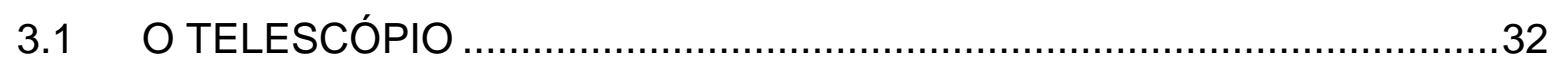

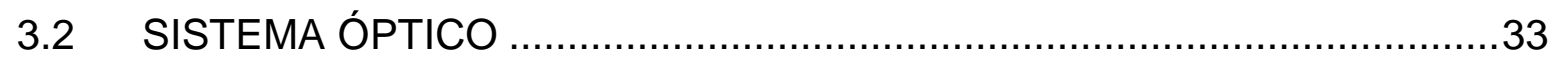

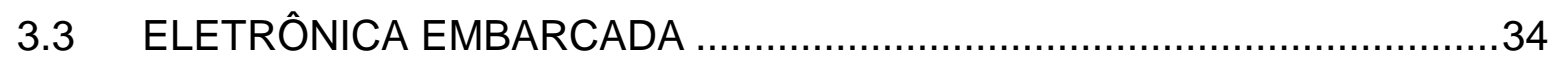

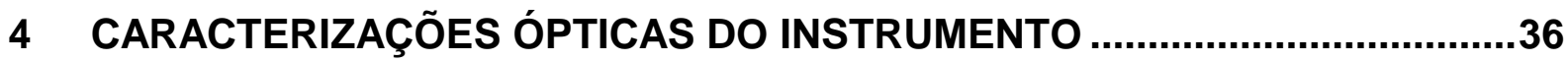

4.1 A ÓPTICA DO INSTRUMENTO

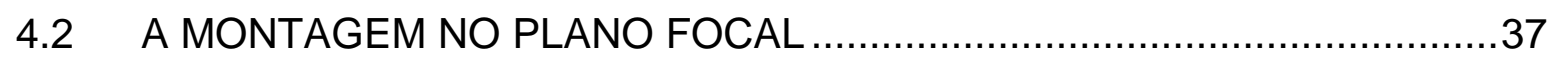

5 CARACTERIZAÇÕES ELETRÔNICAS DO INSTRUMENTO ............................39

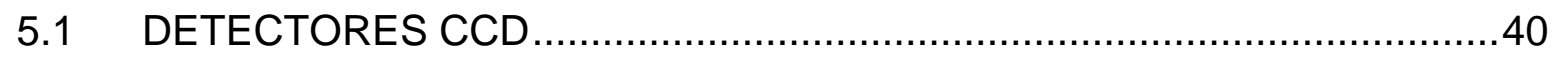

5.1.1 Geração de Cargas ..........................................................................

5.1.2 Resposta Não-Uniforme do Píxel .................................................41

5.1.3 Transferência de carga.................................................................42

5.1.4 Corrente de Escuro (Dark Current) ….........................................42

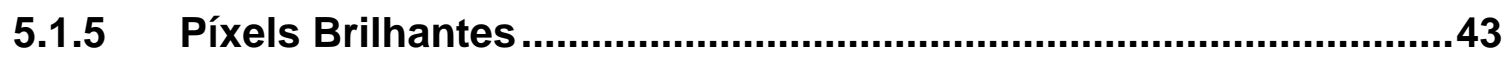

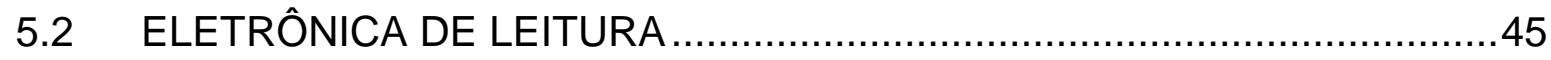

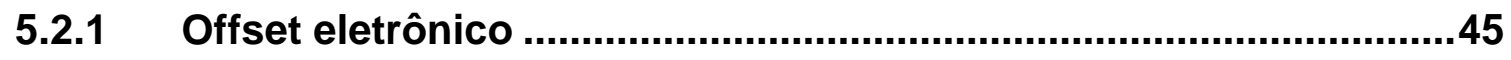

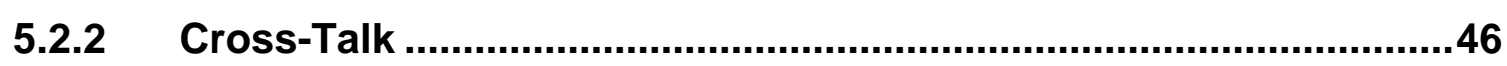

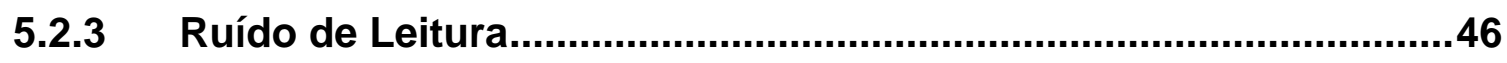

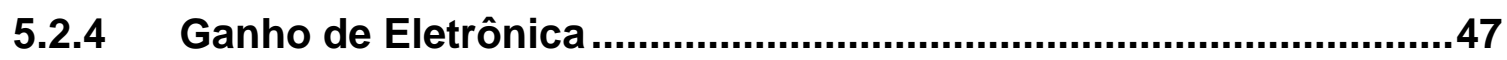

6 CARACTERIZAÇÕES DO AMBIENTE ORBITAL DO SATÉLITE ....................47

7 ANOMALIA MAGNÉTICA DO ATLÂNTICO SUL.........................................47

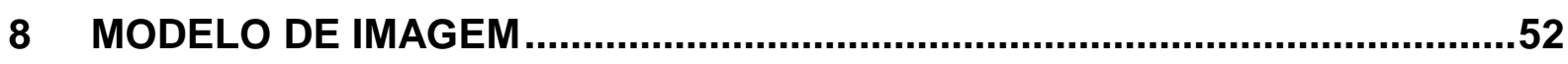




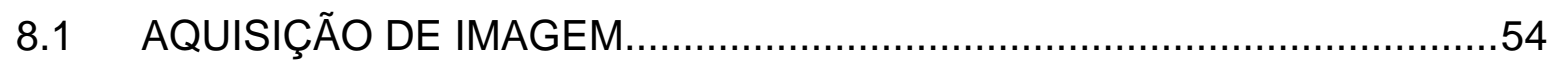

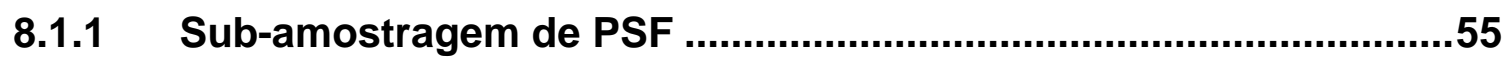

8.1.2 Borramento por Movimento (motion blur) ....................................57

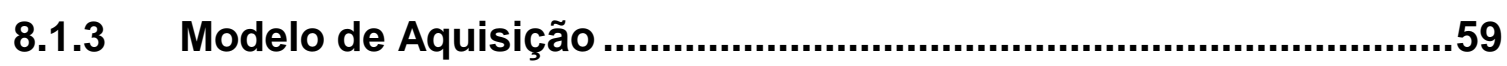

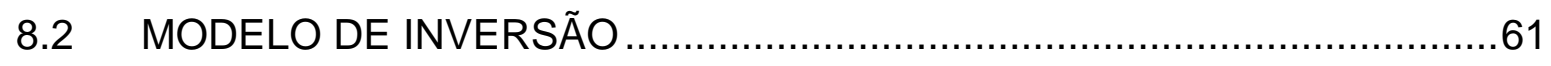

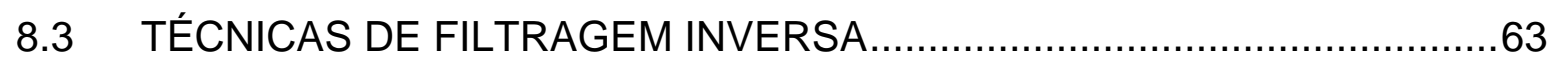

8.3.1 Filtro de Borramento (Blurring Filter) ............................................64

8.3.2 Filtragem Inversa .......................................................................65

8.3.3 Filtragem Inversa - tratamento de ruído......................................65

8.3.4 Filtragem com Pseudo-Inversa .....................................................66

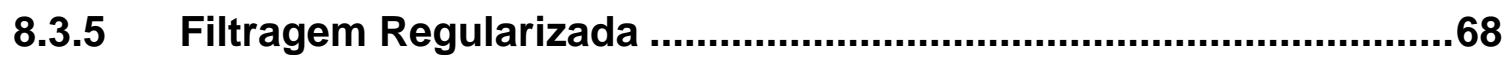

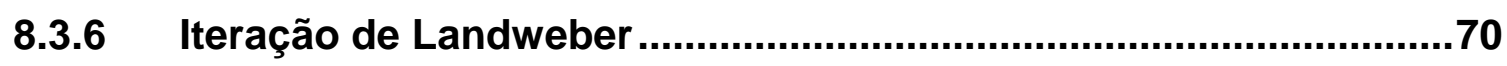

8.3.7 Operadores de Contração e Operadores Não-Expansivos .............70

8.4 TÉCNICAS DE SUPER-RESOLUÇÃO ................................................73

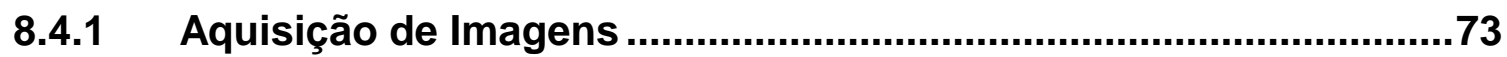

8.4.2 Solução do Problema Inverso ........................................................74

8.4.3 Resolução de Problemas Inversos aplicado à Fotometria por

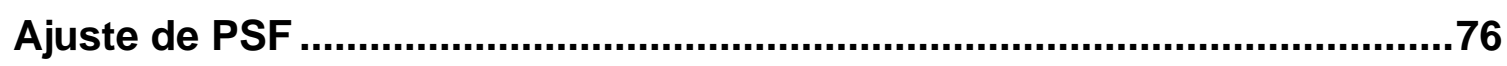

8.4.4 Resultados Práticos ..................................................................78

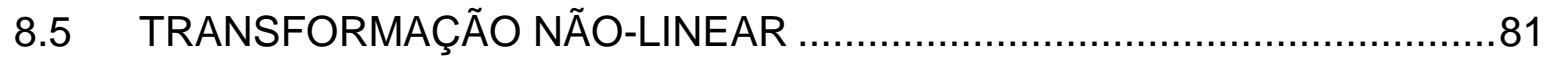

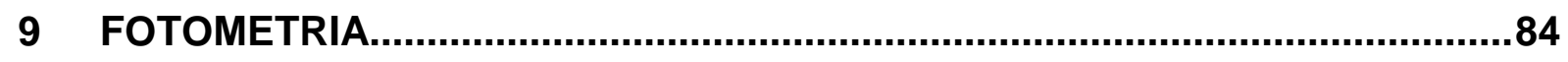

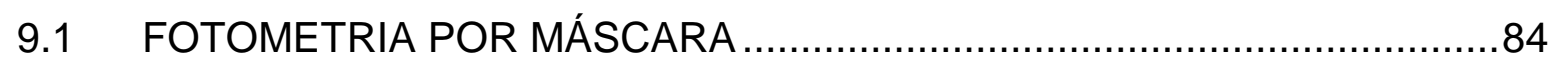

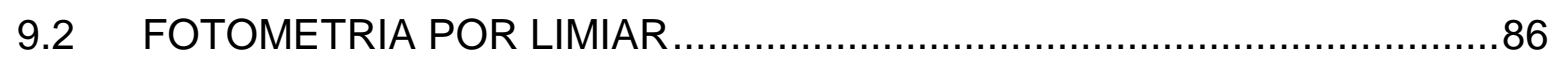

9.3 FOTOMETRIA POR AJUSTE DE RESPOSTA IMPULSIVA …..................86

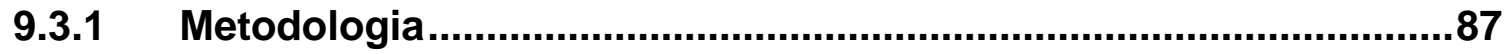

9.3.2 Modelo de Observação..................................................................8

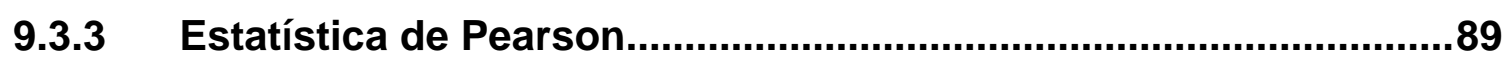

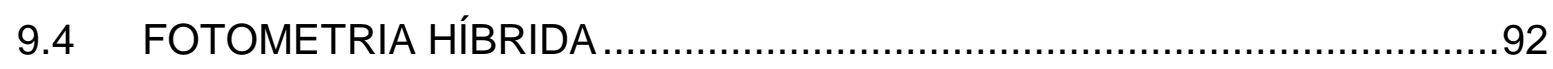

9.5 PARTICIPAÇÃO BRASILEIRA NA RECEPÇÃO DOS DADOS..................92

10 METODOLOGIA

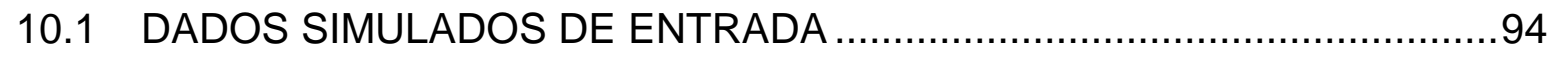

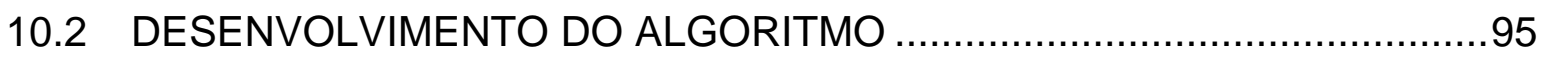

10.2.1 Simulação de Seqüência de Imagens Capturadas .........................95 
10.2.2 Redução de Dados Fotométricos por Abertura ...............................97

10.2.3 Redução de Dados Fotométricos por Ajuste de PSF ......................98

10.2.4 Redução de Dados Fotométricos pelo Método Híbrido ................100

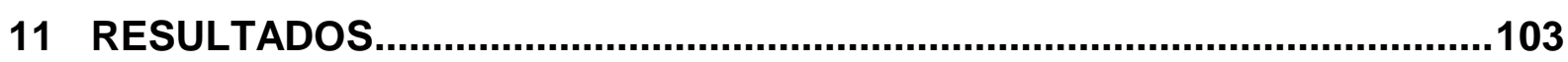

11.1 RESULTADOS DAS SIMULAÇÕES COMPUTACIONAIS ......................103

12 DISCUSSÃO

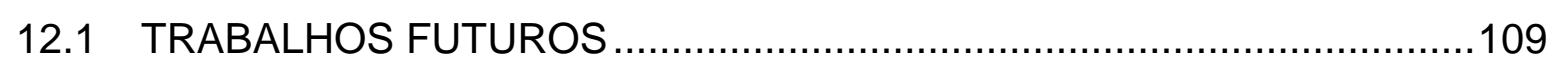

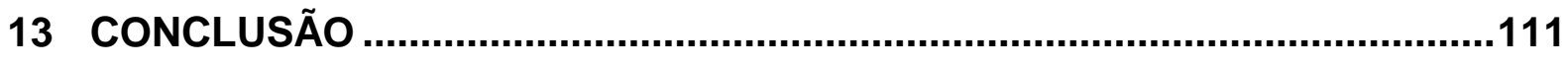

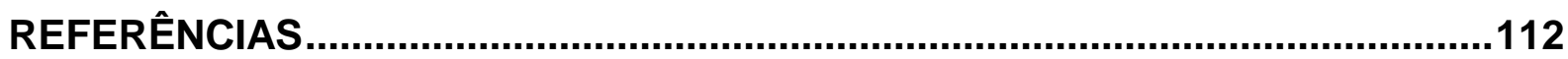

APÊNDICE A

APÊNDICE B 


\section{INTRODUÇÃO E JUSTIFICATIVA}

O satélite CoRoT (Convection, Rotation and planetary Transit) faz parte de uma missão de fotometria estelar de alta precisão dedicada ao estudo de sismologia estelar e à busca por planetas extra-solares (exoplanetas). A missão é liderada pela Agencia Espacial Francesa (CNES) em associação com diversos laboratórios franceses e parceiros internacionais (Áustria, Bélgica, Alemanha, Espanha e Brasil). O instrumento está composto por um telescópio afocal e por uma câmera grande angular, montados em uma plataforma satélite inserida em uma órbita terrestre polar de baixa altitude. Ambos os programas demandam grande estabilidade instrumental e longos períodos de observação ininterrupta, os quais ocorrem simultaneamente em regiões adjacentes do céu.

Para o estudo de oscilações estelares, o instrumento deve ser capaz de medir variações periódicas tão sutis quanto $2 \times 10^{-6}$ do fluxo de fótons coletado de algumas estrelas brilhantes, com magnitudes entre 5.5 e 9. Para a descoberta de exoplanetas, o objetivo é detectar a ocultação temporária da estrela ao redor da qual orbita o planeta em questão - ou seja, detectar um trânsito planetário -, o que pode ser traduzido por uma diminuição tênue do fluxo de fótons estelar coletado, da ordem de $7 \times 10^{-4}$. Para tal, o instrumento foi concebido para observar 60.000 estrelas, de magnitudes entre 12 e 15.5.

A distribuição de dados de ambos os canais (de sismologia e de exoplanetas) entre os colaboradores da missão é ainda voltada a público fechado, composto por cientistas e engenheiros envolvidos na missão. Deve-se, portanto, dar especial atenção a procedimentos de tratamento e análise das imagens capturadas pelo satélite. $O$ acesso a estes dados se dará através de uma colaboração formalizada com o Prof. Dr. Eduardo Janot-Pacheco, do Instituto de Astronomia, Geofísica e Ciências Atmosféricas da Universidade de São Paulo (IAG-USP), presidente do Comitê CoRoT-Brasil. 
A seguir, apresenta-se uma pequena introdução a ambos os programas - de astrossismologia e de busca por planetas extrasolares -, justificando-se o interesse em uma missão espacial como a CoRoT. 


\section{OBJETIVOS CIENTÍFICOS}

O Projeto CoRoT pretende ser a primeira missão científica a detectar exoplanetas do tipo terrestre além de obter dados para uma melhor compreensão dos fenômenos da rotação diferencial e da convecção em estrelas.

\subsection{SISMOLOGIA ESTELAR}

Astrossismologia é o estudo da estrutura interna das estrelas, através de análises de seus modos de oscilação. Estas oscilações fornecem informação sobre o interior estelar, o qual não pode ser observado de outra maneira. A técnica é análoga ao estudo do interior da Terra realizado por geólogos, no qual extraem-se dados sísmicos durante oscilações devidas a terremotos, por exemplo.

Em estrelas, as oscilações podem ser excitadas por turbulência ou por conversões internas de energia térmica em energia cinética de pulsação. Os modos de oscilação resultantes podem ser divididos em dois grupos principais, dependendo da força de restauração dominante: modos de pressão, regidos por flutuações na pressão interna, e modos de gravidade, regidos pela força de empuxo sobre a matéria estelar.

As características destas oscilações dependem exclusivamente da estrutura global da estrela, cujas propriedades físicas podem ser extraídas por inversão de modelos. Neste sentido, a astrossismologia continua sendo a única ferramenta disponível que possibilita a validação de modelos de estruturas internas de estrelas: as informações dela resultantes são relevantes, pois podem ser usadas para restringir e refinar os modelos de evolução estelar.

A função de modo de oscilação, ou harmônica esférica de oscilação estelar, pode ser representada da seguinte forma: 


$$
\xi(r, \theta, \phi, t)=K_{n}(r) \cdot Y_{l, m}(\theta, \phi) \cdot e^{2 i \pi v_{n, l, m} t}
$$

onde $\xi(r, \theta, \phi, t)$ representa o deslocamento de um elemento de fluido, dado em coordenadas esféricas. O índice $n$ é a ordem radial de oscilação, ou seja, o número de nós na direção radial da estrela. Os números de onda $l$ e $m$ determinam a estrutura transversal da oscilação, como representado na Figura 1. O grau $l$ representa o número de linhas nodais na superfície, enquanto que a ordem azimutal $m$ indica quantas destas curvas definem um plano contendo o eixo de rotação da estrela.

$\mathrm{Na}$ Figura 1, o deslocamento de matéria está representado em vermelho e azul (expansão e contração de matéria, respectivamente). Este perfil é alternado durante cada ciclo de oscilação. As regiões claras são as linhas nodais, nas quais os elementos de massa se mantém estáveis.

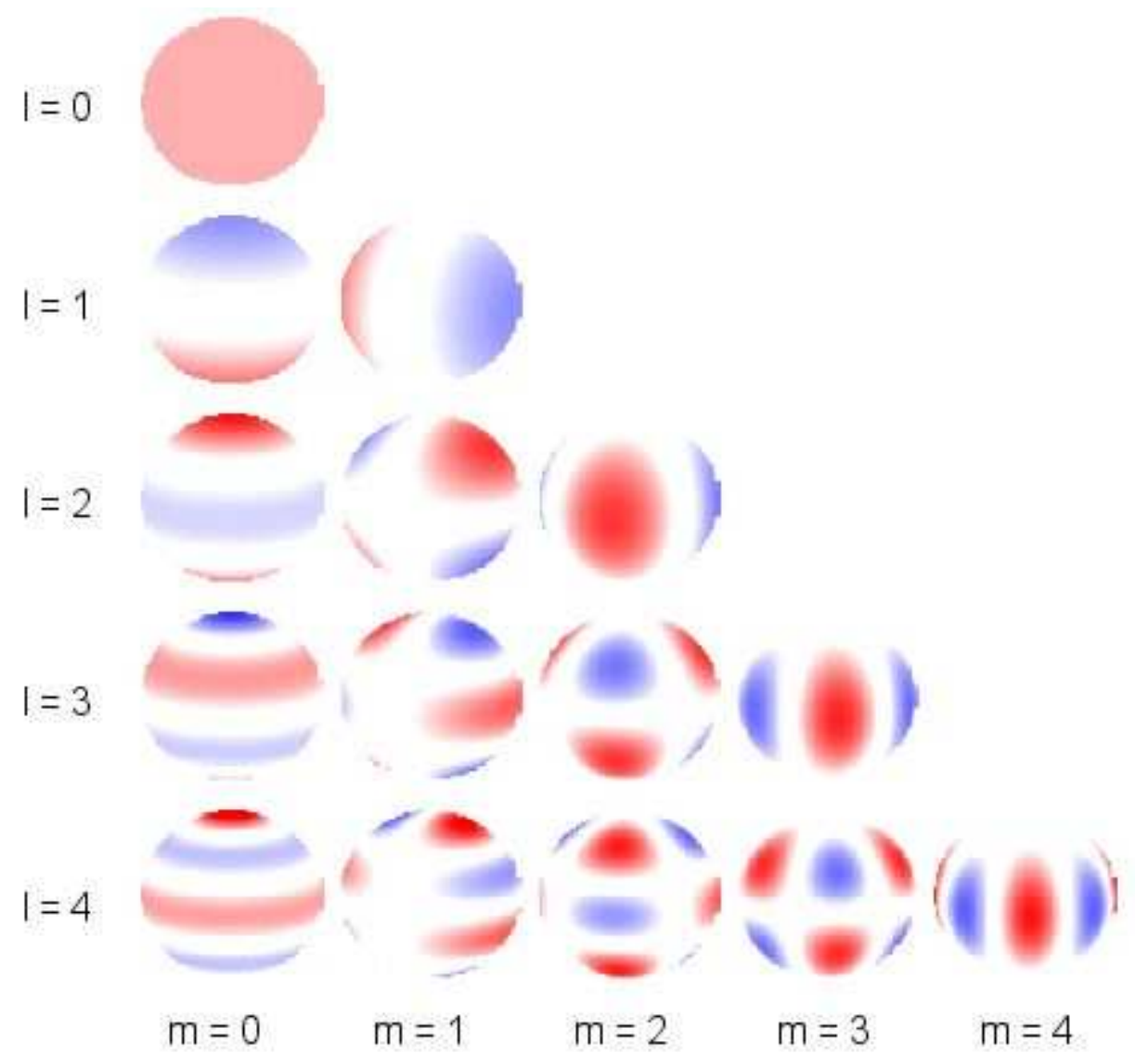

Figura 1. Representação de harmônicas esféricas de oscilação estelar ( $l=0$ a 4 e $m=1$ a $l$ ) (Mosser, 2001).

O deslocamento de matéria na superfície estelar pode, em princípio, ser medido por espectroscopia, dado que ele induz um deslocamento no espectro estelar devido ao 
efeito Doppler. No Sol, por exemplo, ondas de pressão são geradas por turbulência na zona de convecção e diversos modos de oscilação são detectados, como ilustrado na Figura 2.

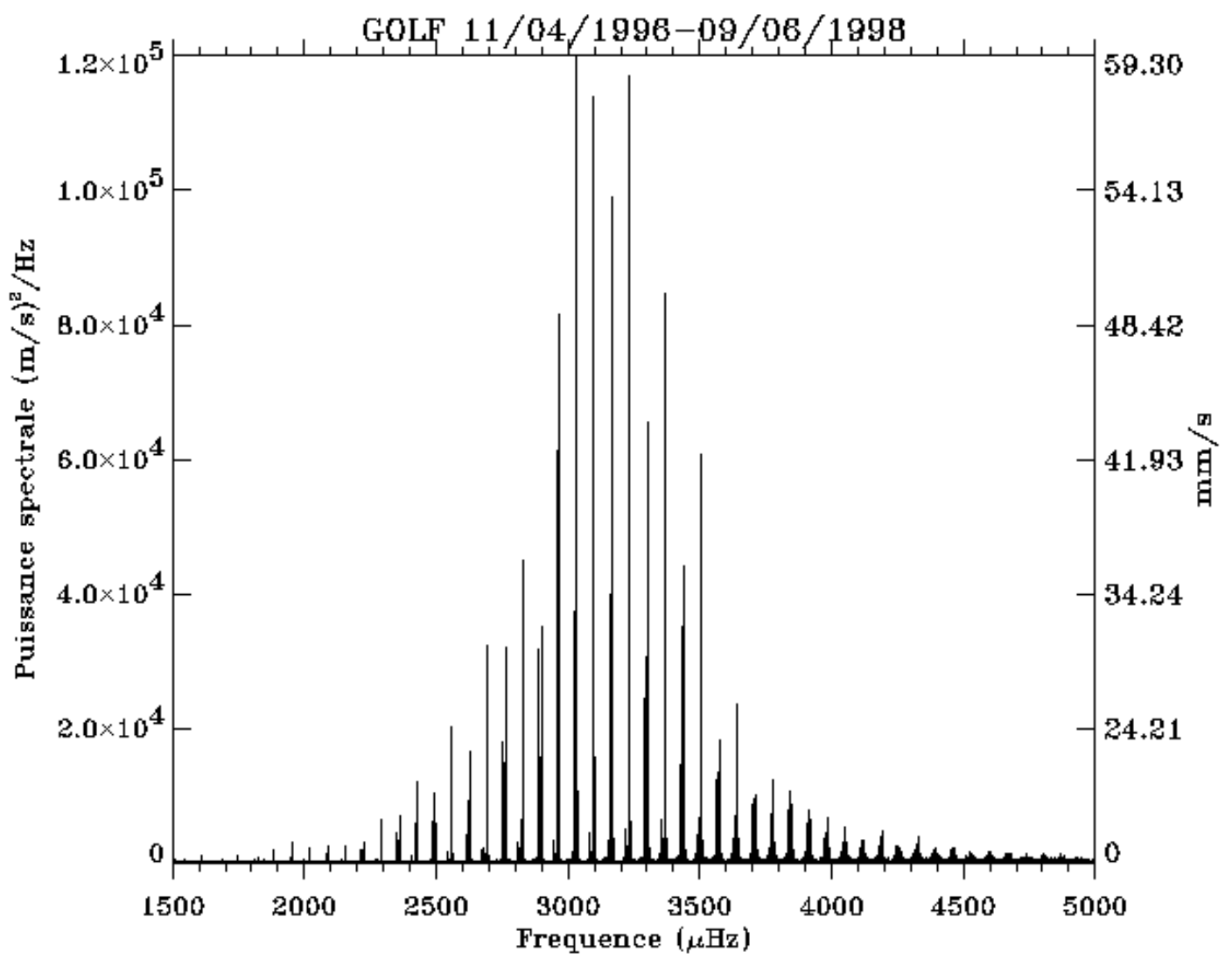

Figura 2. Espectro de freqüência do Sol observado pela sonda GOLF/SOHO (ESA/NASA).

Verifica-se a deteç̧ão de um espectro de freqüências bem-estruturado, que possibilita tanto a estimação precisa da profundidade de zona de convecção, assim como perfis detalhados da rotação interna da estrela.

No entanto, as velocidades radiais em questão são muito baixas, da ordem de $1 \mathrm{~m} / \mathrm{s}$ para estrelas do tipo do Sol. Para outras estrelas, a medição de espectros precisos é extremamente difícil. Uma técnica alternativa é a detecção destas oscilações por meio de seus efeitos no comportamento fotométrico das estrelas. De fato, o fluxo luminoso emitido pelas estrelas é modulado pelas oscilações de acordo com variações periódicas de temperatura nas zonas de contração e expansão, causadas pelas mudanças de pressão durante cada ciclo de oscilação.

No Sol, variações fotométricas periódicas da ordem de 2,5 ppm correspondentes a diversos modos de oscilação têm sido detectadas com sucesso. A detecção de modos de oscilação em outras estrelas, através de medições fotométricas 
extremamente precisas, é um dos objetivos principais do Projeto CoRoT. Freqüências de oscilação típicas para o Sol são da ordem de $3 \mathrm{mHz}$ (ou período de aproximadamente 5 minutos; ver Figura 2). Dependendo do tipo de estrela, períodos de minutos até dias devem ser esperados, com vida média de alguns dias (5 dias para o Sol), tipicamente.

\subsection{A BUSCA POR EXOPLANETAS}

A procura por planetas que orbitam ao redor de outras estrelas que não o Sol tem se destacado desde as primeiras detecções bem-sucedidas realizadas por Wolszczan (1994) [1] e Mayor \& Queloz (1995) [2]. Na última década, mais de 200 exoplanetas foram detectados, sendo a sua maioria através de medições da velocidade radial das estrelas, realizadas por meio de telescópios em solo. Esta técnica explora o efeito gravitacional de um planeta em órbita da estrela-hospedeira: a estrela orbitará ao redor do centro de massa do sistema, aparentando um "bamboleio" em torno de seu próprio centro de massa. Este efeito é particularmente perceptível se o planeta for muito massivo e se encontrar relativamente perto da estrela-hospedeira. Devido a este método de detecção (efeito gravitacional), a maioria dos exoplanetas descobertos pertence à família dos jupiterianos quentes, que geralmente orbitam a menos de 1 UA da estrela. A existência de corpos planetários com essas características jamais havia sido esperada, e obrigou os astrônomos e astrofísicos a realizarem uma revisão e reformulação dos modelos de formação planetária existentes, e ainda aumentou o interesse por novas descobertas de exoplanetas, com propósitos estatísticos.

No entanto, planetas rochosos do tipo terrestre (também chamados de telúricos) continuam inacessíveis empregando-se a tecnologia atual de medição de velocidade radial estelar, apesar de o desempenho dos espectrômetros ter aumentado significativamente nos últimos tempos - o que faz com que se criem grandes expectativas para um futuro próximo. Por outro lado, a detecção de exoplanetas 
também é possível através da análise de seu efeito na fotometria da estrelahospedeira, no caso de uma oclusão parcial temporária do fluxo de fótons provenientes desta estrela, à medida que o planeta percorre sua órbita, como ilustra a Figura 3. Tal fenômeno é também denominado trânsito planetário.

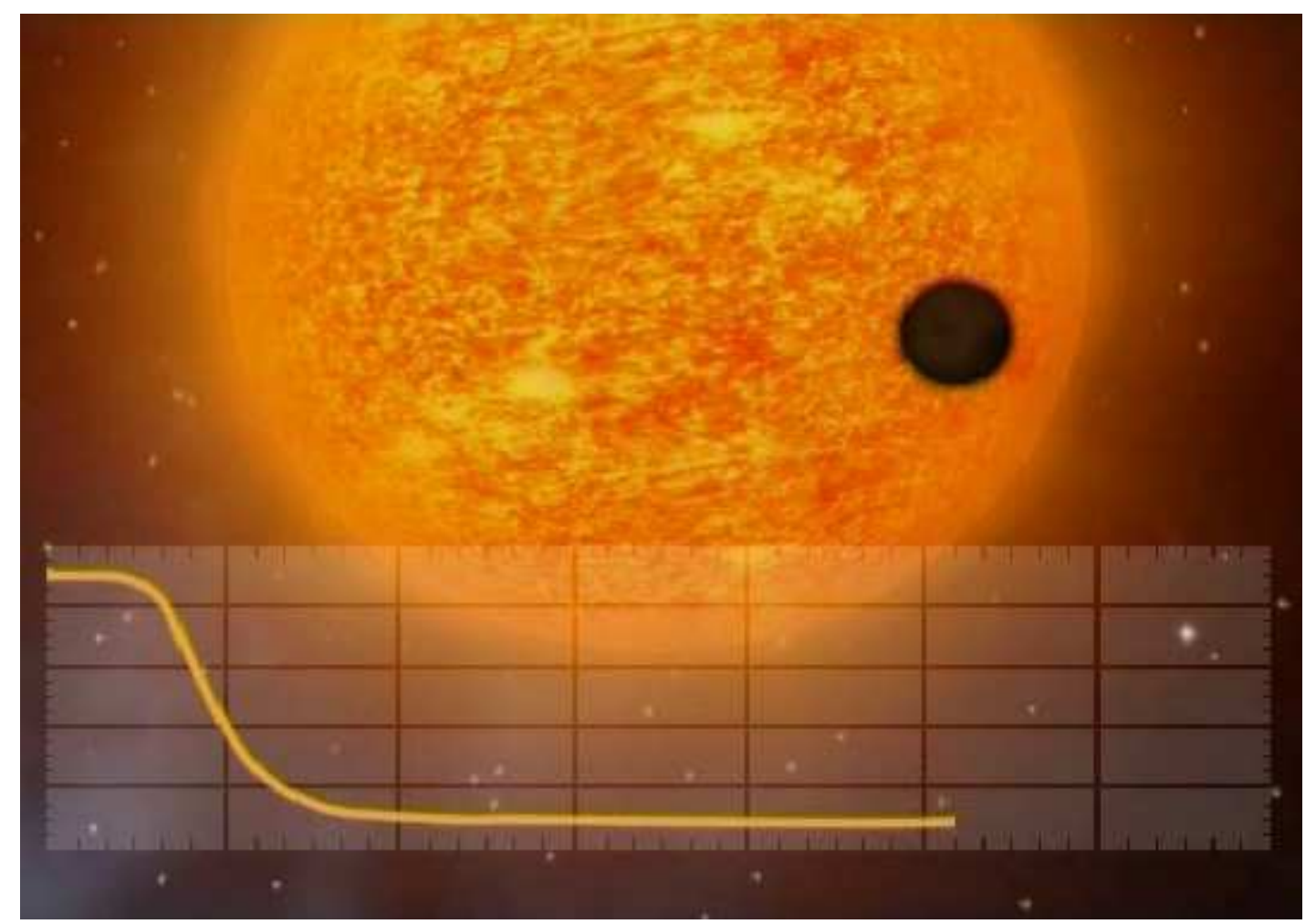

Figura 3. Efeito do trânsito planetário na curva de luz da estrela-hospedeira (CNES).

A quantidade $\Delta F$ de diminuição no fluxo estelar $F$ durante um trânsito é dado por uma relação puramente geométrica:

$$
\frac{\Delta F}{F}=\left(\frac{R_{\text {planeta }}}{R_{\text {estrela }}}\right)^{2}
$$

onde $R_{\text {planeta }}$ é o raio do planeta e $R_{\text {estrela }}$ é o raio da estrela hospedeira. Para um sistema do tipo Sol-Júpiter, a diminuição é da ordem de $1 \%$, enquanto que para o caso de Urano, é de $0.1 \%$ e para a Terra, apenas $0.01 \%$.

A visibilidade de uma ocultação requer uma observação a partir de um ponto de vista privilegiado, isto é, é necessária uma inclinação muito pequena do plano da órbita planetária com a linha de visada. Para um observador fixo na Terra, a probabilidade de tal coincidência ocorrer é dada por: 


$$
P=\frac{R_{\text {estrela }}}{a}\left[\frac{U A}{U A}\right]
$$

onde $a$ é a distância média entre a estrela de raio $R_{\text {estrela }}$ e o planeta em questão. Para uma estrela do tipo do Sol, por exemplo, a probabilidade de ocultação para um planeta a 1 UA é de apenas $0.5 \%$ e de $5 \%$ para $a=0.1$ UA. Portanto, a detecção de exoplanetas através de trânsito planetário requer a observação de um número significativo de estrelas. As observações devem ainda ser feitas por longos períodos, para maximizar a probabilidade de observar o fenômeno. Deve-se ainda confirmar uma detecção através de sua periodicidade, com a ocorrência de pelo menos três trânsitos, para diferenciar este fenômeno de outras atividades solares (como a passagem de manchas solares). Alternativamente, com apenas um ou dois eventos de trânsito planetário, uma análise fotométrica em cores diferentes pode fornecer informações suficientes para distinguir-se um trânsito planetário (um fenômeno acromático) de uma atividade estelar, cuja assinatura fotométrica depende do comprimento de onda. Esta análise cromática permite a descoberta de planetas com períodos orbitais mais longos, para a mesma duração de observação.

Considerando a hipótese de que $10 \%$ das estrelas pode hospedar planetas gigantes gasosos, e que este valor possa alcançar até $50 \%$ para planetas rochosos, pode-se esperar a detecção de 10 a 40 planetas telúricos e de centenas de outros jupiterianos quentes pela missão CoRoT.

\subsection{DESCOBERTAS CIENTÍFICAS ANUNCIADAS}

\subsubsection{Campo Exoplanetas}

Aproximadamente 10 mil estrelas são observadas ao longo de cada período de 5 meses da missão no campo Exoplanetas. O número de observações de trânsitos 
detectados é da ordem de 200 a 250, por período. No entanto, a grande maioria destes eventos provém de estrelas binárias [4]. Até agora, a missão CoRoT descobriu sete planetas fora do nosso sistema solar.

A descoberta do primeiro exoplaneta pela Missão CoRoT foi anunciada em maio de 2007: trata-se de um planeta do tipo "Júpiter quente", batizado de CoRoT-1b, que orbita uma estrela do tipo solar na constelação de Monoceros, a uma distância de 1500 anos-luz do nosso sistema solar. O exoplaneta possui raio aproximado de 1,78 $R_{J}$, massa de 1,3 $M_{J}$, e período orbital de 1,5 dias terrestres.

Em março de 2008, anunciou-se a descoberta do maior exoplaneta já detectado: CoRoT-3b possui massa superior a $21 M_{J}$ e orbita uma estrela da constelação de Águia (Aquila) a 2200 anos-luz do Sol.

Em fevereiro de 2009 foi anunciada a descoberta do exoplaneta CoRoT-7b, o menor planeta fora de nosso sistema solar, do tipo telúrico: $1,7 R_{T}$, com 4,8 $M_{T}$. Seu período orbital é de aproximadamente 20,5 horas terrestres. O CoRoT-7b também encontra-se na constelação de Monoceros, a aproximadamente 490 anos-luz da Terra.

A tabela a seguir lista os exoplanetas anunciados pela Missão CoRoT, até janeiro de 2010 [5]:

Tabela 1. Lista de Exoplanetas descobertos pela Missão CoRoT

\begin{tabular}{llccccc} 
Estrela & Constelação & Planeta & Massa $\left(\boldsymbol{M}_{\boldsymbol{J}}\right)$ & Raio $\left(\boldsymbol{R}_{\boldsymbol{J}}\right)$ & Período Orbital (d) & $\begin{array}{c}\text { Anúncio da } \\
\text { descoberta }\end{array}$ \\
\hline COROT-1 & Monoceros & $\mathrm{b}$ & 1.03 & 1.49 & 1.5089557 & 2007 \\
COROT-2 & Serpens & b & 3.31 & 1.465 & 1.7429964 & 2007 \\
COROT-3 & Aquila & b & 21.66 & 1.01 & 4.25680 & 2008 \\
COROT-4 & Monoceros & b & 0.72 & 1.19 & 9.20205 & 2008 \\
COROT-5 & Monoceros & b & 0.459 & 1.28 & 4.0384 & 2008 \\
COROT-6 & Aquila(?) & b & 3.3 & 1.16 & 8.89 & 2009 \\
COROT-7 & Monoceros & b & $<0.066$ & 0.150 & 0.853585 & 2009
\end{tabular}

Numerosas observações de solo (fotométricas, de alta resolução angular e de velocidade radial) são necessárias para se poder confirmar que um trânsito é produzido por um exoplaneta. Este trabalho complementar é demorado e delicado, e 
não pode ser aplicado senão aos objetos-alvo detectados pelo CoRoT com uma grande probabilidade de ser um planeta.

\subsubsection{Campo Astrossismologia}

Já no campo de astrossismologia, a Missão tem anunuciado descobertas relativas a oscilações e granulações nas superfícies de estrelas distantes, semelhantes às que ocorrem no Sol [6], [7].

A descoberta de oscilações na superfície solar permitiu o desenvolvimento de teorias de movimentos de rotação e convecção das camadas mais profundas do Sol, abrindo caminho ao estudo da sismologia solar. Graças à sensibilidade do telescópio CoRoT e ao seu posicionamento estratégico na órbita terrestre, foi possível estender estes estudos a outras estrelas da seqüência principal, observando-se por logos períodos de tempo o comportamento das atividades sismológicas em diversas estrelas, como as HD49933 (60 dias), HD181420 e HD181906 (150 dias) [6], e registrando-se variações de poucas partes por milhão (ppm) em suas intensidades luminosas.

As amplitudes das oscilações observadas são em geral mais tênues e mais rápidas do que indicavam os cálculos teóricos de sismologia estelar. Estes resultados podem conduzir à revisão dos modelos atualmente adotados pelos pesquisadores. De forma mais surpreendente, oscilações do tipo solar foram também observadas em estrelas muito diferentes do Sol, como por exemplo estrelas quentes do tipo Beta Cefeida [8], e em muitas estrelas do tipo gigante vermelha [9]. Análises espectrais destas observações indicam uma camada convectiva muito maior do que prediziam os modelos de evolução estelar. Para estrelas mais quentes, os baixos níveis de ruído instrumental permitiram a observação de modos de oscilação de baixa freqüência, indicando também neste caso uma camada convectiva maior do que prevêm os atuais modelos de sismologia estelar. 
Através dos dados experimentais observados pelo CoRoT, estende-se o estudo da sismologia solar para a sismologia estelar, ou astrossismologia, e com isso esperase refinar os modelos teóricos de evolução e dinâmica estelar.

Os dois objetivos científicos prioritários do CoRoT são a detecção de exoplanetas telúricos e o estudo de oscilações do tipo solar em estrelas distantes; o telescópio se mostra, desde os seus primeiros resultados, capaz de cumprir satisfatoriamente sua missão. 


\section{INSTRUMENTAÇÃO}

O satélite CoRoT é um telescópio com distância focal de 1,1m, $4 \mathrm{~m}$ comprimento e que pesa $600 \mathrm{~kg}$, baseado em uma plataforma PROTEUS, projetada para missões em baixa órbita e desenvolvida pela CNES e Alcatel Space (ver Figura 4).

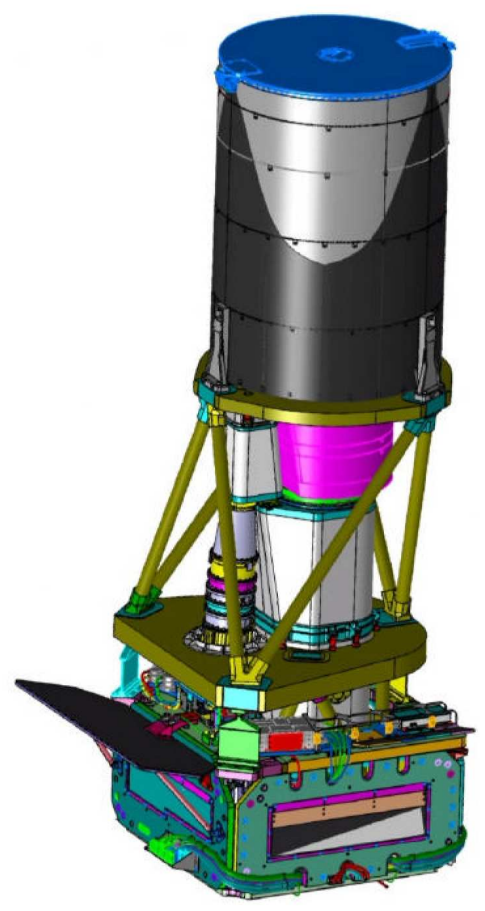

Figura 4. Imagem renderizada do instrumento CoRoT (CNES).

O instrumento pode ser dividido em três componentes principais de hardware, apresentados em linhas gerais nas subseções abaixo.

\subsection{O TELESCÓPIO}

Um telescópio afocal (Figura 5) composto por dois espelhos parabólicos e um defletor externo (baffle), projetado para evitar perturbações devidas a radiações luminosas provenientes da Terra. A pupila de entrada tem $270 \mathrm{~mm}$ de diâmetro. 
Um obturador (shutter) de proteção posicionado na entrada do defletor evita a exposição direta aos raios solares durante a fase de lançamento e de posicionamento do satélite em sua órbita.

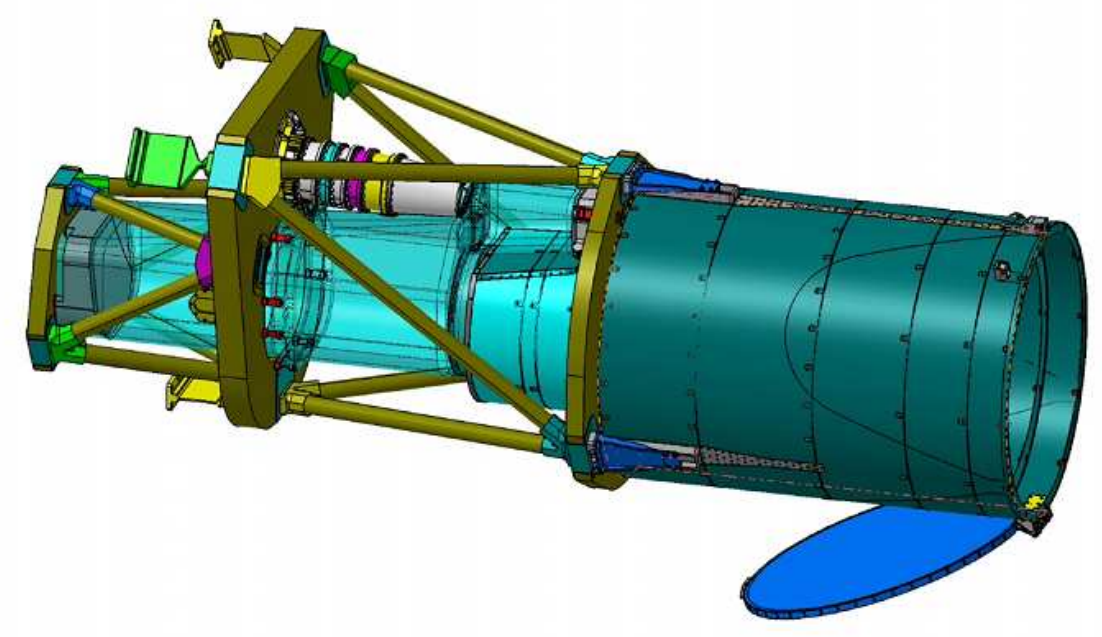

Figura 5: Imagem renderizada do telescópio afocal. (CNES)

\subsection{SISTEMA ÓPTICO}

O sistema óptico de captura de imagens (vide Figura 6) é formado por uma câmera de grande angular composta de uma lente objetiva dióptrica, e um plano focal contendo quatro dispositivos de carga acoplada (CCD) de 2048×4096 píxels e um biprisma (posicionado diante dos detectores da via exoplaneta). Os CCDs totalizam um campo de visão de $3,05^{\circ} \times 2,70^{\circ}$, o que confere escala do plano focal de 2,32 arcsec/píxel ao equipamento. 


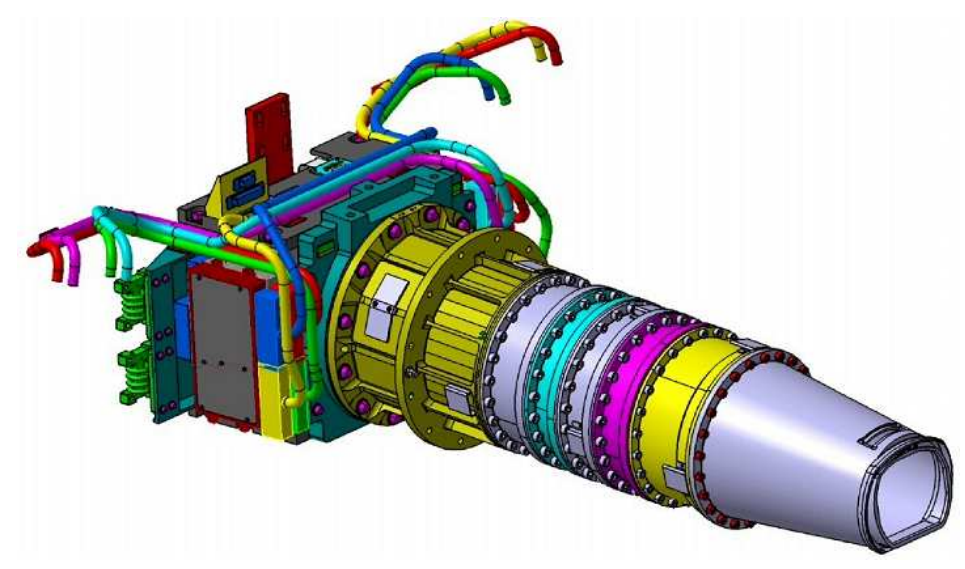

Figura 6: Imagem renderizada da unidade óptica do satélite. (CNES)

\subsection{ELETRÔNICA EMBARCADA}

A eletrônica embarcada do satélite está confinada em uma estrutura mecânica cúbica (Figura 7), e é composta de um sistema eletrônico de controle térmico fino e de leitura dos detectores CCD, que comporta também as unidades de processamento digital dos dados científicos (controle da câmera, processamento digital, controle de atitude, comunicação com bases terrestres, alimentação elétrica, etc). A energia elétrica necessária para o funcionamento provém de oito painéis solares, cada qual com 1,5×0,8 m, que fornecem, ao todo, $530 \mathrm{~W}$ de potência, armazenada em baterias de $\mathrm{NiCd}$ de tensão média $28 \mathrm{~V}$. 


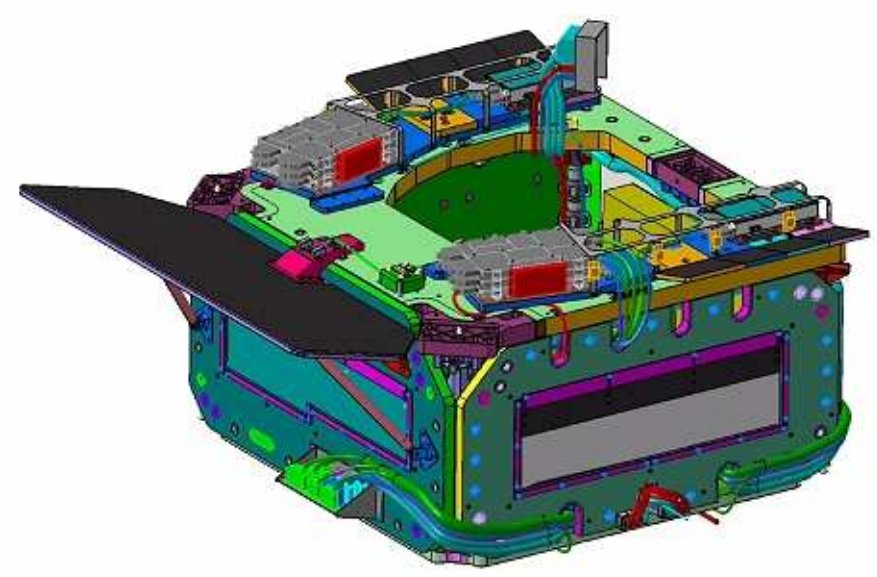

Figura 7: Imagem renderizada da unidade de eletrônica embarcada. (CNES)

Nas seções que se seguem, explicita-se o interesse na formação sólida do pesquisador, à vista da riqueza dos temas envolvidos na modelagem da formação de imagens provenientes de um telescópio em órbita. As caracterizações óptica, térmica, eletrônica e dinâmica completas do comportamento orbital do satélite são de suma importância para a construção de um modelo que represente fielmente as condições de formação e aquisição de imagens estelares. 


\section{CARACTERIZAÇÕES ÓPTICAS DO INSTRUMENTO}

A principal diretriz que guiou o projeto óptico do instrumento foi a minimização da influência de luz difusa, especialmente a que provém da Terra. O conceito final se baseia em um telescópio afocal seguido de uma objetiva dióptrica. As principais vantagens deste projeto são a ausência de obstrução central e uma pupila de saída, ambas limitantes à chegada de luz difusa ao plano focal do instrumento.

\subsection{A ÓPTICA DO INSTRUMENTO}

O sistema óptico do telescópio consiste de dois espelhos parabólicos e um sistema dióptrico composto de seis lentes, projetado para minimizar aberrações ópticas tais como curvaturas do campo de visão. A pupila real, ou obturador, está na entrada da objetiva dióptrica e é feita de material invar, cujo baixíssimo coeficiente de expansão térmica garante notável estabilidade térmica. A forma deste obturador não é circular e está otimizada levando-se em conta restrições mecânicas de projeto. Devido à desfocalização do telescópio, a forma do obturador é reproduzida na função de espalhamento de fonte pontual (point spread function, ou PSF) do instrumento. 


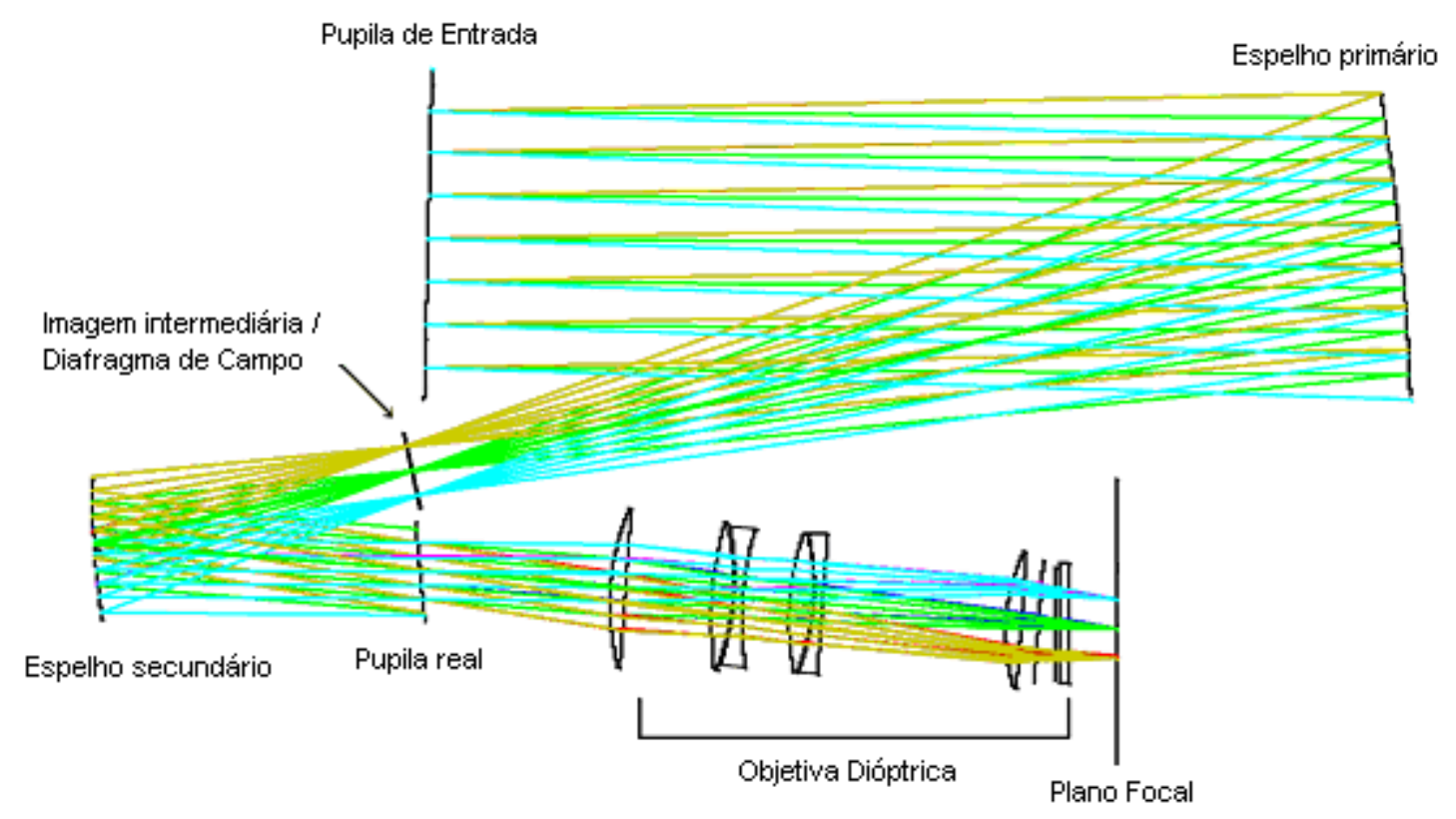

Figura 8. Diagrama ilustrando o caminho óptico desde a pupila de entrada até o plano focal. (Adaptado de Lapeyrere, 2006)

Na Figura 8, estão representados o telescópio afocal e a objetiva dióptrica. llustra-se ainda o caminho óptico de uma fonte luminosa durante a simulação de uma calibração (Lapeyrere, 2006) [10].

\subsection{A MONTAGEM NO PLANO FOCAL}

O bloco focal do telescópio CoRoT contém quatro CCDs, divididos em duas partes correspondentes às necessidades de cada via (Exoplanetas, ou Planet Finder - PF, e Astrossismologia, ou $A S$ ) e um prisma posicionado sobre os dois CCDs da via PF, visível na Figura 9. Este prisma é o último elemento óptico antes dos CCDs.

A via AS apresenta a particularidade de estar desfocalizada [10]. Esta desfocalização intra-focal permite alcançar os requisitos necessários em estabilidade fotométrica, homogeneidade das imagens dentro do campo de visão e não-saturação dos CCDs. Na via $P F$, a função do prisma é dispersar a luz e dar 
acesso à informação cromática sobre a fotometria. Os CCDs PF estão posicionados no plano focal do instrumento, como mostra a Figura 10.

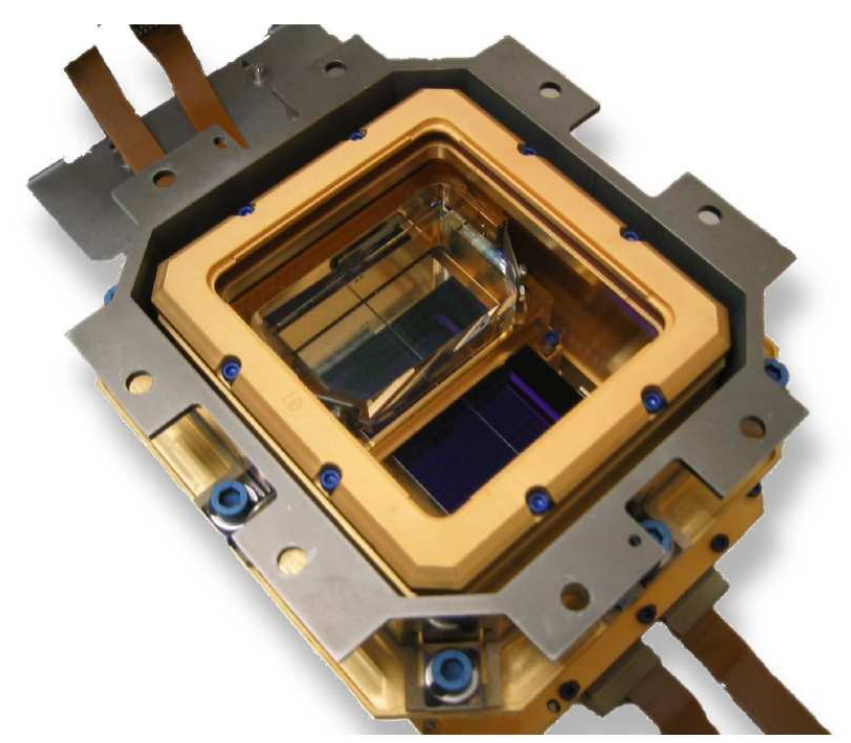

Figura 9. Montagem do plano focal do CoRoT. (CNES)

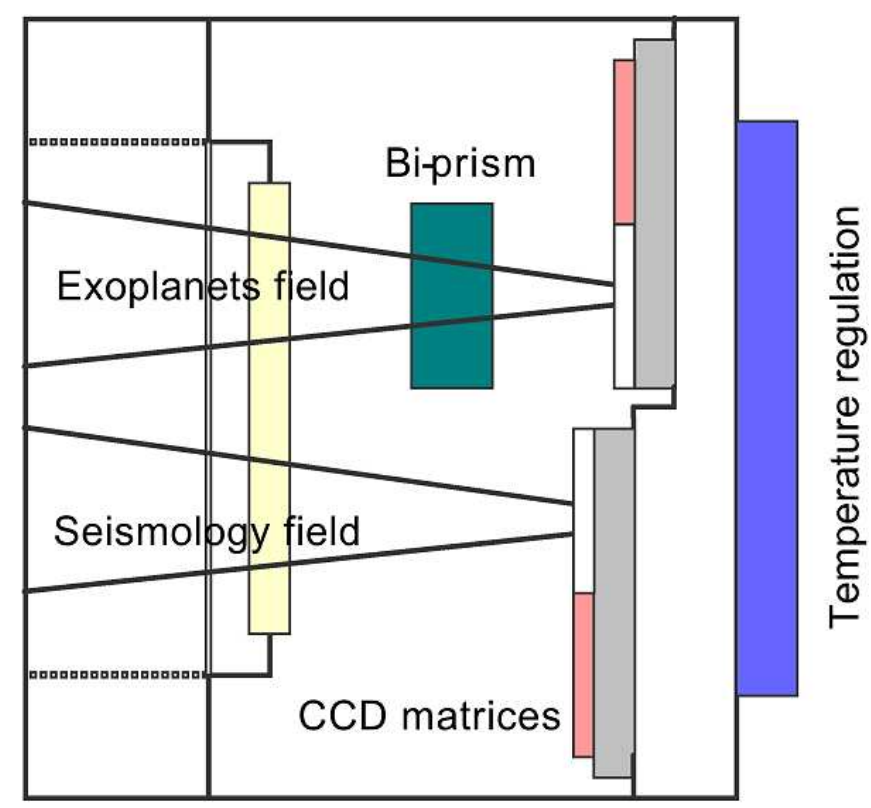

Figura 10. Esquema do bloco focal. (Lapeyrere, 2006)

O bloco focal é refrigerado por um dispositivo térmico passivo, semelhante a um radiador, que deve estar sempre na sombra do satélite e que dispersa o calor acumulado pelo bloco focal e permite a queda de temperatura dos CCDs a aproximadamente $-40^{\circ} \mathrm{C}$. Uma regulação fina é realizada pela plataforma PROTEUS do satélite e minimiza as oscilações de temperatura com uma estabilidade de $5 \mathrm{mK}$. 


\section{CARACTERIZAÇÕES ELETRÔNICAS DO INSTRUMENTO}

A arquitetura eletrônica do telescópio é composta de duas cadeias fotométricas idênticas e independentes, com propósitos de redundância. Cada cadeia realiza a leitura e o controle de dois CCDs, um de cada programa científico. Uma visão esquemática da eletrônica instrumental é ilustrada na Figura 11. Cada saída de CCD está conectada a uma unidade de eletrônica (BEP1 e BEP2) responsável pela pré-amplificação, e a uma unidade de controle de câmera (BCC1 e BCC2) para amplificação e digitalização dos dados. A informação é então direcionada às unidades de extração de píxels (BEX1 e BEX2) e de processamento digital (DPU1 e DPU2). A função das BEXs é extrair porções relevantes das imagens dos CCDs e entregá-las às DPUs, onde é realizada a redução de dados fotométricos e a computação de dados auxiliares. A redução de dados realizada a bordo é limitada pelas restrições de capacidade da telemetria (a memória interna do equipamento é de $2 \mathrm{~GB}$, e a transmissão de dados alcança a taxa de 1,5GB/dia), dado o grande número de alvos observados simultaneamente pelo instrumento. Os dados são finalmente enviados à plataforma PROTEUS para transmissão às estações de recepção terrestres.

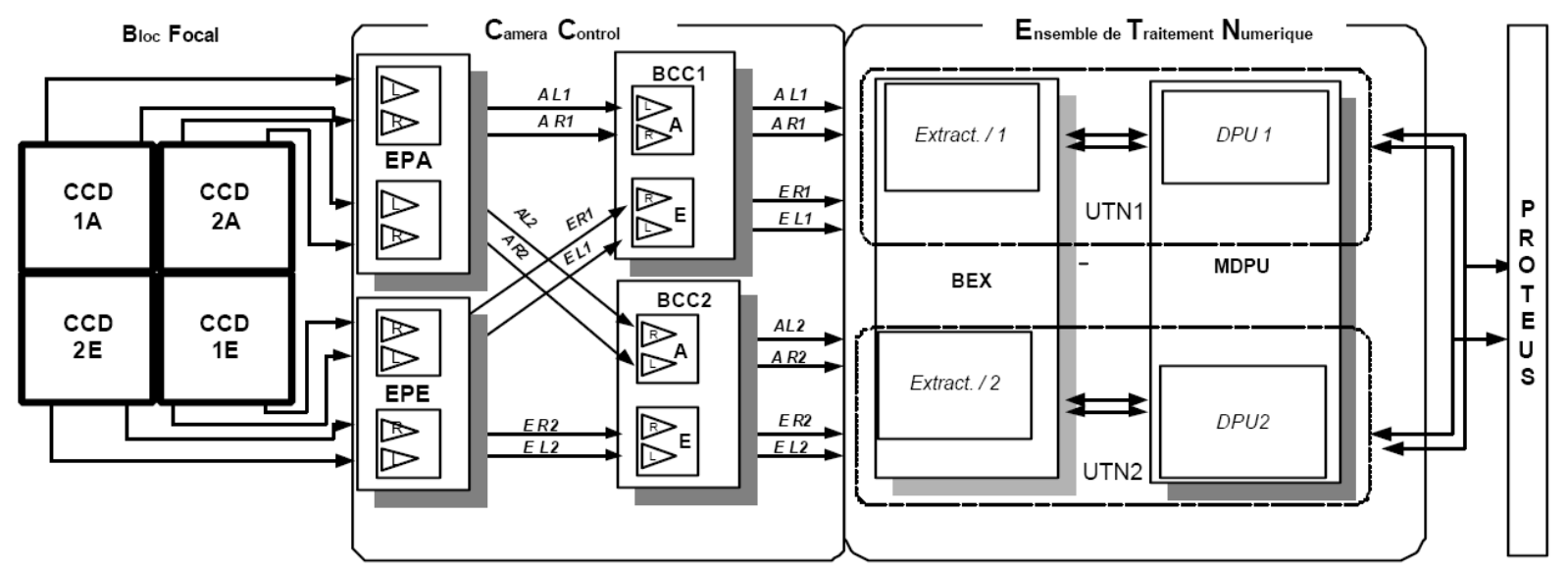

Figura 11. Visão esquemática da eletrônica instrumental do CoRoT. (CNES) 


\subsection{DETECTORES CCD}

O plano focal do CoRoT está composto de quatro dispositivos de carga acoplada (CCDs), especificamente de quatro CCDs série 4280, fornecidos pela E2V Technologies de acordo com as especificações do projeto CoRoT [10]. Estes detectores são do tipo frame-transfer, thinned, e back-illuminated, apresentando uma matriz de 2048x2048 píxels e uma memória de 2048x2054 píxels (vide Figura 12). Cada píxel possui área de $13,5 \times 13,5 \mu \mathrm{m}$, o que corresponde a um ângulo de 2,32 segundos de arco $(\operatorname{arcsec})$. O campo de visão total cobre uma região de $3,05^{\circ} \times 2,70^{\circ}$ no céu.

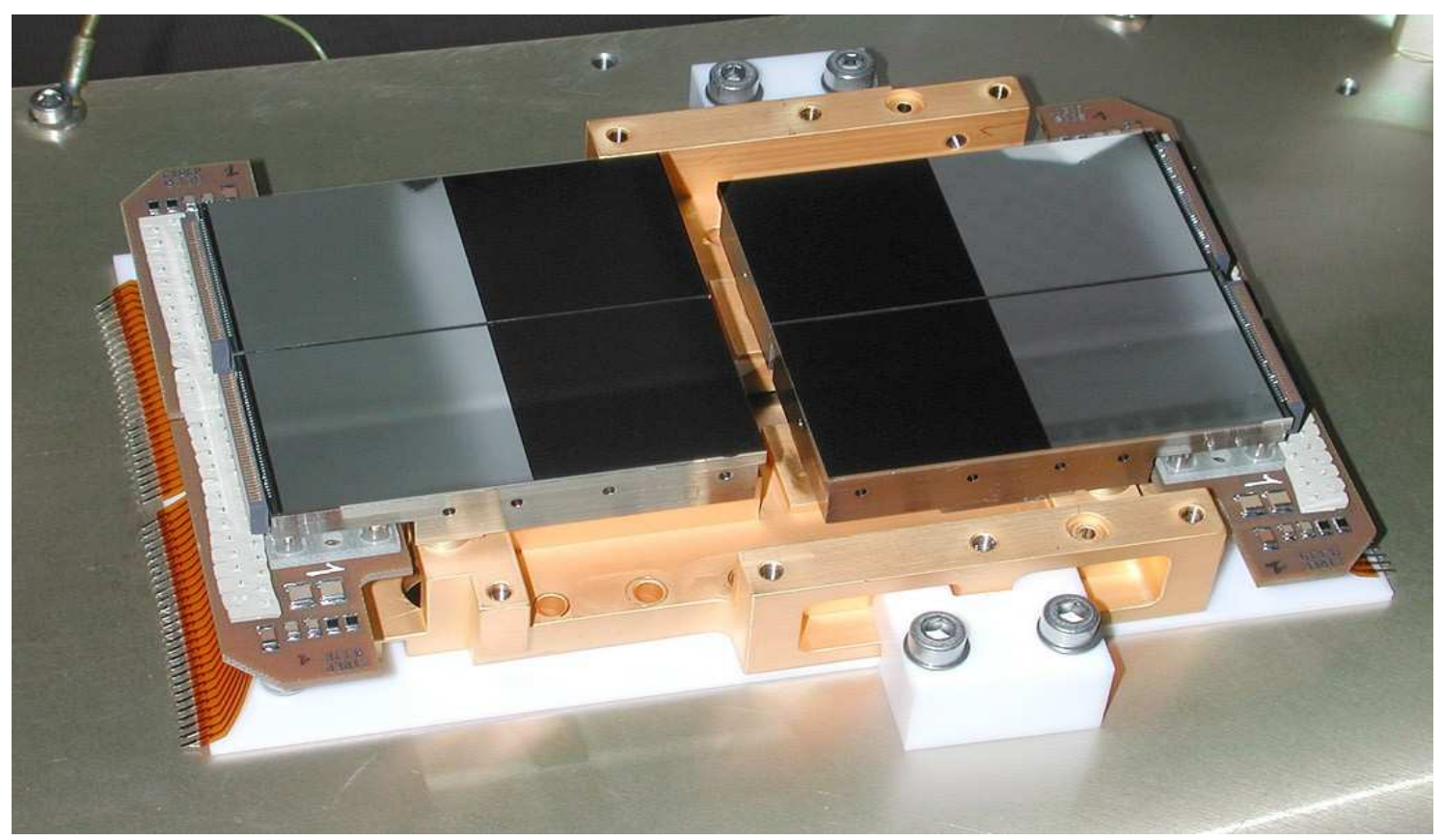

Figura 12: CCDs E2V Technologies série 4280 posicionados no plano focal do telescópio. (CNES)

O processo de calibração a bordo é extensivamente descrito por Lapeyrere em [10], e Pinheiro da Silva (2007) fornece informação adicional detalhada sobre o comportamento dos detectores em órbita em [11]. Para o escopo do presente trabalho, apenas se mencionarão brevemente as calibrações fotométricas realizadas para a missão CoRoT. Nas seções que se seguem, os quatro CCDs do CoRoT são denotados A1 e A2 para a via $A S$, e E1 e E2, caso se trate do programa $P F$. 


\subsubsection{Geração de Cargas}

O processo de aquisição de imagens de um CCD baseia-se no efeito fotoelétrico característico do silício, ou seja, na produção de pares elétron-lacuna (e-h) proporcional à incidência de luz no semicondutor; estes elétrons são acumulados em poços de silício dopado que formam os capacitores, ou píxels). Para que o efeito fotoelétrico ocorra, a energia do fóton incidente deve exceder a diferença de energia entre a banda de valência e a de condução $(1,14 \mathrm{eV}$ para o silício a $300 \mathrm{~K})$.

A eficiência quântica $(\mathrm{QE})$ é uma medida precisa da sensibilidade a luz de um detector, e é definida como a porcentagem de fótons incidentes na superfície fotoreativa que gerarão um par elétron-lacuna. A eficiência quântica de um detector é medida para diferentes intervalos de comprimento de onda, pois a energia do fóton depende do seu comprimento de onda, e é fornecida pelo fabricante. Os CCDs que passam por processos de afinamento (thinning) permitem a iluminação anterior (back-illumination), o que aumenta significativamente a QE para luz visível, dado que a geração $e-h$ acontece mais perto dos poços potenciais, e os elétrons não precisam cruzar todo o substrato de silício para chegar a esta região do detector. Neste caso, a QE do CCD chega a pelo menos $90 \%$.

\subsubsection{Resposta Não-Uniforme do Píxel}

Uma característica comumente chamada de não-uniformidade de resposta de píxel (píxel response nonuniformity, PRNU) é causada por imperfeições no CCD originadas do processo de fabricação (e.g. não-uniformidade na espessura final do detector, dopagem inhomogênea do substrato, etc). Em aplicações de 
imageamento, esta não-uniformidade espacial é normalmente corrigida através de uma imagem plana de referência (flat field) produzida em bancada de calibrações usando-se iluminação uniforme.

\subsubsection{Transferência de carga}

Para o CoRoT, a leitura dos CCDs ocorre a cada segundo para o canal $A S$, e a cada 32 segundos para o canal $P F$, devido à adaptação às diferentes magnitudes estelares de interesse em cada programa científico. Enquanto que no canal $P F$ a leitura completa da imagem é feita a cada ciclo de captura, no canal $A S$, não há tempo hábil para a leitura de toda a imagem no modo de observação. Por isso, no canal PF apenas dez janelas de $10 \times 10$ píxels são extraídas por CCD, correspondentes a 5 estrelas-alvo e 5 imagens para estimação de iluminação de fundo.

\subsubsection{Corrente de Escuro (Dark Current)}

A corrente de escuro é a denominação usual para a geração espontânea de pares $e-h$ nos CCDs, devido a flutuações térmicas no substrato do detector. O fenômeno ocorre quando uma excitação térmica fornece energia suficiente para um elétron de valência alcançar a banda de condução. Esse elétron é eventualmente coletado pelo poço potencial, e portanto é adicionado à imagem. A corrente de escuro, por si só, não é tão problemática quanto o ruído de Poisson. Para minimizar a corrente de escuro, os CCDs E2V 4280 possuem um modo invertido de operação (advanced inverted mode operation, AIMO), que reduz em até 100 vezes a geração de corrente de escuro. No entanto, calcula-se que a taxa de corrente de escuro cresça ao longo 
do tempo de vida do satélite, devido à radiação a que está sujeito o instrumento. Baseado em uma extrapolação de testes de radiação realizados em terra, prevê-se uma radiação de escuro de aproximadamente $27 \mathrm{e}^{-}$/píxel/s [11] ao final da missão, levando a uma contribuição significativa no ruído fotométrico global.

\subsubsection{Píxels Brilhantes}

Danos permanentes devidos a radiação em detectores CCDs podem ser divididos em duas classes: deslocamentos atômicos e impactos ionizantes. CCDs no modo AIMO são robustos aos efeitos de impactos ionizantes, e por isso danos causados por deslocamentos atômicos são mais preocupantes.

Chamam-se deslocamentos atômicos os defeitos criados no substrato de silício causados por impactos de partículas carregadas (normalmente, prótons). Se não houver recombinação entre o átomo deslocado e o espaço deixado por este na rede atômica, o defeito gerado facilitará a geração de corrente de escuro por flutuações térmicas, e dependendo das características deste defeito e de sua posição (por exemplo, em uma região de alto campo elétrico), a taxa de corrente escura pode ser bastante alta, ainda que restrita a uma dada região. Píxels que apresentam taxas de corrente de escuro fora do normal são chamados de píxels brilhantes (hot píxels), e geralmente requerem procedimentos específicos de identificação e correção em processamento de imagens astronômicas. Na fotometria com resolução temporal, estes píxels contribuem com o ruído de Poisson total e podem também introduzir descontinuidades nas curvas fotométricas, como mostram os gráficos abaixo. 

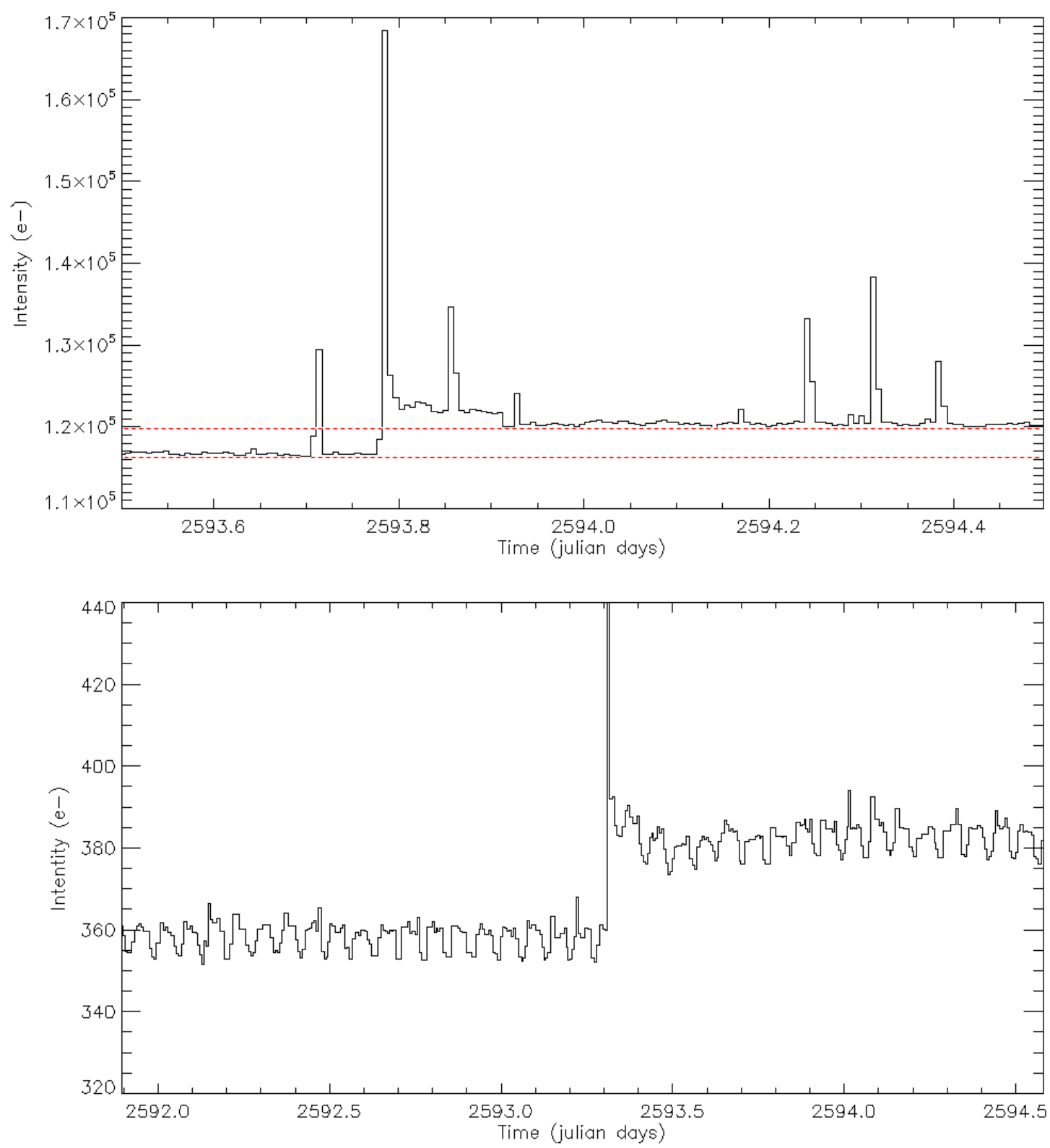

Figura 13. Curvas de luz ilustrando a geração de píxels brilhantes logo depois de um impacto de partículas carregadas, refletida na evolução de uma fotometria estelar (em cima) e de fundo de céu (embaixo). (Pinheiro da Silva, 2006).

A modulação com período orbital observada na Figura 13 corresponde à influência no sinal fotométrico da luz difusa proveniente da atmosfera terrestre.

Verifica-se que o efeito de corrente de escuro é mais pronunciado no canal $P F$, devido ao seu maior tempo de exposição. Este canal é também mais sensível a píxels brilhantes, pois envolve magnitudes de estrelas mais tênues. 


\subsection{ELETRÔNICA DE LEITURA}

A eletrônica de leitura é responsável pelo condicionamento e digitalização do sinal de saída de cada CCD. Cada circuito de saída (um para cada CCD) está composto de dois estágios de amplificação, cujo sinal é então digitalizado por um conversor A/D de 16 bits, com saída de 0 a 5 V, o que corresponde a uma taxa de 73,6 $\mu \mathrm{V} / \mathrm{ADU}$. Para evitar sinais abaixo de zero na entrada dos conversores $\mathrm{A} / \mathrm{D}$ devido a ruídos, um offset eletrônico aditivo é imposto no projeto. Valores típicos de offset estão entre 800 e 1400 ADU por circuito de saída.

\subsubsection{Offset eletrônico}

O offset de cada circuito de saída dos CCDs é medido através da leitura da saída dos CCDs com seus registradores previamente zerados e é registrado a bordo periodicamente (a cada 1s para os CCDs AS e a cada 32s para os CCDs PF). A evolução do offset no tempo consiste de vários efeitos superpostos [11]:

1. a sensibilidade térmica de alguns componentes analógicos leva a oscilações com período orbital ou suas harmônicas, em correlação com suas temperaturas;

2. no canal $A S$, uma variação periódica de 32 s é observada, devido a um acoplamento elétrico indesejado com o ciclo de leitura do canal PF;

3. aparentemente existe uma correlação direta entre a potência instantânea consumida pela eletrônica embarcada e o valor de offset, que precisa ser mais estudada;

4. finalmente adiciona-se ao sinal resultante um ruído branco de leitura. 


\subsubsection{Cross-Talk}

Durante testes de integração, verificou-se que os ciclos diferentes de leitura de cada programa são responsáveis por diversos padrões de perturbação nas imagens capturadas, devido ao acoplamento eletrônico. Uma variedade de padrões de interferência cruzada entre os quatro CCDs pode ser observada nas imagens capturadas, e influencia o valor do offset no sinal fotométrico. No entanto, considerando-se que os padrões de interferência são estáveis, têm-se informações suficientes para a correção de efeitos similares nos dados científicos. A metodologia para correção foi extensivamente descrita em [10].

\subsubsection{Ruído de Leitura}

O chamado ruído de leitura (readout noise) é intrínseco à eletrônica analógica e ao processo de digitalização e pode ser minimizado através de redução da velocidade do processo de leitura. No entanto, há de se balancear, para cada aplicação, a velocidade deste processo e a velocidade de aquisição dos dados, chegando a um ponto ótimo entre quantidade de dados desejável e nível de ruído introduzido pelo processo.

O seu efeito geral pode ser modelado como um ruído gaussiano aditivo. Uma estimação do nível de ruído correspondente a cada parte da cadeia eletrônica tem diversas aplicações, tais como a definição de aberturas fotométricas otimizadas, estimação de PSFs, fotometrias por ajuste de PSF e a configuração de serviços a bordo relacionados com a rejeição de píxels espúrios (outliers). 


\subsubsection{Ganho de Eletrônica}

O ganho global de cada cadeia eletrônica (saída do CCD $\rightarrow$ eletrônica de leitura $\rightarrow$ conversor A/D), expresso em e-/ADU, foi estimado antes da abertura do obturador a partir de um conjunto de imagens de flat field para cada CCD. Estes valores são necessários para a construção de um modelo realístico de erro, como é o caso da otimização de aberturas fotométricas ou fotometria por ajuste por PSF. O método de estimação do ganho global está detalhadamente explicado por Janesick (2001) em [16].

\section{CARACTERIZAÇÕES DO AMBIENTE ORBITAL DO SATÉLITE}

No âmbito da dinâmica orbital do telescópio, são levados em conta, para esta modelagem, os efeitos termo-eletrônicos transitórios e periódicos causados pela passagem do instrumento da zona de sombra para zonas diretamente expostas à radiação solar e vice-versa. Há de se levar em conta também o ruído periódico introduzido na formação de imagens devido ao gradiente gravitacional terrestre nãouniforme ao longo da trajetória do satélite.

Outro fator que gera uma componente aleatória na aquisição da imagem é a precisão finita na definição de posicionamento e direcionamento do satélite (jitter de atitude do satélite) [3] durante o tempo de integração da imagem, que gera um "efeito borramento" (blurring) na mesma.

\section{ANOMALIA MAGNÉTICA DO ATLÂNTICO SUL}


Deve-se atentar também para um fenômeno apontado por Pinheiro da Silva et al.(2006) [11], relacionado ao campo magnético terrestre, mais especificamente, à Anomalia do Atlântico Sul (South Atlantic Anomaly, SAA) [12], resultante do deslocamento entre o eixo geomagnético e o eixo de rotação da Terra (ver Figura 14).

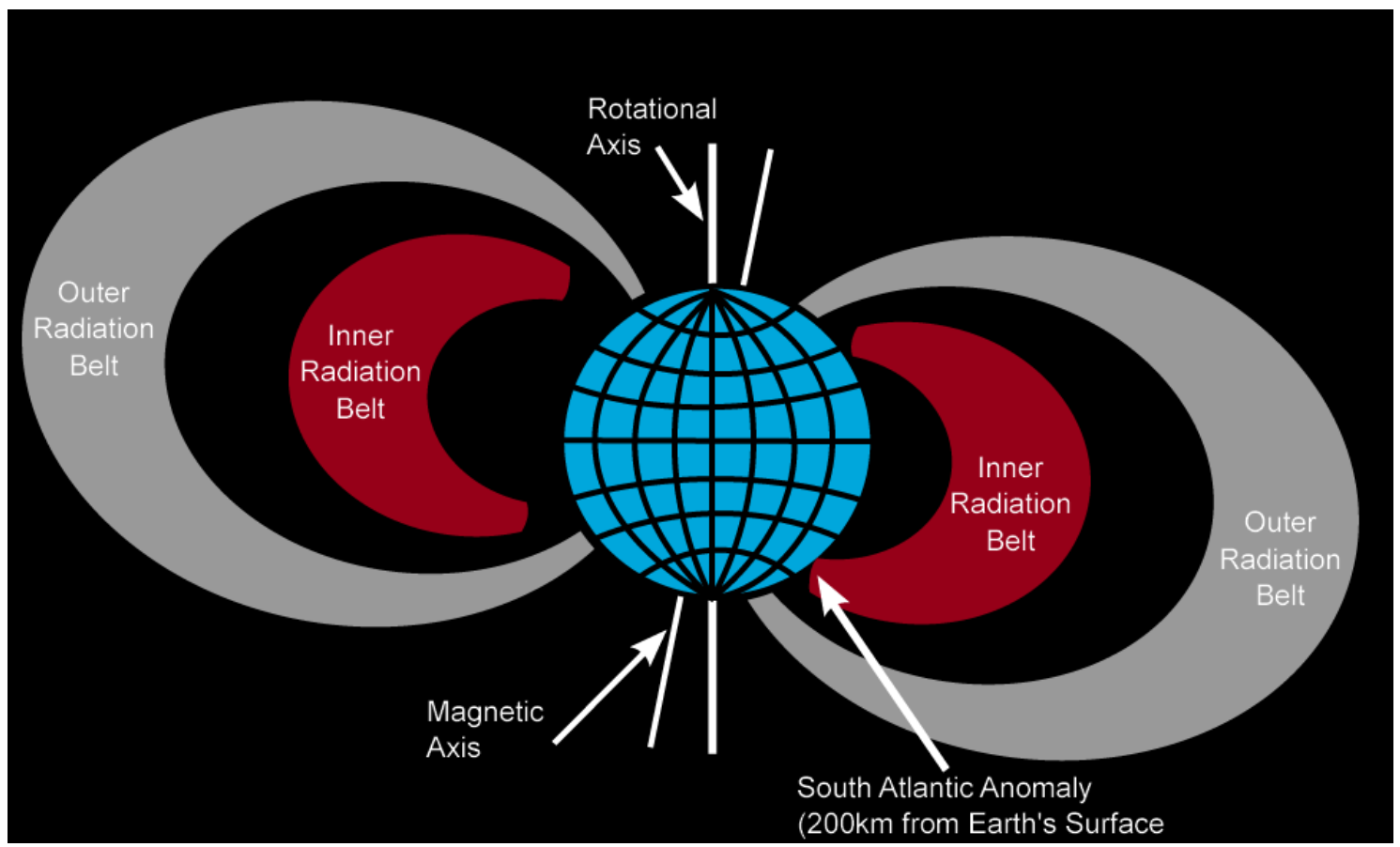

Figura 14. O cinturão radiação de Van Allen e o ponto da Anomalia do Atlântico Sul (NASA).

A SAA é a região onde o cinturão interno de radiação de Van Allen se aproxima mais da superfície da Terra. O resultado deste fenômeno é que, para uma dada altitude, a intensidade de radiação é maior nesta região do que em qualquer outro lugar. A anomalia se desloca para o oeste com uma velocidade de aproximadamente $0,3 \%$ ano, e atualmente encontra-se na região do Atlântico Sul, ilustrada na Figura 15.

A existência da SAA é significativa para satélites e espaçonaves que orbitam a algumas centenas de quilômetros em inclinações orbitais entre $35^{\circ}$ e $60^{\circ}$, pois estas órbitas levam os satélites à zona de anomalia periodicamente, expondo-os a períodos de muitos minutos de alta radiação. Por exemplo, a Estação Espacial Internacional, que orbita com inclinação de $51,6^{\circ}$, foi projetada com proteção extra para lidar com esse problema. O Telescópio Espacial Hubble, por sua vez, que 
possui órbita com inclinação de $28.5^{\circ}$, não realiza observações durante sua passagem nas proximidades da SAA.

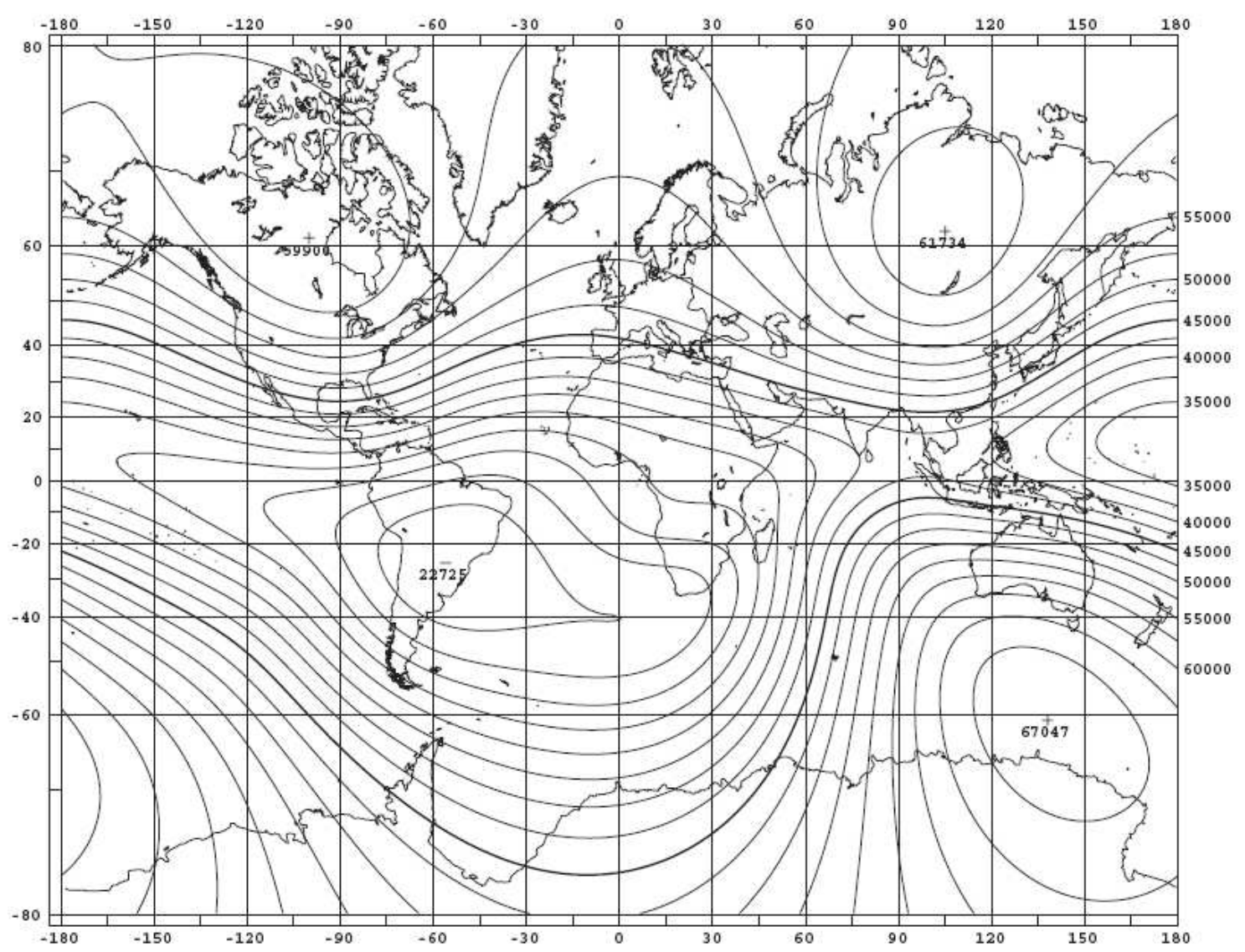

Figura 15: Intensidade do campo magnético terrestre no nível do mar (nT). Observa-se uma assimetria centrada na região do Atlântico Sul, devido ao deslocamento do eixo geomagnético em relação ao eixo de rotação da Terra (International Geomagnetic Reference, IGRF 2005).

O satélite CoRoT, que possui órbita polar (inclinação de $90^{\circ}$ ) a $896 \mathrm{~km}$ de altitude, possui período orbital de aproximadamente 103 minutos, chegando a realizar até 10 travessias da região da SAA por dia. Cada passagem pode durar até 10 minutos, período em que a captura de imagens é bastante degradada, em virtude da zona de forte radiação e conseqüente aumento de impactos de partículas ionizadas. Como resultado desta passagem obrigatória do satélite pela SAA, o seu ciclo de trabalho (duty cycle) é reduzido para aproximadamente $91 \%$. Uma simulação da trajetória do CoRoT é ilustrada de duas formas complementares, nas Figura 16 e Figura 17 abaixo. 


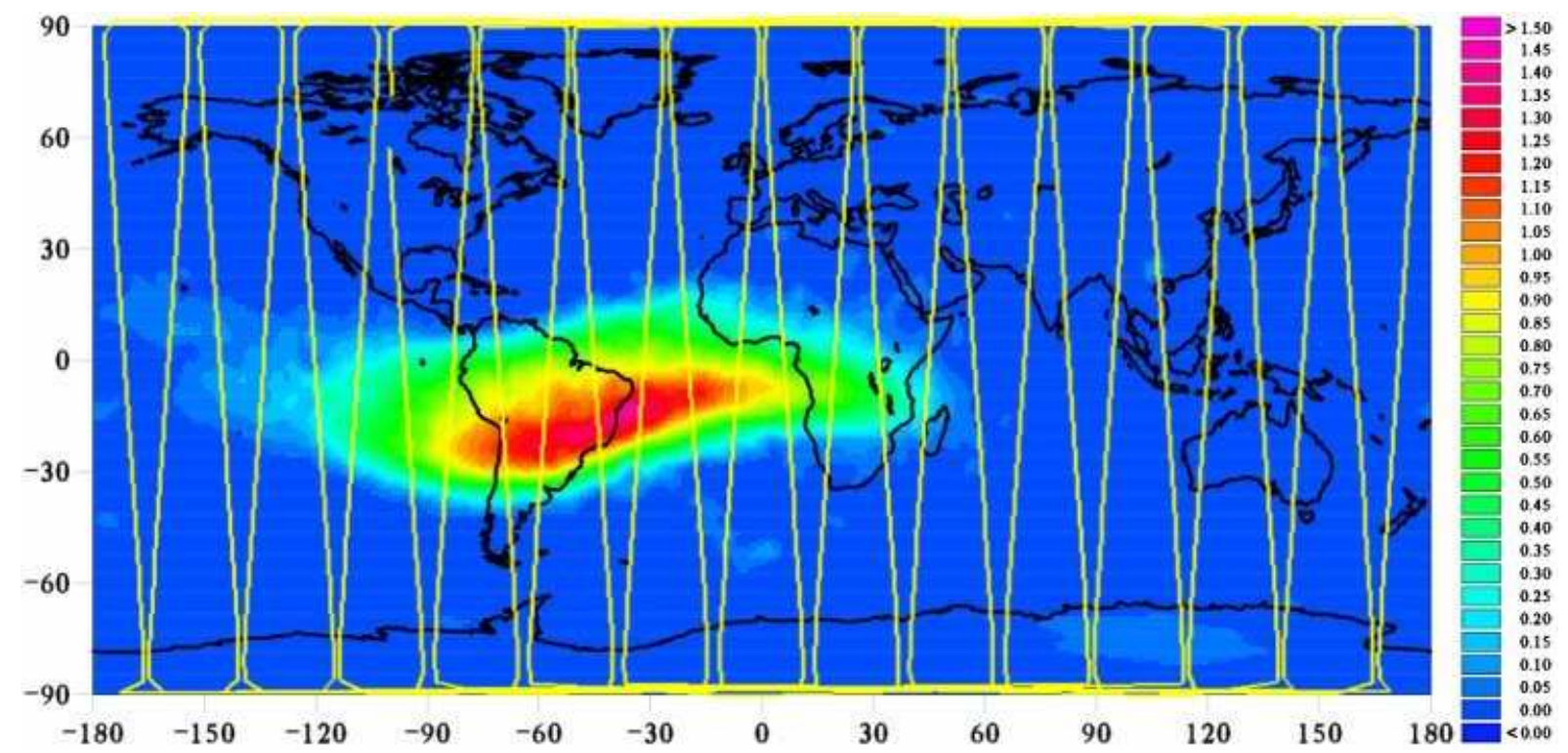

Figura 16: Simulação da passagem do telescópio CoRoT sobre a superfície da Terra, ao longo de um período de 24h. (CNES/CLS. Script de rastreio de satélites: Robert Simpson, Cardiff University)

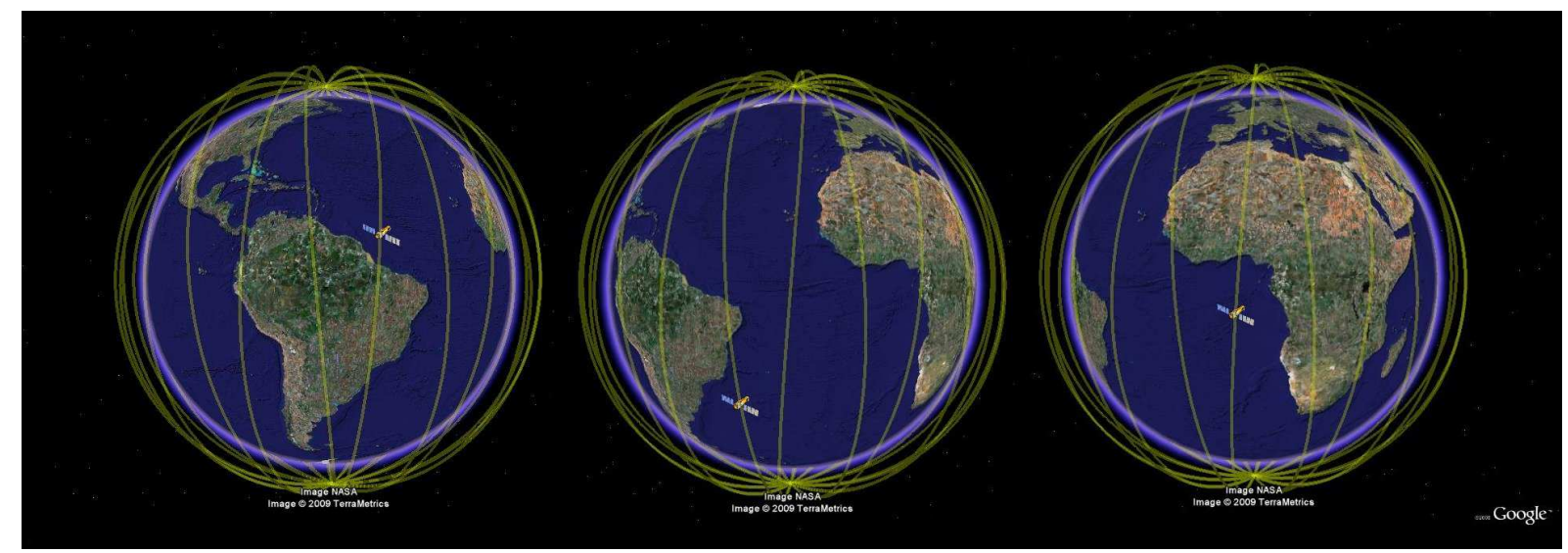

Figura 17: Simulação da passagem do telescópio CoRoT sobre a superfície da Terra, ao longo de um período de 24h. (Terrametrics / Google Earth. Script de rastreio de satélites: Robert Simpson, Cardiff University)

Os efeitos da SAA podem ser esperados nos detectores CCD, na óptica e na eletrônica embarcada, ainda que, na última, tais efeitos podem ser minimizados com o uso de componentes blindados (radiation hard components).

Os efeitos nos CCDs podem ter caráter transiente e aleatório, quando criam-se pares elétron-lacuna durante a passagem de partículas carregadas; ou podem causar danos permanentes, com impactos não-ionizantes que desloquem átomos da superfície de aquisição de fótons [13],[14]. Já a interação entre as partículas de alta energia e as lentes está limitada à fluorescência, que leva a uma pequena contribuição para o espalhamento do fluxo luminoso que entra no sistema óptico. 
Com relação à eletrônica embarcada, devem-se ainda levar em conta na modelagem da formação de imagens, os ruídos relacionados à aquisição dos fótons pelo CCD (com distribuição de Poisson), os ruídos introduzidos pela eletrônica analógica de leitura do CCD, entre outros. Com respeito ao complexo óptico, podese ressaltar também a importância da modelagem espacial de distorções, causadas tanto pelas lentes quanto pela resposta não-homogênea dos CCDs ao longo de sua superfície de aquisição [16]. A modelagem da formação de imagens é amplamente discutida nas seções que se seguem. 


\section{MODELO DE IMAGEM}

A redução de dados astronômicos geralmente demanda um modelo que represente a PSF instrumental, para aplicações tanto astrométricas quanto fotométricas. A PSF descreve a resposta impulsiva de um sistema óptico, ou seja, representa a sua resposta para uma fonte pontual localizada no infinito.

Em geral, uma PSF monocromática é uma função do comprimento de onda da fonte luminosa e de sua posição no plano focal, devido a distorções ópticas do sistema de aquisição. Uma PSF policromática, que corresponde a uma estrela-alvo específica depende, portanto, de sua posição no campo de visão, do tipo espectral da estrela e da transmissão óptica instrumental como uma função do comprimento de onda. Devido a estas particularidades, para uma correta redução de dados necessitam-se PSFs específicas correspondentes a cada alvo.

No caso do CoRoT, modelos de PSF têm muitas aplicações. Eles podem ser usados inicialmente na definição de aberturas fotométricas a serem aplicadas pelo software a bordo, através das quais as curvas de luz de todas as estrelas são geradas. PSFs precisas são também necessárias para um nível mais alto de redução destes dados, por exemplo, em correções a posteriori (em solo) de variações fotométricas associadas a efeitos de borda causados por jitter de atitude do satélite. Finalmente, o uso de PSFs permite o desenvolvimento de algoritmos de fotometria por ajuste de PSF diretamente nas imagens das estrelas, as quais são periodicamente capturadas, o que viabiliza uma alternativa à fotometria por abertura realizada a bordo do satélite.

Algoritmos de ajuste apresentam melhor desempenho em imagens ruidosas, menor sensibilidade a perturbações periódicas como presença de luz difusa e oferecem robustez principalmente contra a ocorrência de impactos de partículas carregadas nos detectores. Dado o projeto óptico, um modelo de PSF pode em princípio ser produzido por simulações numéricas, mas ajustar os diversos parâmetros do instrumento de aquisição, dos quais a PSF é significativamente dependente, é uma tarefa difícil. Além disso, PSFs reais costumam ser particularmente complexas e 
fenômenos inesperados podem levar mesmo sofisticadas derivações computacionais a serem menos realistas do que o desejado.

Para redução de dados astronômicos, modelos de PSF são geralmente obtidos através de ajustes de perfis analíticos (e.g. gaussianos ou de Moffat) às imagens capturadas. No caso de PSFs desfocadas e assimétricas, está claro que tal abordagem não se aplica, e um método alternativo de determinação da PSF é necessário.

Alternativamente, imagens estelares de fontes pontuais podem ser vistas como representações bastante fiéis de PSF, mas a sua resolução espacial é limitada pelas características físicas do sistema de imageamento (por exemplo, o tamanho do píxel dos detectores (CD). Tal resolução pode ser insuficiente quando medições muito precisas são desejadas em múltiplas observações ao longo do tempo. De fato, sob resolução inadequada, o perfil de intensidades das imagens adquiridas se mostra fortemente dependente da localização intra-píxel da estrela no plano focal do instrumento. Neste caso, a PSF deve ser modelada com precisão em nível subpíxel, para que parâmetros científicos sejam estimados com precisão sem qualquer viés entre distintas observações.

Nesta seção, apresenta-se o desenvolvimento de um modelo que representa a formação e aquisição de imagens estelares pelo instrumento CoRoT, considerandose o jitter de atitude. A construção de tal modelo tem duplo interesse para a redução de dados fotométricos: seu uso tanto na reconstrução de PSFs empíricas com precisão sub-píxel quanto como base para o desenvolvimento de algoritmos de fotometria por ajuste. Ainda que o desenvolvimento apresentado nesta seção seja válido tanto para o canal de astrossismologia quanto para o canal de exoplanetas, a sua importância é muito maior no programa de astrossismologia, pois para o programa de exoplanetas, apenas uma pequena fração das imagens estelares é transmitida por telemetria, devido às restrições de capacidade de transmissão da comunicação. Todos os demais alvos neste programa são estudados somente através de curvas de luz processadas a bordo. No entanto, deve-se notar que as restrições de desempenho são muito mais exigentes no programa de astrossismologia, pois neste caso os dados fotométricos são analisados no domínio de freqüências, de modo que os resultados científicos correspondentes são 
particularmente sensíveis à falta periódica de dados de qualidade associados à Anomalia do Atlântico Sul. Neste caso, por exemplo, a robustez a impactos de partículas carregadas oferecida por algoritmos de fotometria por ajuste de PSF é muito mais crítica do que no caso de uma análise temporal que tenha por objetivo a deteç̧ão de exoplanetas.

\subsection{AQUISIÇÃO DE IMAGEM}

O modelo de formação de imagem apresentado nesta seção descreve a operação da câmera do CoRoT (óptica instrumental + CCDs), na presença de jitter de atitude. Neste caso, a aquisição de imagens envolve os seguintes aspectos:

1. a PSF instrumental associada a uma estrela-alvo, que é uma função da temperatura da estrela e de sua posição no campo de visão do CCD;

2. o efeito de movimento relativo dos detectores durante o seu tempo de integração, devido a limitações na estabilidade da atitude do satélite ;

3. a sub-amostragem espacial realizada pelos detectores $C C D$ e seus efeitos na fotometria.

Tais imagens estelares são extrações de pequenas áreas do CCD ao redor do baricentro destas estrelas, e seu tamanho típico é de 30×30 píxels para o canal de astrossismologia e $15 \times 10$ píxels para o canal de exoplanetas.

Dado que os objetos de interesse para observações com este instrumento podem ser considerados fontes pontuais, a própria projeção de uma estrela sobre a superfície do CCD pode ser considerada como uma PSF instrumental para a posição correspondente no campo de visão do CCD. Os efeitos de jitter de atitude e de sub-amostragem do CCD sobre esta PSF serão analisados nas seções que se seguem, e serão modelados como transformações bidimensionais da PSF em uma série de imagens sub-amostradas. 
Também se apresentará a metodologia adotada para a reconstrução de uma PSF empírica a partir da inversão destes modelos, restritos por um conjunto de imagens capturadas e os correspondentes dados de atitude do satélite. Por fim, se explicará a aplicação deste modelo na extração de parâmetros fotométricos.

\subsubsection{Sub-amostragem de PSF}

Como discutido anteriormente, as PSFs do CoRoT são complexas, principalmente devido ao desfoque proposital imposto à óptica instrumental, à pupila assimétrica e ao bi-prisma posicionado na via exoplanetas.

Uma PSF simulada correspondendo a um alvo típico do programa de astrossismologia $\left(m_{v}=6 ; T_{\text {eff }}=6000 \mathrm{~K}\right)$ é ilustrada na Figura 18. Tal PSF foi originalmente derivada de simulações numéricas realizadas com o programa Zemax Optical Design por Pinheiro da Silva em [11] para diversos comprimentos de onda e distintos tempos de integração, de acordo com a temperatura da estrela-alvo e a resposta espectral do CCD para esta estrela-alvo. 

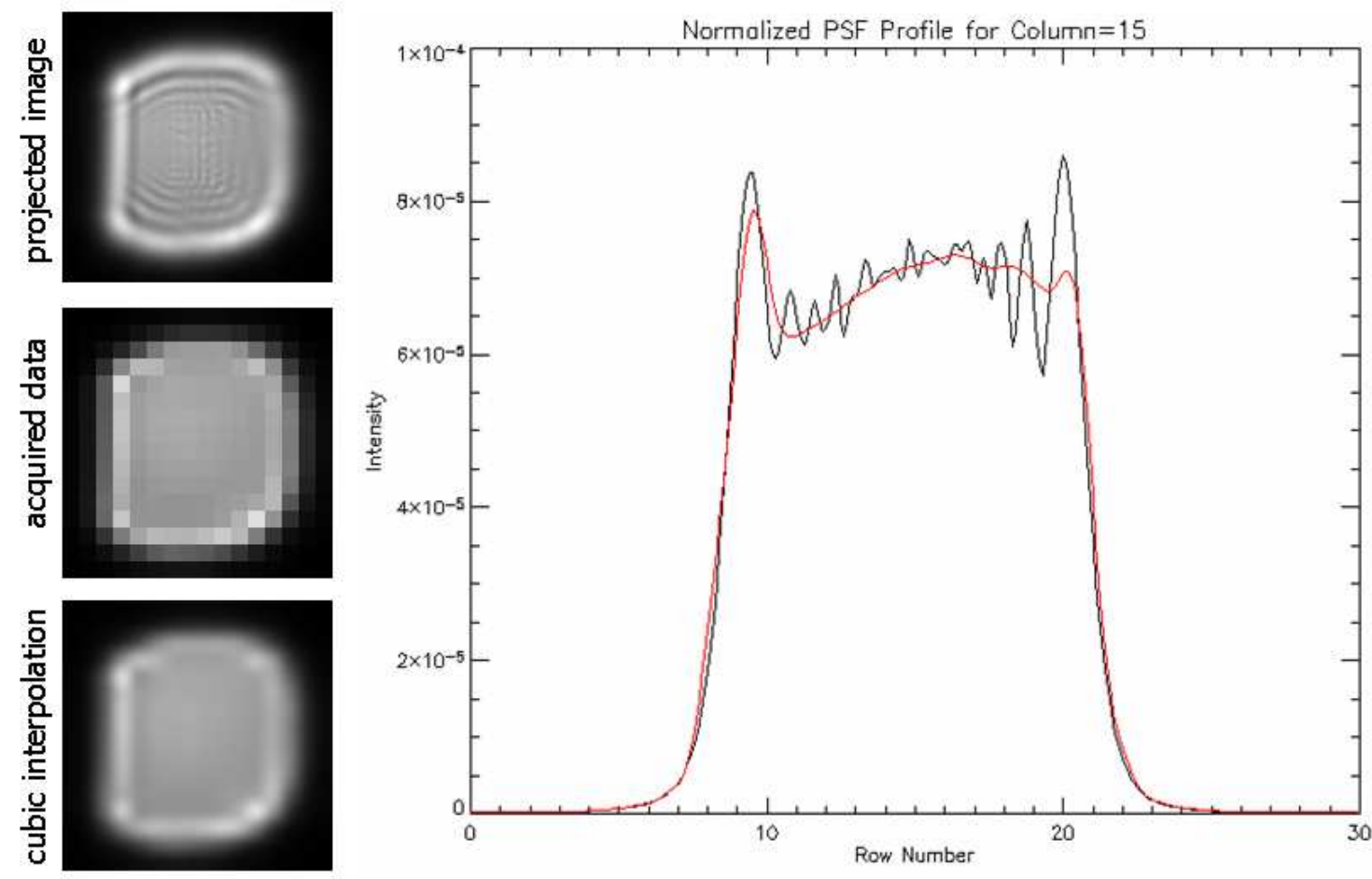

Figura 18. Uma PSF típica do canal de astrossismologia tal como projetada na superfície do CCD (em cima), capturada e sub-amostrada pelo CCD (no meio), e uma interpolação cúbica dos dados para efeitos de comparação (embaixo). À direita são ilustrados os perfis horizontais para a imagem projetada e interpolada. (Pinheiro da Silva, 2007)

Pinheiro da Silva discute em [11] a insuficiência da resolução espacial dos CCDs da missão (píxel de 13,5 $\mu \mathrm{m}$ ) para o registro apropriado de tal PSF, verificando que uma resolução espacial de pelo menos $5 \mu \mathrm{m}$ seria necessária para evitar problemas de aliasing no canal de astrossismologia. Além disso, o processo de amostragem não é ideal, no sentido de que cada amostra capturada corresponde a uma integração sobre a superfície coletora de cada píxel.

Devido à combinação destes efeitos (ver Figura 18), é visível a supressão espacial de detalhes finos da PSF projetada na superfície do CCD e da criação de possíveis assimetrias na imagem capturada.

Além disso, a projeção da PSF na superfície do CCD é susceptível a deslocamentos entre duas exposições consecutivas (Figura 19), dado que a atitude do satélite não é perfeitamente estável. Nesse sentido, usando-se resolução espacial inadequada, o perfil de intensidades da imagem capturada resultaria ser fortemente variável, dependendo da real posição intra-píxel da PSF no plano focal do instrumento. 
Pinheiro da Silva [11] conclui que uma simples imagem capturada, ou uma combinação linear delas, não é capaz de representar a PSF instrumental no caso do CoRoT.

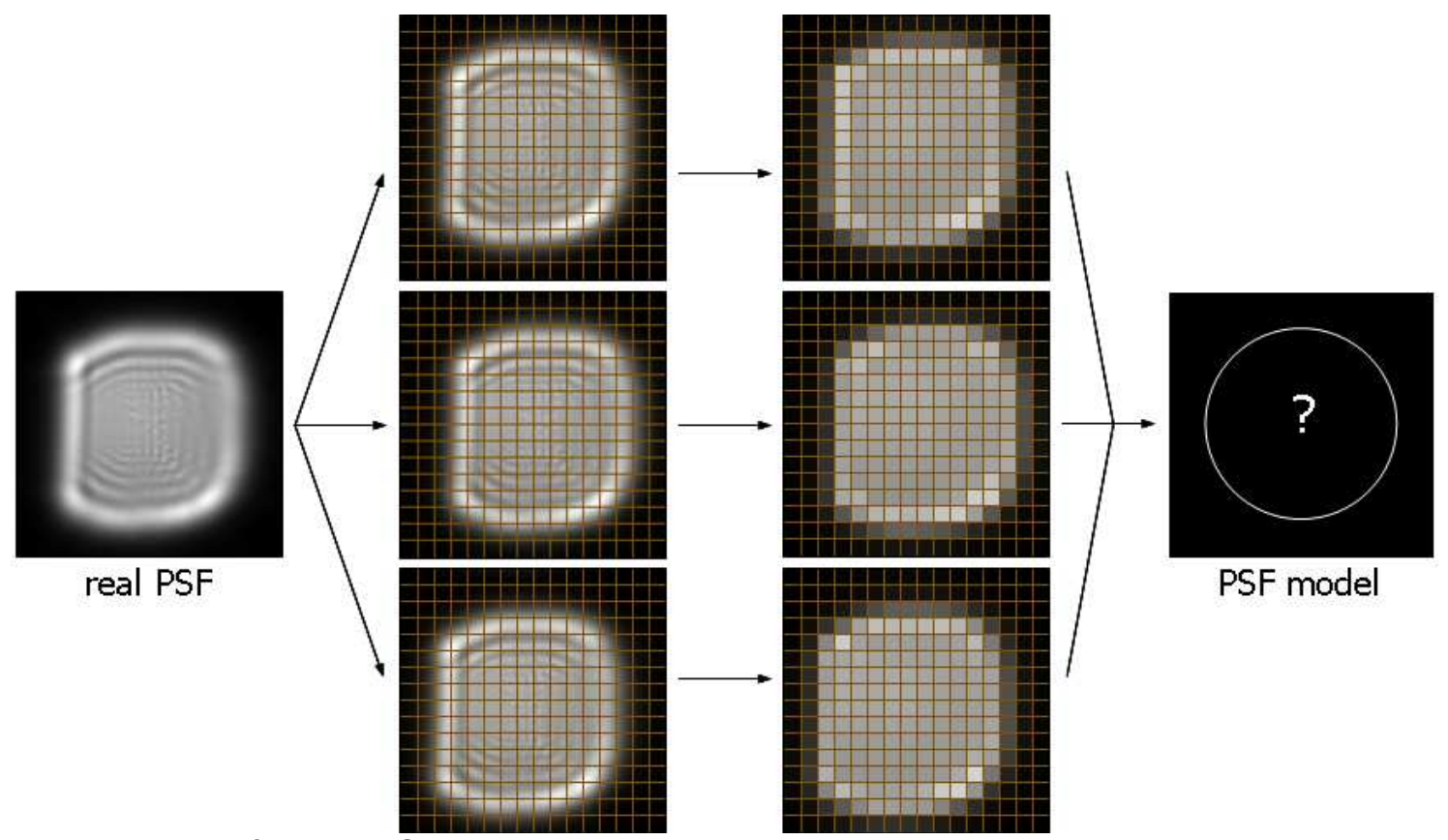

Figura 19. Uma série de PSFs sub-amostradas capturadas na presença de jitter de atitude. Os deslocamentos das imagens em relação à matriz de píxels do CCD estão exagerados para melhor visualização. (Pinheiro da Silva, 2007)

\subsubsection{Borramento por Movimento (motion blur)}

A seção anterior mostrou o efeito da movimentação do satélite (jitter de atitude) entre duas aquisições consecutivas de imagens. Mas, se a variação de posição for rápida em comparação com o tempo de integração efetivo do instrumento, a movimentação do satélite também se fará visível em um efeito de borramento por movimento na imagem capturada do objeto-alvo. A Figura 20 mostra o efeito do borramento por movimento para diferentes tempos de integração de imagem. A figura mostra o efeito de um jitter de atitude gaussiano de \pm 0.3 píxel, para tempos de integração de 1, 8, 16 e 32 segundos. Deve-se lembrar que, no canal de astrossismologia, tempos de integração maiores que 1 segundo são provenientes de 
acumulação de várias aquisições, realizada a bordo devido a restrições de telemetria.

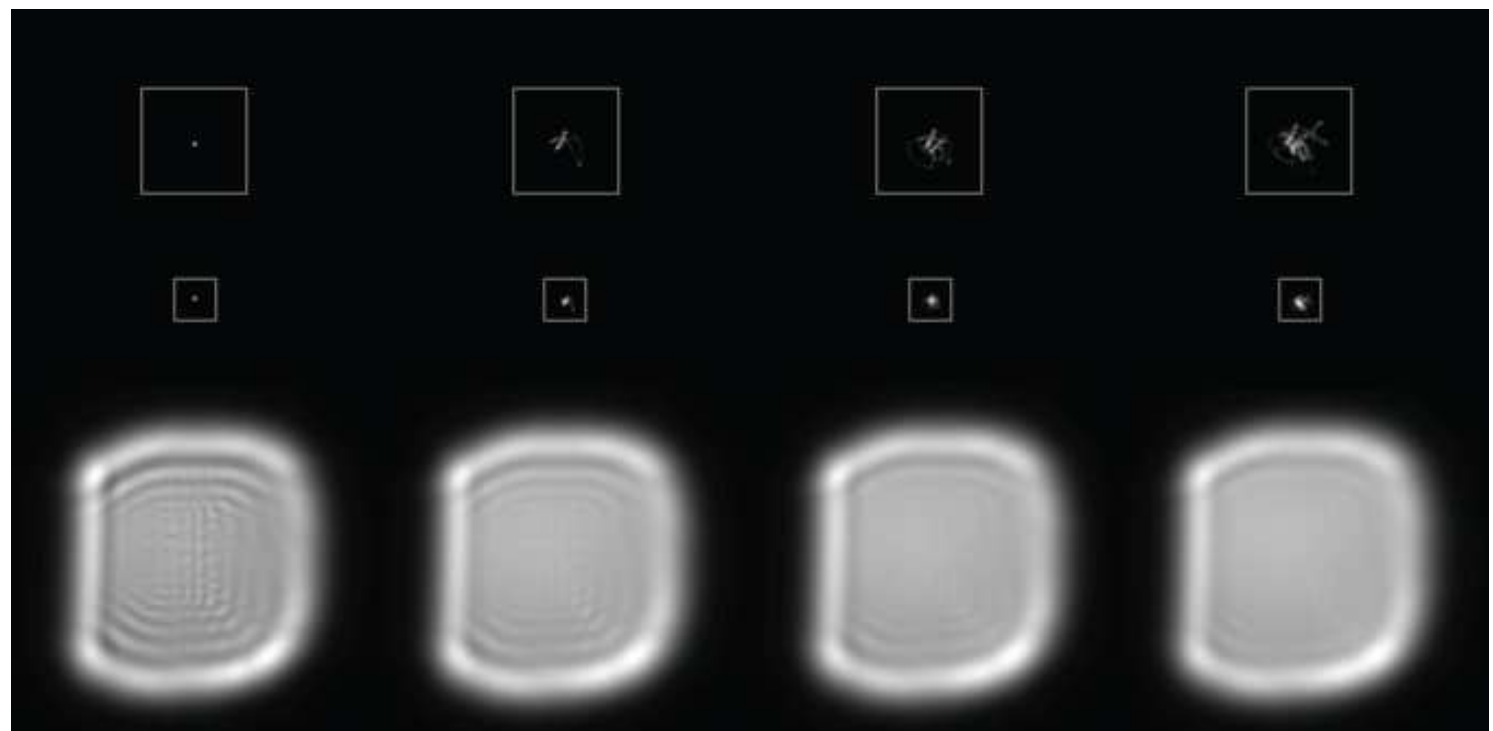

Figura 20. Efeito de borramento por movimento como função do tempo total de integração de captura do CCD. (Pinheiro da Silva, 2007)

O comportamento real de atitude do satélite só pôde ser caracterizado após o seu lançamento, e está composto de pelo menos três componentes distintas: oscilações periódicas, jitter de alta freqüência, e amortecimento de variações abruptas. As variações periódicas são mais visíveis em $P / 2$ (onde $P$ é o período orbital do satélite), juntamente com harmônicas menores em $P / 4$ e $P / 6$, devido a efeitos do campo magnético terrestre e a gradientes gravitacionais na estrutura do satélite. Uma segunda oscilação é visível a $1 / 32 \mathrm{~Hz}$ (e suas harmônicas), tendo origem provavelmente instrumental, dado que corresponde à freqüência de operação da maioria da eletrônica embarcada. O jitter de alta freqüência é introduzido pelo próprio sistema de controle. O sistema garante estabilidade eficaz de até 0.35 segundos de arco (rms) em cada eixo, o que pode ser traduzido como 0.15 píxel em cada direção $(x, y)$ do CCD, pois o tamanho angular do píxel é de 2,32 arcsec.

Finalmente, variações abruptas de atitude são visíveis basicamente durante as transições entre a zona iluminada e a zona de sombra à medida que o satélite orbita a Terra. Estima-se que tais variações sejam devidas a efeitos termo-mecânicos nos painéis solares, que estão posicionados ao longo do eixo $x$ no frame de referência do CCD. De fato, o efeito desta perturbação na posição do baricentro estelar é significativa somente ao longo deste eixo [11]. O efeito de borramento por movimento pode ser significativo para tempos de integração maiores que 1 
segundo. Um tempo de integração de 32 segundos é o valor escolhido para aquisição sistemática no canal de astrossismologia, e pode-se considerar que as imagens correspondentes apresentam um borramento por movimento nãodesprezível. No entanto, dados de atitude do satélite são disponibilizados a $1 \mathrm{~Hz}$, possibilitando a reconstrução de um padrão de convolução (convolution kernel) que representa o borramento por movimento associado a cada imagem estelar.

Uma metodologia efetiva para tal reconstrução foi desenvolvida por Bem-Ezra \& Nayar (2004) em [20]. Primeiro, estima-se a trajetória do satélite durante a integração da imagem projetada no CCD, com interpolação spline bidimensional sobre o conjunto de amostras de baricentro (disponíveis a taxa de $1 \mathrm{~Hz}$ ). Esta trajetória é razoavelmente restrita, dadas as propriedades de diferenciabilidade de uma spline 2D, o que garante mudanças "suaves" de velocidade e aceleração do instrumento. Em seguida, cada ponto da trajetória é ponderado de acordo com o inverso da velocidade instantânea, que pode ser estimada pelo deslocamento entre capturas sucessivas de imagens (ou seja, a distância euclidiana dividida pela taxa de aquisição). Este kernelé então normalizado.

As duas primeiras linhas da Figura 20 mostram as trajetórias derivadas dos valores de baricentro amostrados ao longo das integrações, enquanto que a última linha mostra os kernels derivados destes deslocamentos da PSF sobre a superfície do CCD durante os distintos tempos de integração. Note que regiões mais brilhantes são observadas nos trechos das trajetórias correspondentes a velocidades instantâneas menores, ou seja, onde a imagem foi integrada por mais tempo. A aplicação desta metodologia é usada na reconstrução de PSF para as imagens reais capturadas pelo CoRoT.

\subsubsection{Modelo de Aquisição}

O processo de aquisição descrito na seção anterior pode ser interpretado como uma série de transformações bidimensionais sobre uma PSF de alta resolução, que leva 
a um conjunto de imagens de baixa resolução, tal como representado esquematicamente na Figura 21 abaixo. A PSF instrumental real não é conhecida a priori.

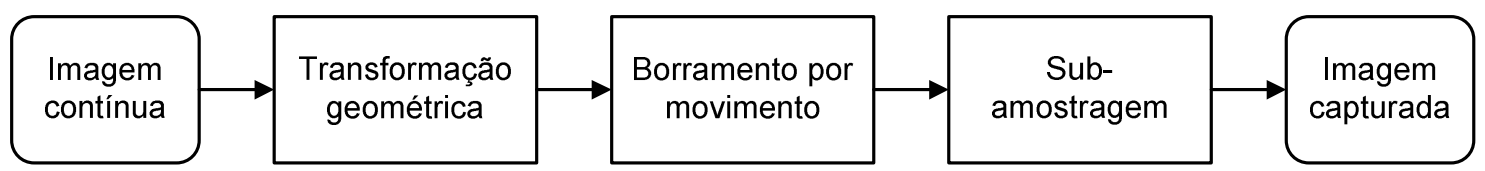

Figura 21. Processo de aquisição instrumental do CoRoT sob efeito de jitter de atitude.

As imagens registradas, à resolução de 1 píxel, são versões sub-amostradas da PSF instrumental (contínua). O efeito de uma resolução pobre de uma PSF na precisão fotométrica pode ser ilustrado com um conjunto de imagens sintéticas, no caso em que a PSF de entrada é obviamente conhecida a priori sem nenhuma incerteza incorporada e pode ser usada posteriormente para efeitos de comparação.

A Figura 22 apresenta os resultados obtidos com a fotometria por ajuste de PSF aplicada a um conjunto de 2000 imagens simuladas de acordo com o modelo de aquisição apresentado na seção anterior (ou seja, um conjunto de imagens transladadas e sub-amostradas). A simulação corresponde a uma estrela brilhante $\left(m_{v}=6\right)$, de modo que os níveis de ruído sejam mínimos e qualquer variação espúria no fluxo luminoso seja visível. A quantidade de dados corresponde a aproximadamente 10 períodos orbitais do instrumento. As translações foram impostas com períodos orbitais e suas harmônicas.

A Figura 22 mostra, em cima, a PSF original, de alta resolução, usada na fotometria por ajuste, e o seu respectivo resultado no sinal fotométrico; embaixo, ilustra-se a PSF sub-amostrada derivada diretamente do conjunto de imagens simuladas, através de compensação do movimento relativo (recentralização do baricentro) e cálculo da média, e seu respectivo resultado no sinal fotométrico.

Como discutido, verifica-se que uma resolução insuficiente leva a medições desiguais de fluxo luminoso para distintas posições da estrela em nível sub-píxel. 0 sinal é portanto significativamente perturbado por variações de atitude do satélite, especialmente em freqüências orbitais e suas harmônicas, mas também em altas freqüências. Quando uma PSF de alta resolução é aplicada, no entanto, o ruído se limita à estatística de Poisson. 

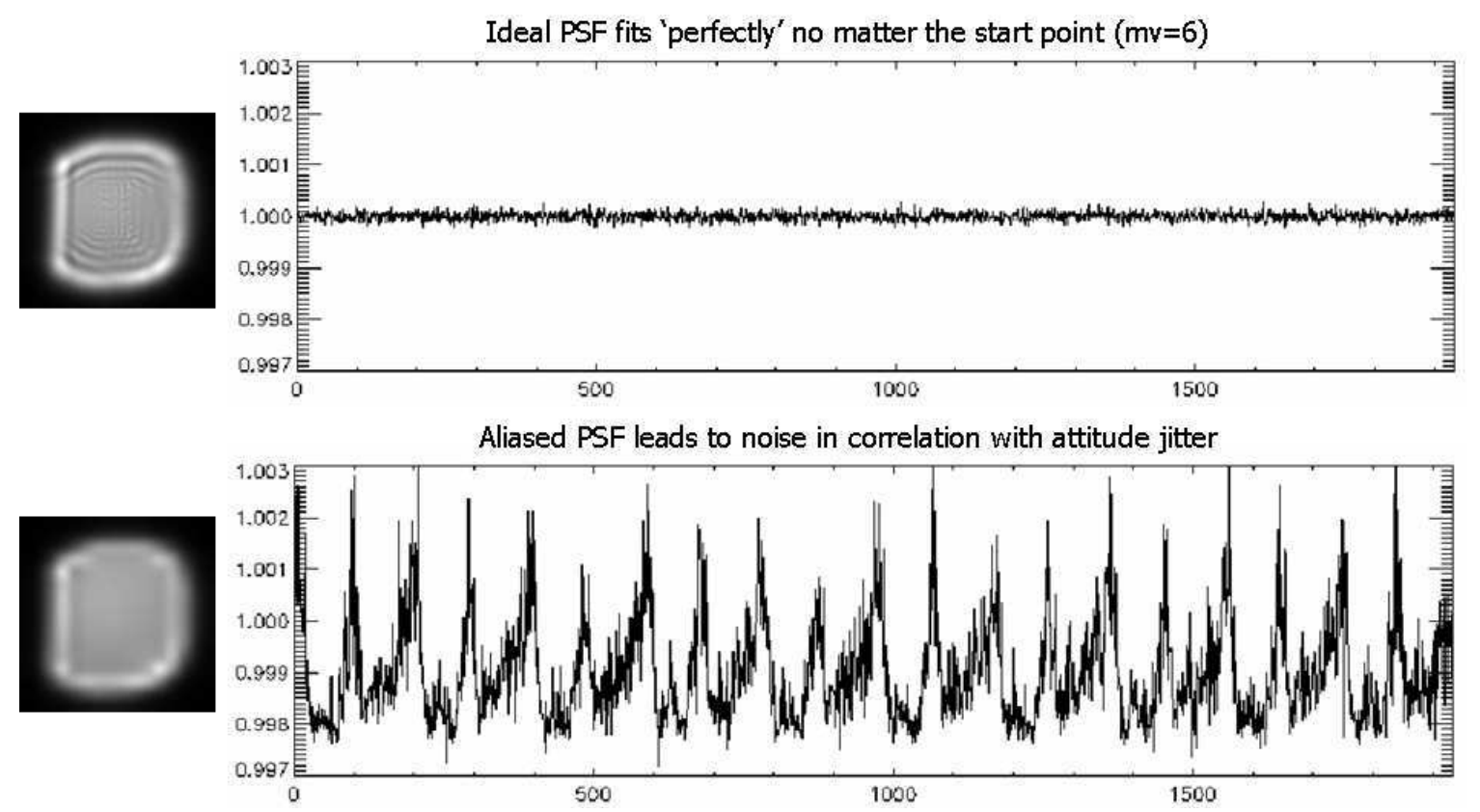

Figura 22. Distintas medições fotométricas causadas pela sub-amostragem e movimento relativo durante o intervalo de captura da imagem: (em cima) uma PSF contínua e definida gera um sinal fotométrico estável e de fácil interpretação astronômica, enquanto que (embaixo) uma PSF subamostrada, borrada, e deslocada gera um sinal fotométrico irregular, de difícil interpretação. (Pinheiro da Silva, 2007)

Na seção seguinte, investiga-se a reconstrução de um modelo de PSF com precisão sub-píxel, através da inversão do próprio modelo de observação.

\subsection{MODELO DE INVERSÃO}

Em geral, técnicas de restituição de dados de alta resolução a partir de um conjunto de dados de baixa resolução são reunidos no domínio da teoria da super-resolução. Diversos algoritmos deste tipo têm sido desenvolvidos nas últimas décadas (por exemplo, Park et al. (2003) [21]; Elad \& Feuer, (1997) [22]). Apesar de seus resultados precisos quando aplicados a cenas comuns, estes algoritmos não estão otimizados para o caso especial de imagens estelares do espaço, pois eles 
assumem um grau de suavidade da solução do problema que não se aplica no caso de um modelo de PSF instrumental.

Um problema é dito bem-posto, no sentido de Hadamard [23], quando sua solução é única e existe para qualquer dado de entrada, e existe uma dependência contínua entre a solução e os dados (pequenas oscilações nos dados geram pequenas oscilações na solução). Um problema que não atenda a estas exigências é dito malposto e, portanto, sua solução ou não é única, ou não existe para um dado de entrada arbitrário, ou não é continuamente dependente deste.

Na prática, a "regra de ouro" para resolver problemas inversos que são mal-postos é buscar soluções aproximadas (regularizadas) que satisfaçam restrições adicionais provenientes da física do problema estudado.

Nesta seção, serão abordadas algumas técnicas de resolução de problemas inversos e seu estudo teórico, e é descrita também uma metodologia particularizada para a estimação de PSFs com detalhes nítidos.

Matematicamente, podem-se entender os processos de degradação de imagem por borramento e por ruídos como um operador linear contínuo (e compacto) $H$ que transforma um elemento $x$ pertecente ao espaço de objetos $X$, em um elemento $y$ pertencente ao espaço de imagens $Y$ '. O espaço $Y$ ' está contido no espaço de imagens ruidosas $Y$. Tal processo pode ser representado por

$$
y=H x+w
$$

onde $y$ é a imagem capturada, $x$ é o objeto de interesse, $H$ é um operador compacto e $w$ é o ruído associado. A figura que se segue ilustra o processo de degradação durante a aquisição de uma imagem bidimensional por um instrumento genérico (câmera fotográfica, de vídeo, etc):

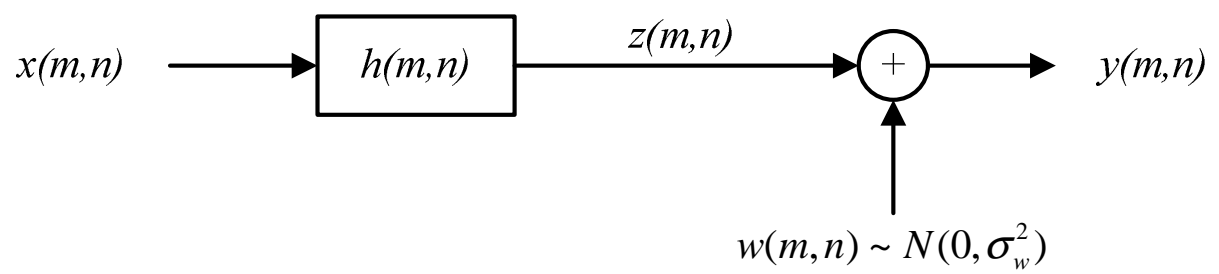

Figura 23. Processo de aquisição de imagens por um instrumento genérico: o efeito borramento pode ser modelado pro um filtro linear, enquanto que o ruído associado à captura pode ter propriedades estatísticas conhecidas. 
Note que o filtro linear $h(m, n)$ é uma instanciação prática do operador compacto $H$. Note ainda que a imagem $z(m, n)$ pertencente ao espaço $Y^{\prime}$ é uma convolução entre o objeto $x(m, n)$ e o operador $h(m, n)$, também chamado de função resposta impulsiva ou point spread function (PSF) do sistema linear de imageamento. O termo PSF deriva do fato de que $h(m, n)$ é a imagem de uma fonte pontual produzida pelo sistema. De fato, uma imagem capturada nada mais é do que a resposta impulsiva integrada sobre infinitas fontes pontuais que caracterizam o brilho (próprio ou refletido) de um objeto, o que caracteriza a operação de convolução.

\subsection{TÉCNICAS DE FILTRAGEM INVERSA}

A restauração das degradações sofridas pela imagem durante a sua captura envolve basicamente a inversão do filtro de borramento. No entanto, como se verá a seguir, a simples filtragem inversa é um problema mal-posto, no sentido de Hadamard, e, portanto, sua solução ou não é única, ou não existe para um dado de entrada arbitrário, ou não é continuamente dependente deste.

Usando-se da Transformada de Fourier (FT) [23], pode-se interpretar a Eq. 4 como sendo o processo de aquisição de imagens no domínio espacial, enquanto que sua contrapartida no domínio espectral pode ser definido como:

$$
\hat{y}\left(\omega_{1}, \omega_{2}\right)=\hat{H}\left(\omega_{1}, \omega_{2}\right) \hat{x}\left(\omega_{1}, \omega_{2}\right)+\hat{w}\left(\omega_{1}, \omega_{2}\right)
$$

onde $\hat{y}\left(\omega_{1}, \omega_{2}\right)$ é a contrapartida espectral da matriz espacial bidimensional $y(m, n)$ ilustrada na Figura 23. A seguir serão apresentados os filtros de borramento comumente utilizados e algumas das técnicas de filtragem inversas desenvolvidas ao longo de recentes décadas. 


\subsubsection{Filtro de Borramento (Blurring Filter)}

O operador compacto $H$ da Eq. 4 é ilustrado como um filtro linear $h(m, n)$ na Figura 23 e, como regra geral, pode ser aproximado por um filtro gaussiano, no caso de um borramento por desfoque, e por um filtro passa-baixas 2D na direção do movimento, no caso de borramento por movimento relativo. As figuras a seguir ilustram estas aproximações:

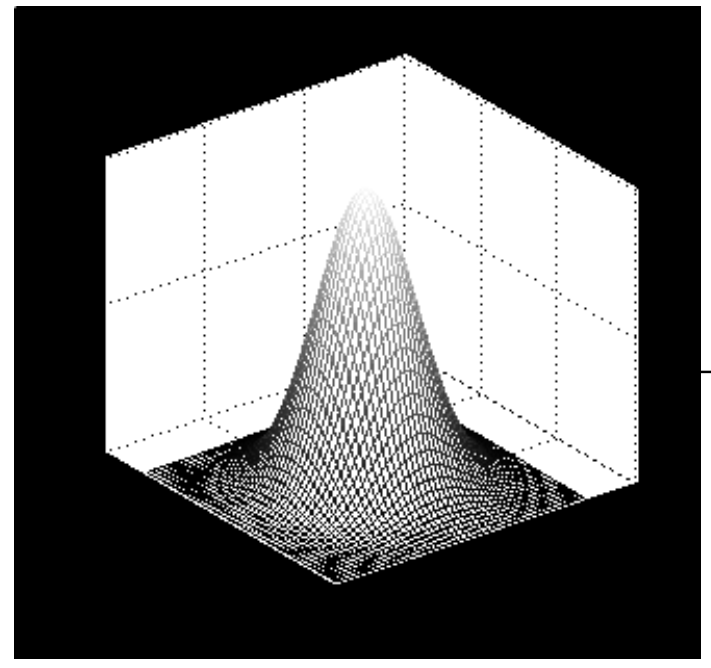

(a) $h(m, n)=\exp \left(-\frac{m^{2}+n^{2}}{2 \sigma^{2}}\right)$

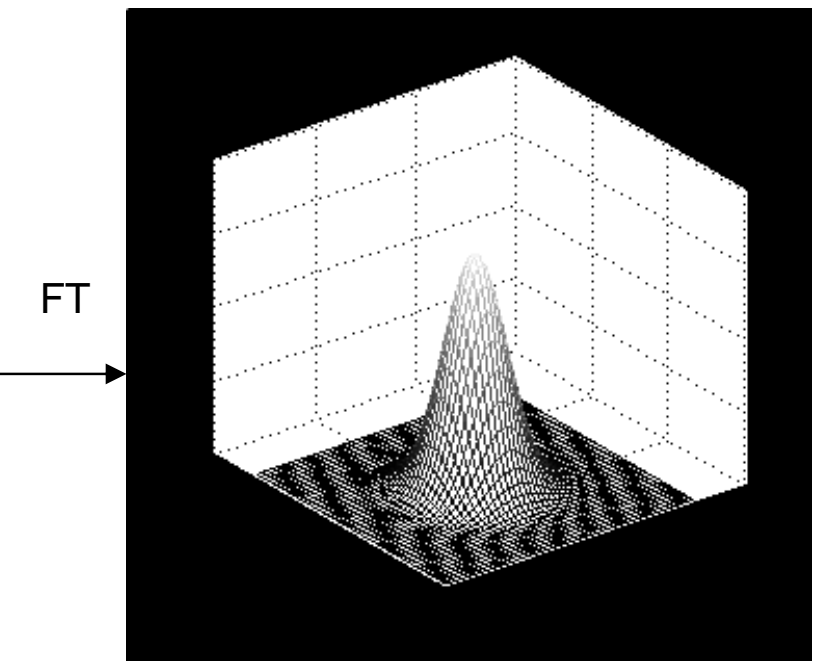

(b) $\hat{H}\left(\omega_{1}, \omega_{2}\right)=\exp \left(-\frac{\omega_{1}^{2}+\omega_{2}^{2}}{2 \sigma^{2}}\right)$

Figura 24. Um filtro gaussiano pode ser usado como aproximação do operador $h(m, n)$.

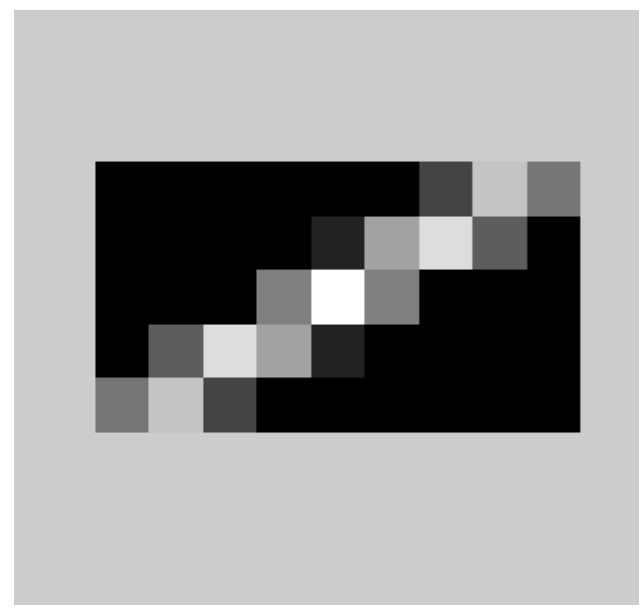

(a) $h(m, n)$

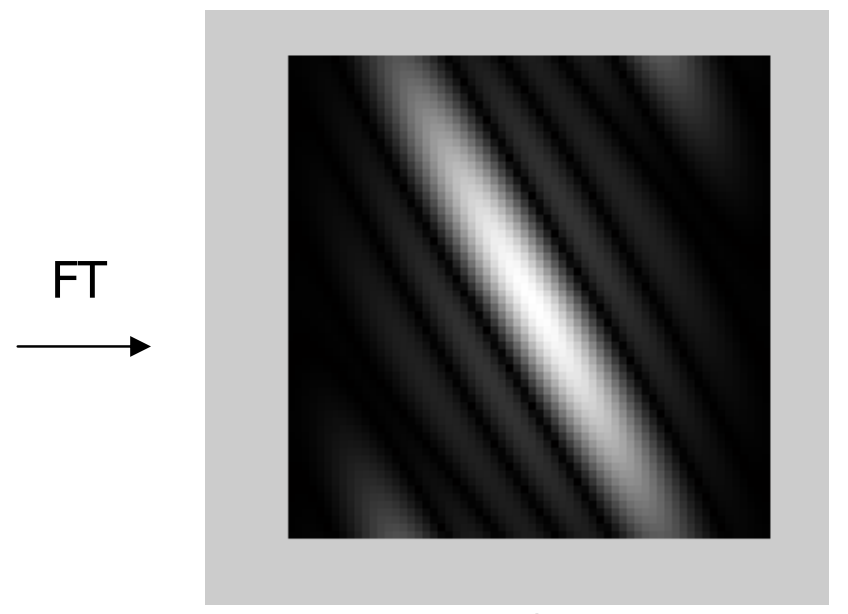

(b) $\hat{H}\left(\omega_{1}, \omega_{2}\right)$

Figura 25. Um filtro passa-baixas pode ser usado como aproximação para um borramento por movimento. 
Ambas as figuras apresentam o filtro de borramento no domínio espacial, $h(m, n)-$ Figura 24(a) e Figura 25(a) - e seu correspondente $\hat{H}\left(\omega_{1}, \omega_{2}\right)$ no domínio espectral - Figura 24(b) e Figura 25(b).

\subsubsection{Filtragem Inversa}

Considere-se uma versão sem ruído da Eq. 4, dada por

$$
y=H x
$$

Eq. 6

onde as imagens $x$ e $y$ são vetores lexicográficos. Sua TF, dada por

$$
\hat{y}\left(\omega_{1}, \omega_{2}\right)=\hat{H}\left(\omega_{1}, \omega_{2}\right) \hat{x}\left(\omega_{1}, \omega_{2}\right)
$$

A solução imediata para o problema acima pode ser então dada por

$$
\hat{x}\left(\omega_{1}, \omega_{2}\right)=\frac{\hat{y}\left(\omega_{1}, \omega_{2}\right)}{\hat{H}\left(\omega_{1}, \omega_{2}\right)} \Rightarrow \hat{x}=\frac{\hat{y}}{\hat{H}} \Rightarrow \hat{x}=\hat{H}^{-1} \hat{y}
$$

Não se pode garantir, no entanto, que $\hat{H}\left(\omega_{1}, \omega_{2}\right)$ seja sempre invertível. A solução $\hat{x}\left(\omega_{1}, \omega_{2}\right)$ dependente da inversa $\hat{H}^{-1}\left(\omega_{1}, \omega_{2}\right)$ não existirá, em última análise, quando $\hat{y}\left(\omega_{1}, \omega_{2}\right)$ convergir a zero mais lentamente que $\hat{H}\left(\omega_{1}, \omega_{2}\right)$, o que transforma a Eq. 8 em um problema mal-posto, no sentido de Hadamard (sua solução não é continuamente dependente da entrada).

\subsubsection{Filtragem Inversa - tratamento de ruído}


Voltando-se à versão ruidosa do sistema de aquisição de imagens da Figura 23, as Eq. 5 e Eq. 8 implicam que a FT da solução do problema proposto pela Eq. 4 pode ser dada por

$$
\hat{x}=\hat{H}^{-1} \hat{y}=\hat{H}^{-1}\left(\hat{H} \hat{x}_{0}+\hat{w}\right)=\hat{x}_{0}+\frac{\hat{w}}{\hat{H}}
$$

onde $\hat{x}$ é a imagem restaurada e $\hat{x}_{0}$ é o objeto (ou cena) original. Note que o termo de ruído é amplificado caso $\hat{H}$ possua pelo menos um elemento igual a zero. Matematicamente, $H$ contínua não possui inversa contínua, o que classifica o problema proposto pela Eq. 4 como mal-posto.

\subsubsection{Filtragem com Pseudo-Inversa}

Observando-se a Eq. 9 acima, é fácil perceber que a solução aproximada $\hat{x}$ (imagem restaurada) em geral não coincide com a imagem original $\hat{x}_{0}$. A diferença entre a imagem computada $H x$ e a imagem medida y é chamada de resíduo e denotada por

$$
r=|H x-y| .
$$

Eq. 10

A norma quadrada do resíduo é chamada de discrepância, e no caso discreto, é definido como a raiz do erro médio quadrático cometido ao se estimar $y$ através de $H x$.

Considere a Eq. 6 e o funcional discrepância $\phi_{d}$ definido a seguir:

$$
\phi_{d}=\|H x-y\|^{2}
$$

O elemento $x$ que minimiza o funcional discrepância $\phi_{d}$ é também solução para o problema proposto pela Eq. 6 (e vice-versa). Devido à definição de $\phi_{d}$, tal solução $x$ é também chamada de solução do problema dos mínimos-quadrados. 
Observe, agora, que na Eq. 8, $\hat{H}^{-1}$ representa o operador inverso do operador compacto $\hat{H}$ definido na Eq. 6. Pode-se, então, definir um operador inverso generalizado de $\hat{H}$, denotado por $\hat{H}^{\dagger}$, tal que

$$
\hat{x}^{\dagger}=\hat{H}^{\dagger} \hat{y}
$$

Eq. 12

onde $\hat{x}^{\dagger}$ é a solução generalizada do problema proposto pela Eq. 4.

Desta forma, a solução generalizada $\hat{x}^{\dagger}$ é também solução para o problema proposto pela Eq. 4 (e, em particular, para a Eq. 6).

Pode-se provar [23] que a solução do problema dos mínimos quadrados, $\hat{x}$, é também uma solução generalizada $\hat{x}^{\dagger}$ quando o operador inverso generalizado $\hat{H}^{\dagger}$ for dado por

$$
\hat{H}^{\dagger}=\left(\hat{H}^{*} \hat{H}\right)^{-1} \hat{H}^{*}
$$

ou seja, quando a Eq. 12 for dada por

$$
\hat{H}^{*} \hat{y}=\hat{H}^{*} \hat{H} \hat{x}
$$

onde $\hat{H}^{*}$ é o operador adjunto (transposto conjugado) de $\hat{H}$. O operador $\hat{H}^{\dagger}$ definido na Eq. 13 acima é também chamado de operador pseudo-inverso.

Em aplicações práticas, há um tratamento particular dos elementos do operador $H$ que estão muito próximos de zero, para que o operador pseudo-inverso $\hat{H}^{\dagger}$ possa existir matematicamente:

$$
\hat{H}^{\dagger}=\left\{\begin{array}{c}
\frac{1}{\hat{H}}, s e|\hat{H}| \geq \delta \\
0, s e|\hat{H}|<\delta
\end{array},\right.
$$

onde $\delta>0$ é um valor não-negativo arbitrariamente pequeno, ajustado pelo programador. 


\subsubsection{Filtragem Regularizada}

Como visto na seção anterior, a definição de um operador pseudo-inverso $\hat{H}^{\dagger}$ como o da Eq. 13 não garante a sua linearidade e, portanto, o problema original (Eq. 12) continua mal posto. Porém, introduzindo-se um termo de restrição na solução $x$ do problema, pode-se regularizar o operador generalizado $\hat{H}^{\dagger}$, tornando-o contínuo. $O$ funcional discrepância $\phi_{d}$ assume então a seguinte forma:

$$
\phi_{d}=\|H x-y\|^{2}+\mu\|x\|^{2}
$$

onde $\mu\|x\|^{2}$ é o termo de restrição imposta à solução $x$. Dependendo da literatura, o coeficiente $\mu>0$ é chamado de multiplicador de Lagrange [23] ou de regularizador de Tikhonov. Note que se $\mu=0$, a Eq. 16 acima volta a assumir a forma da Eq. 13 e, portanto, volta-se a trabalhar com o operador pseudo-inverso.

Pode-se provar [23] que a solução $\hat{x}$ que minimiza $\phi_{d}$ acima definida também é uma solução generalizada $\hat{x}^{\dagger}$ quando o operador inverso generalizado $\hat{H}^{\dagger}$ for dado por

$$
\hat{H}^{\dagger}=\left(\hat{H}^{*} \hat{H}+\mu I\right)^{-1} \hat{H}^{*},
$$

ou seja, quando a Eq. 12 for dada por

$$
\hat{H}^{*} \hat{y}=\hat{H}^{*} \hat{H} \hat{x}+\mu \hat{x}=\left(\hat{H}^{*} \hat{H}+\mu I\right) \hat{x} .
$$

onde $\hat{H}^{*}$ é o operador adjunto de $\hat{H}$. Reescrevendo-se a Eq. 18 acima, pode-se encontrar a solução generalizada $\hat{x}^{\dagger}$ através de

$$
\hat{x}=\left(\hat{H}^{*} \hat{H}+\mu I\right)^{-1} \hat{H}^{*} \hat{y} .
$$

e, portanto, a solução $\hat{x}$ do problema original (Eq. 4).

Note que o termo de restrição $\mu\|x\|^{2}$ inserido em $\phi_{d}$ poderia ser modificado para impor continuidade nas derivadas de 1a, 2a, (etc), ordem da solução $x$ através de 


$$
\phi_{d}=\|H x-y\|^{2}+\mu_{0}\|I x\|^{2}+\mu_{1}\left\|C_{1} x\right\|^{2}+\mu_{2}\left\|C_{2} x\right\|^{2}+\ldots
$$

onde $C_{1}$ e $C_{2}$ podem, por exemplo, ser operadores gaussianos e laplacianos, respectivamente (Generalização de Sobolev).

Deve-se observar que a própria definição do operador regularizado (Eq. 17) implica, para o problema original (Eq. 4), que a norma do resíduo $r$ (por igualdade de Parseval, [23]) será dada por

$$
\|r\|^{2}=\|\hat{H} \hat{x}-\hat{y}\|^{2}=\frac{\mu^{2}}{\left(|\hat{H}|^{2}+\mu\right)^{2}}\left|\hat{x}_{0}\right|^{2}+\frac{|\hat{H}|^{2}}{\left(|\hat{H}|^{2}+\mu\right)^{2}}|\hat{w}|^{2} .
$$

A norma do resíduo, $\|r\|^{2}$, também é chamada de erro de restauração, e é limitada pela soma do erro de aproximação com o erro de propagação de erro. O erro de aproximação (primeiro termo do lado direito da Eq. 21) é devido à aproximação do operador inverso pelo operador regularizado, enquanto que o erro de propagação de erro (segundo termo do lado direito da Eq. 21) quantifica a propagação do erro da imagem capturada $y$ à solução generalizada e regularizada $x$.

É importante ressaltar que o erro de aproximação é uma função contínua crescente com o valor de $\mu$, enquanto que 0 erro de propagação de erro é uma função contínua decrescente com o valor de $\mu$. Portanto, haverá sempre um compromisso entre estes dois termos em relação ao valor $\mu$ escolhido: ao decrescer-se um valor inicial de $\mu$, a solução regularizada $x$ se aproxima da solução exata $x_{0}$ em um primeiro momento e então diverge deste. Esta propriedade é chamada de semiconvergência [23]. Portanto, para uma imagem sem ruídos $z$, a solução regularizada $x$ converge para a solução exata $x_{0}$, enquanto que para uma imagem ruidosa $y$, a solução regularizada $x$ apresenta semi-convergência para a solução exata $x_{0}$. A semi-convergência é uma propriedade adicional, desejada para a implementação prática de um algoritmo regularizado de solução de problemas inversos. 


\subsubsection{Iteração de Landweber}

A velocidade e versatilidade dos computadores modernos permitem a restauração interativa de imagens, através do controle de parâmetros de regularização. Sintonizando o parâmetro $\mu$, o usuário é capaz de selecionar a melhor restauração com base em sua intuição visual ou em algum critério pré-definido.

Métodos iterativos vêm sendo utilizados para a solução de problemas lineares malpostos. A característica principal deles é que o número de iterações atua como parâmetro de regularização, devido à propriedade de semi-convergência dos operadores regularizados para imagens ruidosas: à medida que o número de iterações aumenta, a solução regularizada se aproxima da solução exata em um primeiro momento e então diverge. $\mathrm{O}$ algoritmo iterativo mais simples que apresenta estas propriedades é o chamado método de Landweber ou método das aproximações sucessivas [23].

\subsubsection{Operadores de Contração e Operadores Não-Expansivos}

O fundamento matemático em que se baseia o método de Landweber é o conceito de operadores de contração e operadores não-expansivos [23].

Um operador $T$ em um espaço $X$ de Hilbert é dito contração se existe uma constante $\rho<1$ tal que, para qualquer par $x_{1}, x_{2} \in X$ vale a relação

$$
\left\|T x_{1}-T x_{2}\right\| \leq \rho\left\|x_{1}-x_{2}\right\| .
$$

Um ponto fixo de uma contração $T$ é qualquer elemento $x \in X$, tal que

$$
T x=x
$$


e sua existência está assegurada pelo princípio de contração: para qualquer elemento inicial $x_{0}$, pode-se provar por seqüência de Cauchy [23] que a seqüência de aproximações sucessivas

$$
x_{j+1}=T x_{j}
$$

é convergente e seu limite é o único ponto fixo de $T$.

Já um operador $T$ em um espaço $X$ de Hilbert é dito não-expansivo se valer a relação

$$
\left\|T x_{1}-T x_{2}\right\| \leq\left\|x_{1}-x_{2}\right\|
$$

e, neste caso, pode-se provar que $T$ possui um ponto fixo, mas o princípio da contração não se aplica neste caso, ou seja, não se pode provar que a seqüência da Eq. 24 seja convergente.

Considere, no contexto de solução de problemas inversos, o operador

$$
T x=x+\tau(y-H x)
$$

onde $\tau$ é o parâmetro de relaxação, responsável pela aceleração da convergência (menos iterações são necessárias ao aumentar-se $\tau$ ) [23].

O método de aproximações sucessivas, acima descrito, é o modo mais natural de se aproximar iterativamente um elemento $x$ ao ponto fixo de uma contração $T$.

Matematicamente, o operador da Eq. 26 é em geral um operador não-expansivo; porém, em espaços discretos, torna-se um operador de contração, e pode-se usar o método de aproximações sucessivas para encontrar o seu ponto fixo. Assim, podese substituir a Eq. 26 por

$$
x_{j+1}=x_{j}+\tau\left(y-H x_{j}\right)
$$

e seu par espectral

$$
\hat{x}_{j+1}=\hat{x}_{j}+\tau\left(\hat{y}-\hat{H} \hat{x}_{j}\right) .
$$


Em particular, considerando-se o regularizador de Tikhonov descrito na seção anterior, obtém-se

$$
\hat{x}_{j+1}=\hat{x}_{j}+\tau\left(\hat{H}^{*} \hat{y}-\left(\hat{H}^{*} \hat{H}+\mu I\right) \hat{x}_{j}\right) .
$$

Com isso, obteve-se um método iterativo que realiza a solução de problemas inversos usando o número de iterações como parâmetro regularizador do algoritmo. Este método é chamado de Método de Landweber.

Uma das principais vantagens práticas da iteração de Landweber é o fato de este não envolver nenhuma operação inversa, o que a torna mais rápida do que algoritmos que usem, por exemplo, divisão por matriz. Outra vantagem está relacionada com a propriedade de semi-convergência do método: com o número de iterações, $j$, atuando como parâmetro de regularização, pode-se parar a iteração para evitar a amplificação do ruído.

Finalmente, outra característica interessante deste método é que ele permite a incorporação de conhecimento a priori sobre a solução. Esta informação adicional sobre o objeto imageado "compensa" a informação perdida durante o processo de aquisição de imagem. Ela é dita adicional, pois não pode ser derivada diretamente da imagem ou das propriedades do operador $H$ que descreve o processo de imageamento, mas sim de propriedades físicas esperadas do objeto a ser imageado. Sua função é reduzir o conjunto de objetos compatíveis com uma dada imagem.

O exemplo mais simples de informação a priori sobre um dado objeto é que ele não pode ser muito "grande". Isto implica que deve existir um limite superior para o objeto em si na imagem, ou para a sua intensidade, ou para a sua energia, etc. Outro tipo de informação adicional pode ser a suavidade do objeto, ou seja, suas derivadas devem ser contínuas. Também pode-se considerar a não-negatividade de um objeto real como informação adicional, ou mesmo propriedades estatísticas do mesmo.

O princípio dos métodos de regularização acima descritos é o uso explícito de informação adicional para a construção de famílias de soluções aproximadas. Estes métodos são uma das ferramentas mais poderosas para a solução do problema 
inverso, juntamente com métodos bayesianos [23], nos quais a informação adicional é de natureza estatística.

\subsection{TÉCNICAS DE SUPER-RESOLUÇÃO}

Nesta seção se apresentará a aplicação prática do método iterativo de Landweber como técnica de super-resolução para o projeto CoRoT, ou seja, a partir de uma seqüência de imagens de baixa-resolução, chegar-se a uma imagem de alta resolução do objeto imageado.

A qualidade do método de fotometria por ajuste de PSF depende, em grande parte, do conhecimento da própria PSF, que pode variar de acordo com a estrela. Pode ser então necessária a disposição de um modelo para cada estrela, que deve ser conhecido com uma resolução melhor (maior) que a do instrumento de aquisição. A determinação deste modelo pode ser feita por uma abordagem analítica com a ajuda de um modelo matemático, ou por uma abordagem empírica, interpolando-se as imagens observadas. A primeira abordagem limita-se a partir do momento em que a imagem borrada torna-se complexa, e a segunda demanda precauções relacionadas às imagens sub-amostradas, como já descrito anteriormente (Seção 8.1). Uma vez que estes modelos sejam conhecidos, o ajuste pode ser realizado pelo método clássico de mínimos quadrados.

As principais vantagens deste método são a precisão apresentada e a robustez ao deslocamento da imagem borrada da estrela ao longo do CCD. Sua principal desvantagem, no entanto, é a demanda de tempo de processamento.

\subsubsection{Aquisição de Imagens}


A abordagem clássica para a reconstrução de uma imagem super-resolvida através da inversão de um modelo de observação será apresentada nesta seção, juntamente com as derivações matemáticas e seus detalhes teóricos.

Seja agora $X$ uma imagem (ou cenário) de resolução arbitrária, registrada por um dado sistema de aquisição, na presença de movimento relativo do dispositivo (em relação ao cenário) entre distintas aquisições, e considerando uma resolução espacial finita de seu detector (CCD, por exemplo). Cada aquisição $Y_{k}(k=1,2, \ldots, M)$ da imagem $X$ pode ser descrita como

$$
Y_{k}=D \cdot B_{k} \cdot W_{k} \cdot X+\eta_{k}
$$

onde $B_{k}$ é uma matriz que representa o borramento associado ao sistema óptico, $W_{k}$ é a transformação geométrica apresentada em cada imagem devido ao movimento relativo, supostamente conhecido (pois o satélite CoRoT envia esta informação via telemetria), e $D$ representa a sub-amostragem realizada pelo detector. O ruído intrínseco ao processo de aquisição da imagem é representado por $\eta_{k}$. As imagens $X$ e $Y_{k}$ são vetores no formato lexicográfico. Note que a Eq. 30 acima é uma instanciação prática da Eq. 4 matemática.

\subsubsection{Solução do Problema Inverso}

A teoria da super-resolução lida com a solução do problema inverso. Dado um conjunto de imagens $Y_{k}$ de baixa resolução, e supondo que $D, B_{k}$ e $W_{k}$ são conhecidos, deseja-se estimar uma imagem $X$ de alta resolução. Seja $\hat{X}$ a imagem estimada baseada no método dos mínimos quadrados, que minimiza a função discrepância $\phi_{d}$, dada matematicamente pela Eq. 11 e definida na prática por

$$
\phi_{d}=\sum_{k=1}^{N}\left[Y_{k}-D \cdot B_{k} \cdot W_{k} \cdot X\right]^{T}\left[Y_{k}-D \cdot B_{k} \cdot W_{k} \cdot X\right]
$$


A solução teórica pode ser derivada da expressão acima, igualando-se a sua primeira derivada a zero, o que leva à equação matricial

$$
\sum_{k=1}^{N}\left[W_{k}^{T} B_{k}^{T} D^{T} D B_{k} W_{k}\right] \hat{X}=\sum_{k=1}^{N}\left[W_{k}^{T} B_{k}^{T} D^{T} Y_{k}\right]
$$

Infelizmente, a solução direta desta equação é raramente possível, pois, matematicamente, o operador acima não possui inversa contínua. O problema da super-resolução é conhecido por ser, em geral, mal-posto, tal que não necessariamente exista uma solução única, e a matriz do termo à esquerda da igualdade é geralmente singular. Além disso, as dimensões das matrizes crescem rapidamente com a resolução desejada, deixando a operação de inversão de matrizes computacionalmente impraticável.

Estes problemas são normalmente tratados em dois passos. Primeiro, para estabilizar a solução, um termo de regularização é introduzido no funcional discrepância

$$
\phi_{d}=\sum_{k=1}^{N}\left\|Y_{k}-D B_{k} W_{k} X\right\|^{2}+\mu\|C X\|^{2},
$$

onde $C$ é geralmente um operador que penaliza as altas freqüências nas imagens reconstruídas e, portanto, que favorece soluções suavizadas (um operador laplaciano, por exemplo), e $\mu$ é um parâmetro de regularização ajustável (regularizador de Tikhonov). Note que a Eq. 33 acima é uma particularização da Eq. 20. Derivando-se a equação acima, tem-se, então

$$
\sum_{k=1}^{N}\left[W_{k}^{T} B_{k}^{T} D^{T} D B_{k} W_{k}+\mu C^{T} C\right] \cdot \hat{X}=\sum_{k=1}^{N}\left[W_{k}^{T} B_{k}^{T} D^{T} Y_{k}\right]
$$

Segundo, um algoritmo iterativo é empregado na solução desta equação, para possibilitar a sua implementação computacional prática, independente das dimensões das matrizes envolvidas. Uma escolha comum para este algoritmo é a do método de Landweber descrito na seção anterior. Neste caso prático, a Eq. 29 será então instanciada como 


$$
\hat{X}_{j+1}=\hat{X}_{j}+\tau \sum_{k=1}^{N}\left(\left[W_{k}^{T} B_{k}^{T} D^{T} Y_{k}\right]-\left[W_{k}^{T} B_{k}^{T} D^{T} D B_{k} W_{k}+\mu C^{T} C\right] \cdot \hat{X}_{j}\right),
$$

onde $\tau$ é o passo de convergência (parâmetro de relaxação) definido pelo usuário.

\subsubsection{Resolução de Problemas Inversos aplicado à Fotometria por Ajuste de PSF}

O algoritmo descrito na seção anterior representa a solução regularizada clássica para o problema de restauração de características de altas freqüências de um conjunto de imagens. Nos últimos anos, muitas variantes têm evoluído em busca de uma melhor performance computacional, ou objetivando ultrapassar algumas de suas limitações intrínsecas. Particularmente, para a reconstrução de PSF, o desempenho computacional não é um tópico crítico em sua implementação, dado que imagens de estrelas individuais são tipicamente pequenas e um algoritmo simples é normalmente suficiente para alcançar a convergência dentro de um intervalo razoável de tempo.

No entanto, um método alternativo de regularização será necessário se deseja-se preservar e restaurar as bordas acentuadas. Para uma estimação voltada para fotometria por ajuste com resolução temporal, uma escolha efetiva é usar um termo de regularização baseado na comparação entre os candidatos a solução $\hat{X}_{j}$ e uma estimação, denominada $\hat{X}_{0}$, sub-amostrada da PSF com bordas bem-definidas desejada. Isto corresponde à minimização de

$$
\phi=\sum_{k=1}^{N}\left\|Y_{k}-D B_{k} W_{k} X\right\|^{2}+\lambda\left\|X-\hat{X}_{0}\right\|^{2}
$$

O parâmetro $\hat{X}_{0}$ é calculado a priori como a média de todas as imagens de entrada, após uma etapa de recentralização para compensar o movimento relativo e outra de interpolação cúbica para alcançar a resolução desejada. Este parâmetro é 
denominado $\hat{X}_{0}$ pois parece ser interessante utilizá-lo como ponto de partida no processo recursivo, para obtenção de resultados mais rápidos, apesar de isto não ser um requisito para a convergência. Pode-se mostrar que a regra recursiva correspondente a esse raciocínio é

$$
\hat{X}_{j+1}=\hat{X}_{j}+\tau \sum_{k=1}^{N}\left(\left[W_{k}^{T} B_{k}^{T} D^{T}\right] Y_{k}-\left[W_{k}^{T} B_{k}^{T} D^{T} D B_{k} W_{k}\right] \hat{X}_{j}-\mu\left[\hat{X}_{j}-\hat{X}_{0}\right]\right)
$$

onde o parâmetro de relaxação, $\tau$, controla a velocidade de convergência e $\mu$ (regularizador de Tikhonov) permite um compromisso entre a rejeição de artefatos numéricos e a fidelidade da solução para os dados de entrada.

Para o telescópio CoRoT, dada a observação de uma estrela pontual, cada matriz de transformação $W_{k}$ representa um movimento puramente translacional da imagemsolução $X$. Isto é válido mesmo no caso de rotação do instrumento de aquisição ao redor da linha de visada, e independente do formato da PSF. A translação da estrela-alvo para cada imagem $Y_{k}$, dada em píxels em ambas as direções do plano em relação a uma referência arbitrária, deve ser conhecida com precisão subpíxel para a reconstrução da PSF. A translação pode ser derivada algebricamente dos dados de atitude do satélite ou diretamente deduzida das próprias imagens adquiridas pelo instrumento.

O filtro de borramento devido ao instrumento óptico, $B_{k}$, pode ser obtido através de simulações computacionais do caminho óptico pelo qual o fluxo luminoso de uma fonte pontual passa ao longo do instrumento construído.

A matriz $D$, no caso de um detector CCD, representa a integração do fluxo luminoso efetuada sobre cada píxel do dispositivo, e pode ser visto como um operador de sub-amostragem não ideal, que realiza a soma de valores adjacentes em $X$ para produzir uma imagem $Y_{k}$ de menor resolução.

Ainda que estas matrizes sejam necessárias para as derivações teóricas, não há em realidade a necessidade de suas construções na prática. De fato, para uma implementação computacional do algoritmo, todas as transformações podem ser convenientemente aproximadas por operadores píxel-a-píxel (píxel-wise). A computação de translações puras $(W)$ e de operações de sub-amostragem $(D)$ para 
manipulação de imagens é simples. As matrizes $B_{k}$ e $B_{k}^{T}$ podem ser interpretadas como uma ponderação do fluxo ao redor do centróide da fonte pontual. Pode-se também verificar que a multiplicação pela matriz transposta $W_{k}^{T}$ pode ser substituída por uma translação na direção oposta com relação a $W_{k}$, e que $D^{T}$ pode ser implementada através de uma operação de reamostragem sem interpolação.

\subsubsection{Resultados Práticos}

Como resultado, obtém-se um modelo com precisão sub-píxel de PSF do instrumento, estimado a partir de imagens capturadas pelo próprio telescópio. Tal modelo é calculado pelo método de Landweber com regularizador de Tikhonov modificado com a estimação $\hat{X}_{0}$, descrito acima (Eq. 37). A figura que se segue mostra, da direita para a esquerda, um exemplo de imagem capturada pelo CCD, um modelo com resolução de $1 \frac{1}{2}$ píxel, outro com resolução de $1 / 4$ de píxel e, finalmente, o modelo (simulado) contínuo desejado, ao qual não se tem acesso nas aplicações reais.

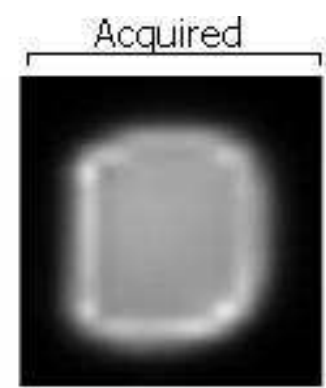

1 pixel

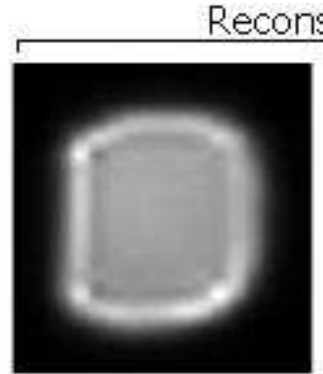

$1 / 2$ pixel
Reconstructed

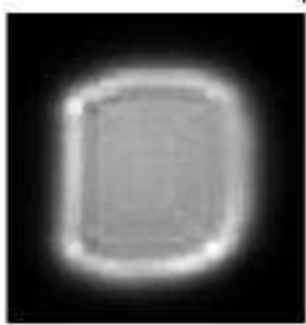

$1 / 4$ pixel

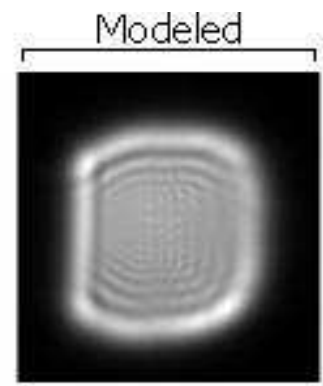

no alias

Figura 26. Da esquerda para a direita: PSF capturada pelo CCD, PSF reconstruída com precisão de $1 / 2$ píxel, PSF reconstruída com precisão de 1/4 de píxel e PSF modelada.

Verifica-se a recuperação adequada da maior parte da estrutura espacial e a restauração de simetrias originalmente perdidas na PSF capturada (sub-amostrada). Este fato é melhor ilustrado na Figura 27, através da comparação das seções verticais e horizontais das PSFs capturada e reconstruída. 


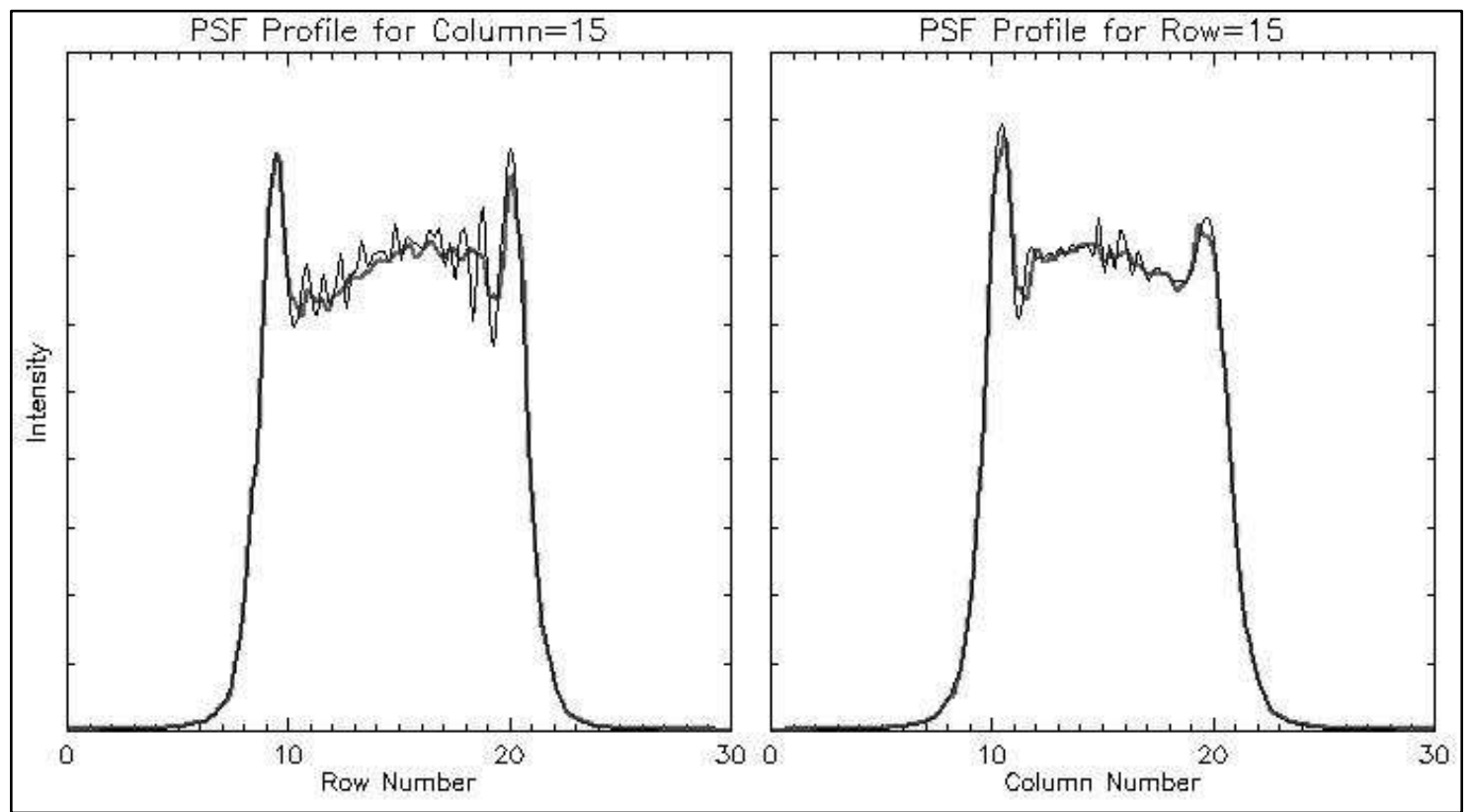

Figura 27. Seções vertical e horizontal das PSFs capturada (linha fina) e reconstruída (linha espessa) (1/4 de píxel).

A eficácia destes modelos reconstruídos, aplicados na fotometria por ajuste é ilustrada na Figura 28, onde são apresentados os sinais fotométricos resultantes quando distintas PSFs são utilizadas como modelo para o ajuste.

A Figura 28 (a) ilustra o sinal fotométrico obtido através de redução por ajuste de PSF usando-se a PSF capturada diretamente pelo CCD. Note que o sinal é extremamente ruidoso devido ao efeito borramento causado pelo movimento relativo e à sub-amostragem intrínseca ao uso de um detector do tipo CCD, e a informação relevante se perde no ruído. Usando-se a metodologia acima apresentada, pode-se obter um modelo de PSF com maior precisão, e as Figura 28 (b) e Figura 28 (c) mostram dois modelos assim obtidos, com resolução de 1/2 píxel e de 1/4 de píxel, respectivamente. O resultado é que a relação sinal/ruído do sinal fotométrico melhora à medida que se aumenta a resolução do modelo de PSF e, desta forma, o tratamento dos dados é muito mais eficaz. Por fim, a Figura 28 (d) ilustra o sinal fotométrico obtido através do ajuste por PSF a partir da PSF contínua (simulada), a qual, em uma aplicação real, não é possível obter. 


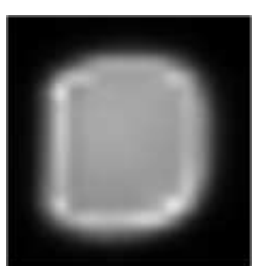

1 pixel

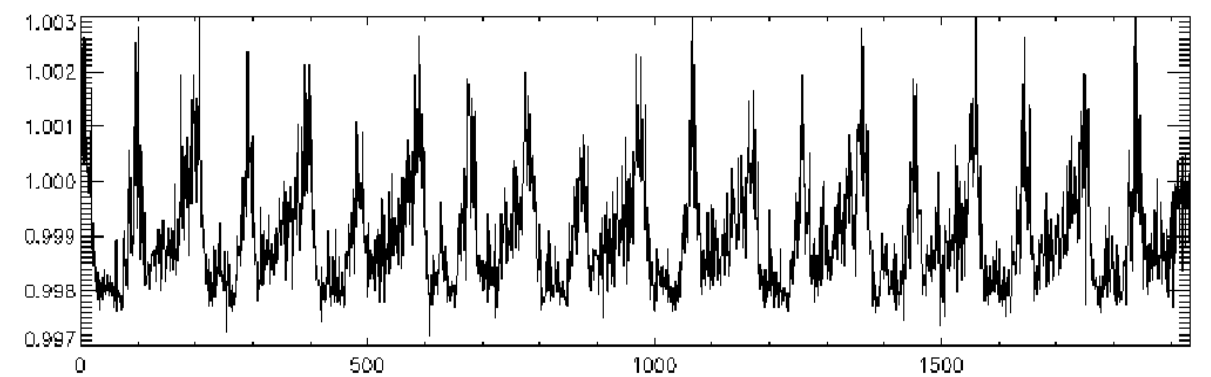

(a) Redução com ajuste da PSF capturada pelo CCD.

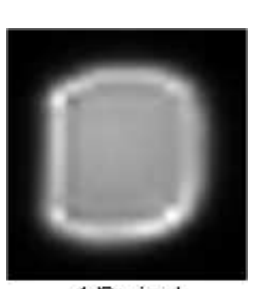

$1 / 2$ pixel

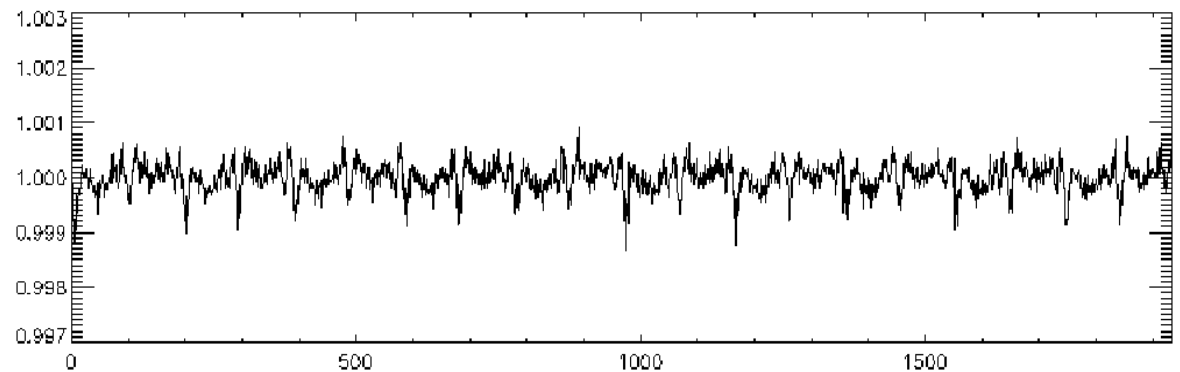

(b) Redução com ajuste da PSF restaurada com resolução de 1/2 píxel.

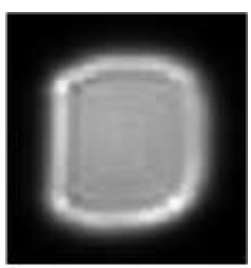

$1 / 4$ pixel

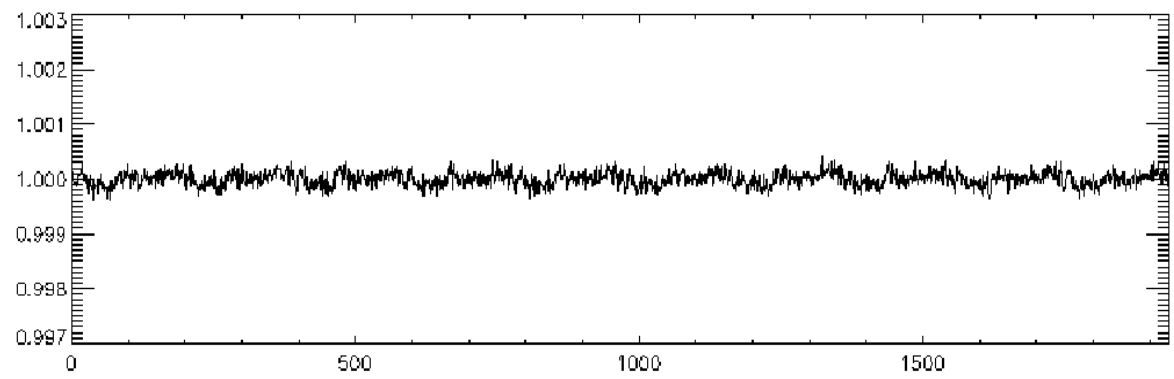

(c) Redução com ajuste da PSF restaurada com resolução de 1/4 píxel.
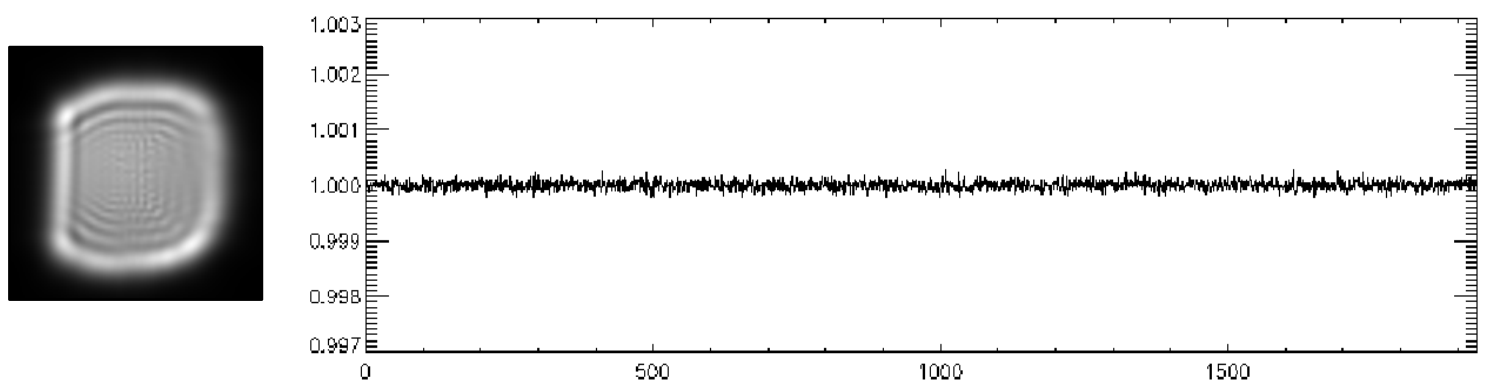

(d) Redução com ajuste da PSF contínua (simulada), inatingível na prática.

Figura 28. Sinais fotométricos resultantes da utilização de distintas PSFs no processo de redução de dados. (Pinheiro da Silva, 2005)

Finalmente, como simples ilustração, a Figura 29 repete a Figura 19, com o modelo de PSF restaurado com precisão de 1/4 de píxel, obtido pelo método de Landweber com regularizador de Tikhonov modificado com a estimação $\hat{X}_{0}$. 


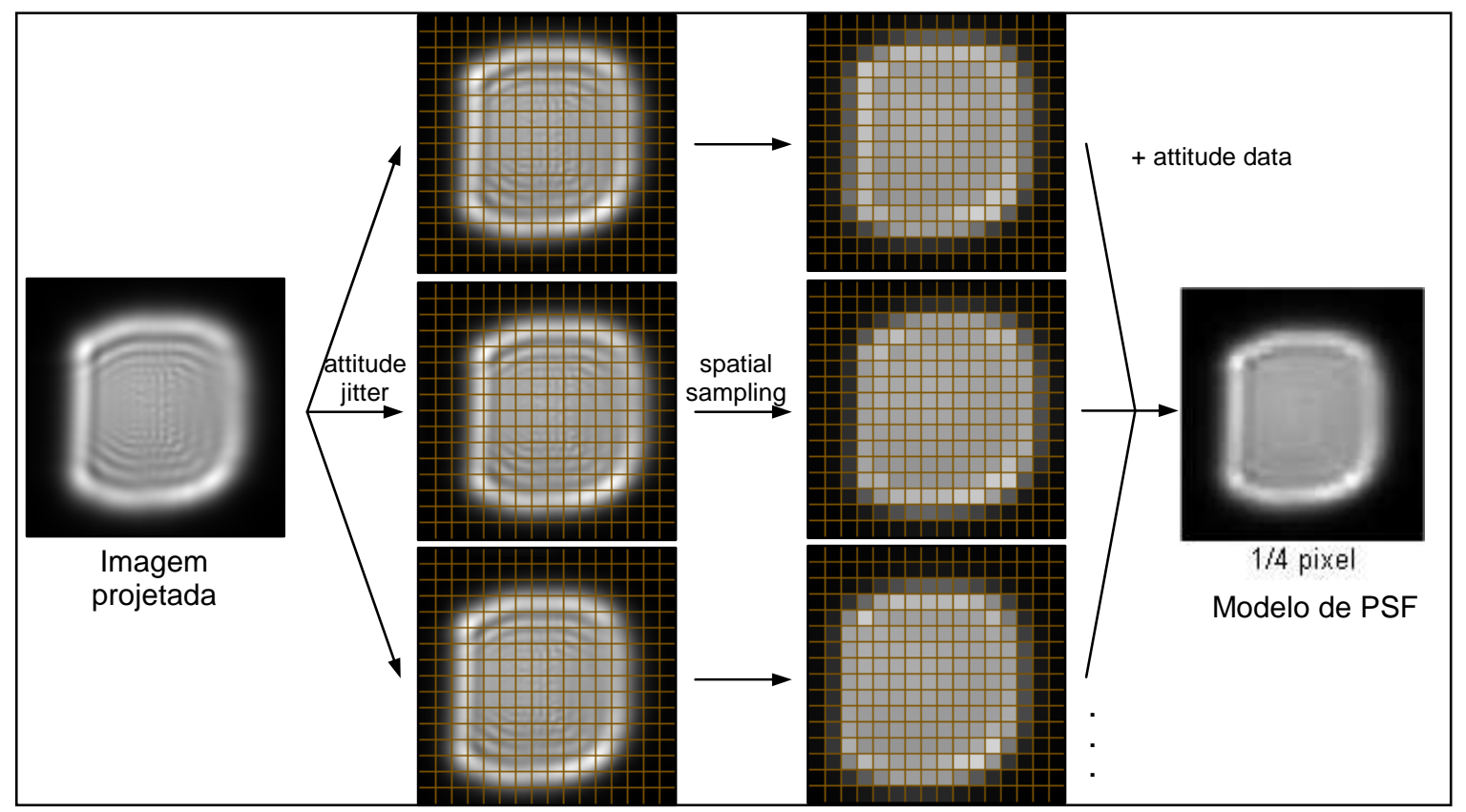

Figura 29. O modelo de PSF com precisão de 1/4 de píxel, obtido através de solução de problema inverso, é suficiente para a redução de dados fotométricos do telescópio CoRoT. (Pinheiro da Silva, 2005)

\subsection{TRANSFORMAÇÃO NÃO-LINEAR}

Um algoritmo de mínimos quadrados, tal como o apresentado na seção anterior proporciona uma solução de máxima verossimilhança no caso de ruído gaussiano puramente aditivo e independente de outras variáveis [22]. Este ruído foi representado por $\eta_{k}$ nos desenvolvimentos matemáticos anteriores (Eq. 30).

Para imagens reais do CCD utilizado, no entanto, cada píxel apresenta um ruído híbrido composto tanto por uma componente poissoniana (Poissonian shot noise), que depende da intensidade do fluxo integrado durante a exposição, quanto por uma componente aditiva de ruído de leitura. Com isso, conclui-se que assumir um ruído puramente gaussiano não é rigoroso o suficiente para as imagens reais capturadas pelo CoRoT.

O efeito é a penalização de píxels de baixa intensidade, particularmente os correspondentes às "asas" da PSF, pois sua baixa incerteza estatística não é levada 
em conta de forma apropriada. Portanto, uma simples minimização através de mínimos quadrados pode levar à criação de artefatos, ou seja, de estruturas artificiais ausentes na imagem original (projetada sobre a superfície do CCD, antes de ser amostrada por ele).

Uma solução possível para este problema seria a aplicação de uma transformação não-linear sobre as imagens "puras", provenientes da telemetria do satélite, de modo a normalizar a incerteza estatística associada a cada píxel da imagem. A função inversa desta transformação deve então ser aplicada à imagem de saída do algoritmo de reconstrução, para acesso à PSF de alta-resolução. Pinheiro da Silva mostra [11] que esta estratégia é equivalente a uma adaptação simplificada da função custo $\phi_{d}$ apresentada na seção anterior e que ela se aplica em um domínio de translações de baixa velocidade (menores que 1 píxel/s) e de alvos de alta resolução (e.g., de 1/4 de píxel).

Seja $Y_{k}$ uma imagem estelar, já convertida (ADU $\rightarrow e^{-}$) e corrigida para o offset eletrônico e subtração de fundo de céu. Uma função não-linear que leve esta imagem a outra de incerteza normalizada para cada píxel (em um domínio transformado), é do tipo

$$
F\left(Y_{k}\right)=\frac{Y_{k}}{\sqrt{Y_{k}+\mu_{s k y}+N_{a c c} \cdot \sigma_{r o}^{2}}}
$$

onde $\mu_{s k y}$ é o fundo de céu (em e $), N_{a c c}$ é o número de acumulações realizadas a bordo e $\sigma_{r o}^{2}$ é o ruído de leitura (readout noise) (em $e^{-} /$píxel/readout). O sinal de divisão representa uma operação píxel-a-píxel.

No entanto, esta transformação não é conveniente, dado que não é facilmente invertível. Por outro lado, pode-se adicionar um valor constante à imagem original, sem efeitos colaterais na estatística envolvida. Com isso, define-se:

$$
F\left(Y_{k}\right)=\frac{Y_{k}+\mu_{s k y}+N_{a c c} \cdot \sigma_{r o}^{2}}{\sqrt{Y_{k}+\mu_{s k y}+N_{a c c} \cdot \sigma_{r o}^{2}}}=\sqrt{Y_{k}+\mu_{s k y}+N_{a c c} \cdot \sigma_{r o}^{2}}
$$

A função inversa correspondente é então dada simplesmente por: 


$$
F^{-1}\left(Y_{k}\right)=\frac{1}{\sqrt{Y_{k}+\mu_{s k y}+N_{a c c} \cdot \sigma_{r o}^{2}}}
$$

Uma representação esquemática da metodologia completa de reconstrução de PSF é ilustrada na Figura 30.

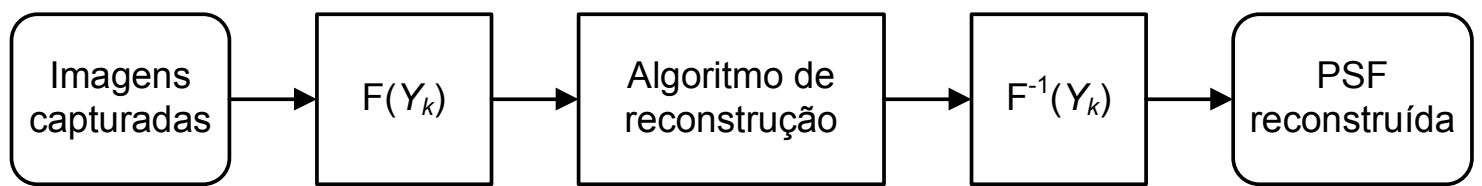

Figura 30. Representação esquemática de um algoritmo não-linear de reconstrução de PSF.

A seção seguinte trata da fotometria, suas diferentes modalidades e as principais características de uma delas. Trata, em especial, da fotometria por ajuste de PSF, usada no projeto CoRoT no segmento solo. 


\section{FOTOMETRIA}

Fotometria é um ramo da astronomia observacional relacionado com a medição de fluxo luminoso, ou intensidade luminosa da radiação eletromagnética visível de um objeto astronômico, de modo correspondente à sensibilidade do olho humano. Quando não somente a quantidade de radiação, mas também a distribuição espectral é medida, então o termo espectroscopia deve ser utilizado.

Quando se utiliza uma câmera CCD para realizar fotometria, há distintas formas possíveis de se extrair uma medida fotométrica (por exemplo, a magnitude de uma estrela) a partir da imagem pura do CCD [15][17]. O telescópio CoRoT deve coletar os fótons incidentes sobre a superfície de seus detectores CCDs, tratar e reduzir estes dados, e transmitir por telemetria o fluxo fotométrico proveniente de cada estrela-alvo observada.

Adda (2000) realizou um estudo fotométrico preparatório da missão CoRoT em [18]. Neste trabalho, foram avaliados diversos métodos de fotometria CCD e suas conseqüências sobre a carga da Unidade de Processamento Digital do satélite e sobre a precisão dos resultados. Os métodos estudados foram os de fotometria por abertura fixa, por abertura variável (por threshold) e por ajuste de resposta impulsiva. A seguir, são listados os principais tipos de fotometria encontrados na literatura.

\subsection{FOTOMETRIA POR MÁSCARA}

A fotometria por máscara, ou fotometria de abertura fixa, consiste em simplesmente somar as intensidades dos píxels que representam uma estrela. Definem-se, para tal, quais os píxels que pertencem à estrela, ou ainda, aqueles que contêm mais sinal proveniente da estrela que de ruído ou sinal parasita. Deste modo, o que se 
define é uma máscara fotométrica que permite somar somente os píxels da imagem que estão contidos nela. A máscara pode ser definida simplesmente por um diafragma circular cujo raio é determinado de modo a não se levar em conta os píxels que estão longe do centro da estrela e que, portanto, não aportam ao cálculo nada além de ruído. Howell (1989) apresenta também uma definição mais complexa da máscara fotométrica, por maximização da relação sinal/ruído [19]. Para tal, classificam-se os píxels por intensidade decrescente, e observa-se a evolução da relação sinal/ruído em função do número de píxels incluídos dentro da máscara, adicionando-se a cada iteração os píxels de intensidade imediatamente inferior. Esta curva passa por um máximo que define a máscara ótima. A figura que se segue ilustra esta estratégia de definição da máscara fotométrica a ser utilizada.

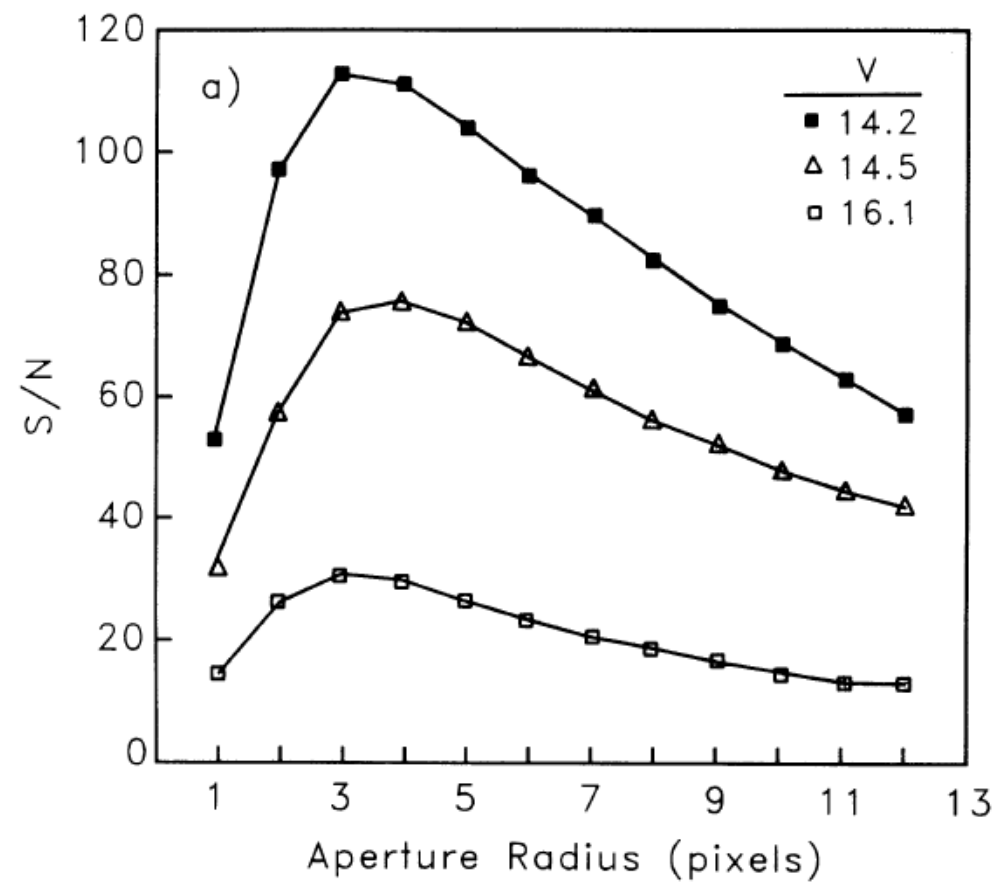

Figura 31. Relação SNR (S/N) plotada em função do raio de abertura da máscara para distintas fontes pontuais de luz. O gráfico mostra que as estrelas deste intervalo de magnitude visual aparente apresentam um máximo de SNR para um raio específico, relativamente pequeno. (Adaptado de Howell, 1989.)

É conveniente considerar-se se para calcular a curva de luz, esta máscara deve ser reavaliada a cada captura de imagem ou se ela deve ser determinada somente uma vez. Os limites de uma máscara fixa se farão sentir (efeito de borda) quando a imagem borrada da estrela se deslocar, que é o caso de um instrumento espacial para o qual o jitter do satélite desloque constantemente a estrela ao longo do CCD. Nesse caso, alguns píxels úteis podem sair da máscara e introduzir um ruído 
importante na fotometria. Se a máscara for recalculada a cada captura, tem-se a vantagem de se seguir a estrela que se desloca no CCD; em contrapartida, a superfície da máscara não será constante. Um píxel que se encontre bem no limiar ora pode ser computado, ora não. A solução eleita para o CoRoT, tanto para a via exoplanetas $(P F)$ quanto para a via astrossismologia $(A S)$, é de fazer a fotometria de abertura com uma máscara fixa. As máscaras são definidas no início da observação através do cálculo de maximização da relação sinal/ruído e da consideração das especificações de jitter de atitude definidas para o sistema de controle do satélite (ACS).

\subsection{FOTOMETRIA POR LIMIAR}

A fotometria por limiar (ou por threshold), ou fotometria por abertura variável, consiste na definição de um limiar de intensidade, acima do qual os valores dos píxels de cada imagem são considerados no cálculo fotométrico desejado. A vantagem deste método é a sua robustez ao deslocamento da imagem causado por jitter de atitude do satélite, característica ausente no método de fotometria por máscara. A desvantagem é que ao não se fixar previamente o número de píxels a serem levados em conta durante uma seqüência de aquisição de imagens, adicionase uma fonte de ruído ao sistema, pois o referido número torna-se variável. Portanto, em casos de baixas amplitudes de jitter de atitude do satélite, como é o caso do CoRoT (apresenta jitter da ordem de 0,2 píxel RMS), o método não se justifica, pois resulta em desempenho inferior devido à inserção da fonte de ruído acima citada.

\subsection{FOTOMETRIA POR AJUSTE DE RESPOSTA IMPULSIVA}


A fotometria por ajuste de resposta impulsiva, também chamado de ajuste de função de espalhamento do ponto (point-spread function, PSF) consiste em ajustar um modelo de formação de imagem de uma estrela à imagem propriamente dita, gerada a partir da estrela. Sendo a imagem de uma estrela - localizada em um ponto no infinito -, a própria PSF do instrumento de aquisição, então fala-se de fotometria por ajuste de PSF (PSF fitting) [25]. A qualidade deste método depende, em grande parte, do conhecimento da própria PSF, que pode variar de acordo com a estrela. Pode ser então necessária a disposição de um modelo para cada estrela, que deve ser conhecido com uma resolução melhor (maior) que a do instrumento de aquisição. A determinação deste modelo pode ser feita por uma abordagem analítica com a ajuda de um modelo matemático, ou por uma abordagem empírica, interpolando-se as imagens observadas. A primeira abordagem limita-se a partir do momento em que a imagem capturada (e borrada) torna-se complexa, e a segunda demanda precauções relacionadas às imagens sub-amostradas. Uma vez que estes modelos sejam conhecidos, o ajuste pode ser realizado pelo método clássico de mínimos quadrados. As vantagens principais deste método são a precisão apresentada e a robustez ao deslocamento da imagem borrada da estrela ao longo do CCD. Sua principal desvantagem, no entanto, é a demanda de tempo de processamento.

Tendo em conta as especificações de desempenho do instrumento, Adda (2000) chegou à conclusão de que a fotometria por abertura fixa apresentava o melhor compromisso entre simplicidade de implementação e performance fotométrica [18]. A fotometria por ajuste de PSF, por sua vez, é realizada pelo segmento solo da equipe de redução de dados.

\subsubsection{Metodologia}


Algoritmos de fotometria por ajuste podem ser bastante eficientes caso um modelo preciso de PSF esteja disponível. Técnicas de ajuste por PSF têm sido extensivamente estudadas e rotineiramente aplicadas em fotometria estelar principalmente em campos densos, ao passo em que a fotometria por abertura tem sido aplicada no caso de estrelas isoladas ou brilhantes. Os modelos de PSF são geralmente obtidos através de ajustes de perfis analíticos (gaussianos ou de Moffat) às imagens capturadas, algumas vezes acompanhados de uma descrição numérica do resíduo do ajuste. Na fotometria com resolução temporal, no entanto, o emprego de algoritmos de ajuste de PSF pode ser justificado até mesmo pra estrelas isoladas, pois estes possibilitam uma melhor exploração de muitas classes de imagens degradadas ou ruidosas, e apresentam menor sensitividade a perturbações periódicas, tais como luz difusa (stray light) e jitter de atitude do satélite (como nas transições entre zonas de sombra e de iluminação solar) e apresentam robustez especialmente contra a ocorrência de impactos de partículas carregadas. A robustez é uma característica particularmente importante para missões em baixas órbitas terrestres, como é o caso do CoRoT, que passa de 5 a 10\% de seu tempo de vida cruzando a Anomalia do Atlântico Sul.

O uso de funções analíticas como aproximações ao perfil estelar, no entanto, está restrito a PSFs com formas regulares; nesta seção, se descreverá o uso de PSF empíricas, reconstruídas com precisão sub-píxel a partir de um conjunto de imagens capturadas pelo instrumento, aplicadas à fotometria por ajuste de PSF com resolução temporal (Pinheiro da Silva et al., 2006 [25]).

\subsubsection{Modelo de Observação}

O processo de ajuste se baseia no modelo de formação de imagem apresentado na Seção 5. Para a redução de dados de cada estrela observada, a PSF de alta resolução correspondente é primeiramente convoluída com o kernel de convolução que representa o borramento por movimento durante a integração da imagem; o 
movimento é deduzido dos dados de atitude do satélite transmitidos por telemetria. A imagem resultante é então sub-amostrada no tamanho do píxel do CCD. O resultado é um modelo de observação que é normalizado e iterativamente ajustado a cada imagem capturada.

O procedimento de ajuste se baseia na implementação do algoritmo de LevembergMarquardt [27]. Inicialmente, até oito parâmetros do modelo de observação podem variar livremente para que a convergência ocorra:

1. Um fator multiplicativo puro, que corresponde ao próprio valor fotométrico;

2. Um fundo de céu aditivo, representado por três variáveis: o valor médio e dois coeficientes lineares (linear tilts) $(x, y)$;

3. A posição $(x, y)$ do baricentro em relação ao frame de imagem de referência;

4. Uma transformação homotética $(x, y)$ para considerar-se uma eventual mudança de desfoque.

\subsubsection{Estatística de Pearson}

A comparação entre dados e modelo é definida de acordo com uma estatística de Pearson modificada [28], levando em consideração tanto o ruído de Poisson quanto o de leitura. A melhor estimação fotométrica é então obtida através da minimização de

$$
\chi^{2}=\frac{\left(\operatorname{data}_{i}-\operatorname{model}_{i}\right)^{2}}{\operatorname{model}_{i}+N_{a c c} \cdot \sigma_{r o}^{2}}
$$

onde data $_{i}$ e $\operatorname{model}_{i}$ são o -ésimo píxel da imagem de dados e do modelo, respectivamente. $N_{a c c}$ é o número de acumulações a bordo e $\sigma_{r o}^{2}$ é o ruído de leitura (readout noise) (em e-/píxel/readout). O sinal de divisão representa uma operação píxel-a-píxel. 
Um loop externo de redução de dados também é implementado, para rejeição de sinais atípicos, (outliers, geralmente provenientes de impactos). A Figura 32 mostra exemplos de imagens degradadas por impactos de partículas eletricamente carregadas durante a passagem do satélite pela região da Anomalia do Atlântico Sul.

A incerteza estatística associada a cada píxel $i$ particular, causada pelos ruídos de Poisson e de leitura, pode ser definida por

$$
\sigma_{i}=\sqrt{\operatorname{model}_{i}+N_{a c c} \cdot \sigma_{r o}^{2}} .
$$

As rejeições de sinais espúrios (outliers) consistem em uma comparação píxel-apíxel entre o modelo ajustado e a imagem capturada, e na exclusão de píxels anormais (por exemplo, píxels onde $\operatorname{data}_{i}>\operatorname{model}_{i}+6 \cdot \sigma_{i}$ ). $O$ modelo é então recursivamente reajustado, até que nenhum píxel espúrio esteja presente no modelo ajustado. Para aumento de robustez, somente poucos píxels são ajustados a cada passo da iteração, possibilitando uma convergência mais suave do modelo ao dado observado. $O$ objetivo de tal procedimento encontra-se ilustrado na Figura 33.

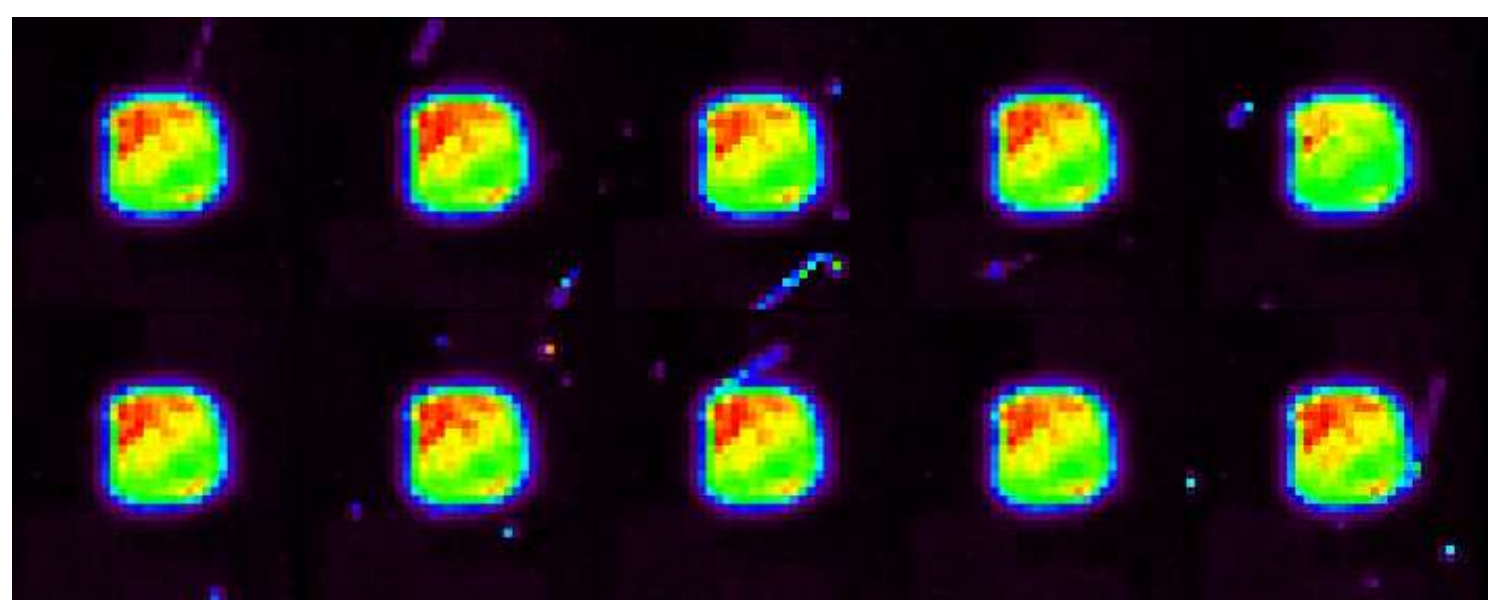

Figura 32. Exemplos de imagens degradadas por impactos de partículas carregadas eletricamente durante a passagem do satélite pela região da Anomalia do Atlântico Sul. (Pinheiro da Silva, 2007) 

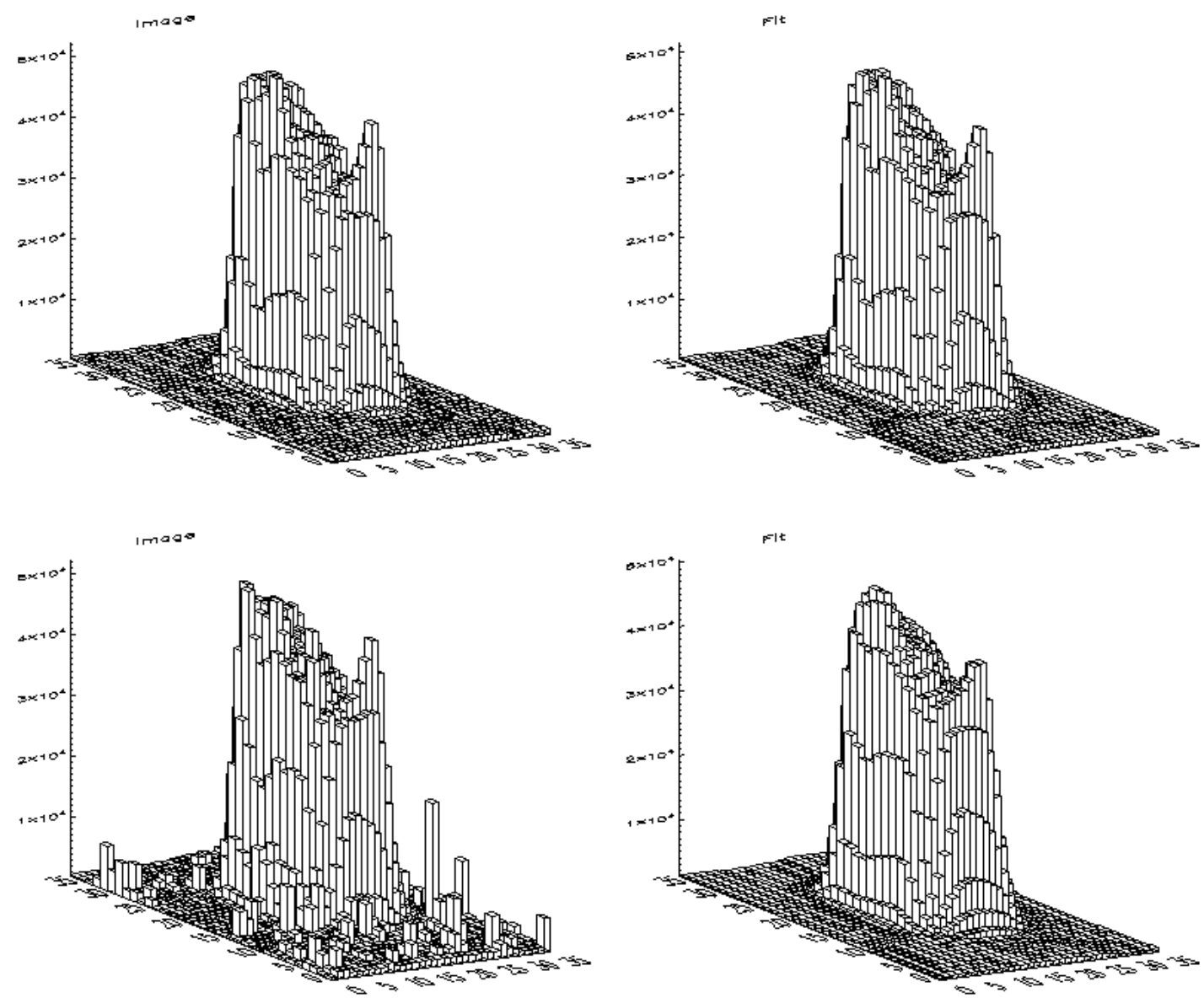

Figura 33. Comparação entre imagens de dados observados e os correspondentes modelos ajustados de PSF. Dois casos são ilustrados: (acima) sem a incidência de radiação e (abaixo) com a incidência de radiação. (Pinheiro da Silva, 2007)

Verifica-se que parâmetros fotométricos precisos podem ser extraídos de imagens altamente impactadas por radiação.

Em resumo, as especificidades deste procedimento de ajuste em relação ao que tradicionalmente é feito na fotometria por ajuste são:

- O uso de um modelo empírico de PSF de alta resolução, dando grande generalidade e possibilitando sua aplicação em imagens estelares de formas arbitrariamente complexas;

- O emprego de dados super-amostrados de atitude do satélite para a reconstrução do modelo de borramento por movimento, possibilitando sua aplicação a imagens estelares capturadas com tempos de integração mais longos; 
- A introdução de um loop externo no algoritmo para a rejeição de píxels espúrios (outliers) e conseqüente reajuste do modelo, resultando em maior robustez à radiação espacial.

As estatísticas de chi-quadrado e de erro são válidas somente para imagens estelares expressas em $\mathrm{e}^{-}$, e corrigidas de offset eletrônico. $\mathrm{O}$ ajuste é portanto aplicado a imagens que já passaram pela redução de dados de primeiro nível.

\subsection{FOTOMETRIA HÍBRIDA}

Kjeldsen \& Frandsen (1992) mostraram que mesmo no caso de imagens nãodegradadas de estrelas isoladas, melhores performances podem sempre ser alcançadas combinando-se técnicas de fotometria por abertura e por ajuste [26].

O objetivo deste Projeto é desenvolver um algoritmo híbrido de redução de dados fotométricos que alie o conhecimento da PSF modelada do sistema de aquisição de imagens (ou seja, do telescópio) ao processo de fotometria por abertura fixa já realizado a bordo do CoRoT, tirando proveito das melhores características de cada uma destas técnicas, de forma a maximizar a relação sinal/ruído das imagens capturadas. Tal algoritmo permitirá um ganho substancial de precisão fotométrica, resultando em uma melhor exploração dos dados disponíveis, dada a sua potencial robustez em caso de degradação dos dados de entrada.

\subsection{PARTICIPAÇÃO BRASILEIRA NA RECEPÇÃO DOS DADOS}

É importante ressaltar que a utilização prática da fotometria por ajuste de PSF só foi possível graças à participação brasileira no segmento solo da missão, provendo a 
recepção de dados na base de Alcântara, no Maranhão. Devido à sua órbita polar, o satélite CoRoT tem oportunidade de sobrevoar a área de recepção de Alcântara várias vezes ao dia, momento em que envia, por telemetria, as informações referentes às imagens ainda não-processadas das estrelas observadas.

Estas informações enviadas à base brasileira diferem em conteúdo das informações enviadas às demais bases, no Ártico, na Espanha e na Áustria, onde os dados descarregados correspondem à fotometria por máscara, efetuada a bordo para redução prévia de volume de informação.

O uso da base de Alcântara, além de permitir um aumento no número de estrelas observadas de 70 mil para 100 mil, possibilitou o envio de dados de imagens sem processamento, que por sua vez estimulou o estudo da metodologia de fotometria por ajuste de PSF. Aliadas a este fato, encontram-se as contribuições financeira e científica brasileira diretamente na construção do satélite, o que concedeu aos pesquisadores brasileiros, pela primeira vez, os mesmos direitos dos colegas europeus de exploração dos dados científicos. 


\section{METODOLOGIA}

Para o desenvolvimento deste trabalho, foi empregada a linguagem de programação IDL - Interactive Data Language - [30], amplamente utilizada para processamento de dados (imagens, fotometria, etc.) nos laboratórios franceses envolvidos na missão CoRoT. Além disso, foram também utilizados simuladores e bibliotecas de imagem customizados para o instrumento CoRoT, já desenvolvidos nos laboratórios franceses envolvidos na missão. Para a validação do algoritmo desenvolvido, utilizou-se de dados reais do satélite CoRoT, disponibilizados no Arquivo Público de Dados de Vôo do CoRoT [31]. Nas subseções que se seguem será descrita a metodologia empregada no desenvolvimento do algoritmo híbrido de fotometria estelar.

\subsection{DADOS SIMULADOS DE ENTRADA}

Para o projeto e avaliação do sistema óptico do telescópio CoRoT, foi utilizado o software Zemax, capaz de analisar os efeitos combinados de lentes e espelhos, sendo este, portanto, ideal para a caracterização e parametrização do modelo geométrico da propagação de luz através do telescópio.

Para o desenvolvimento do algoritmo híbrido de fotometria estelar, tal caracterização é uma caixa preta que entrega uma série de funções de espalhamento da fonte pontual (PSF), que servirão de entrada para o algoritmo. As propriedades de cada PSF dependem da posição geométrica $(X, Y)$ do $C C D$ em que se está projetando a fonte e do comprimento de onda da mesma (que está relacionada com o tipo espectral e temperatura de superfície da estrela simulada).

A figura que se segue ilustra as PSFs utilizadas no desenvolvimento deste trabalho. 


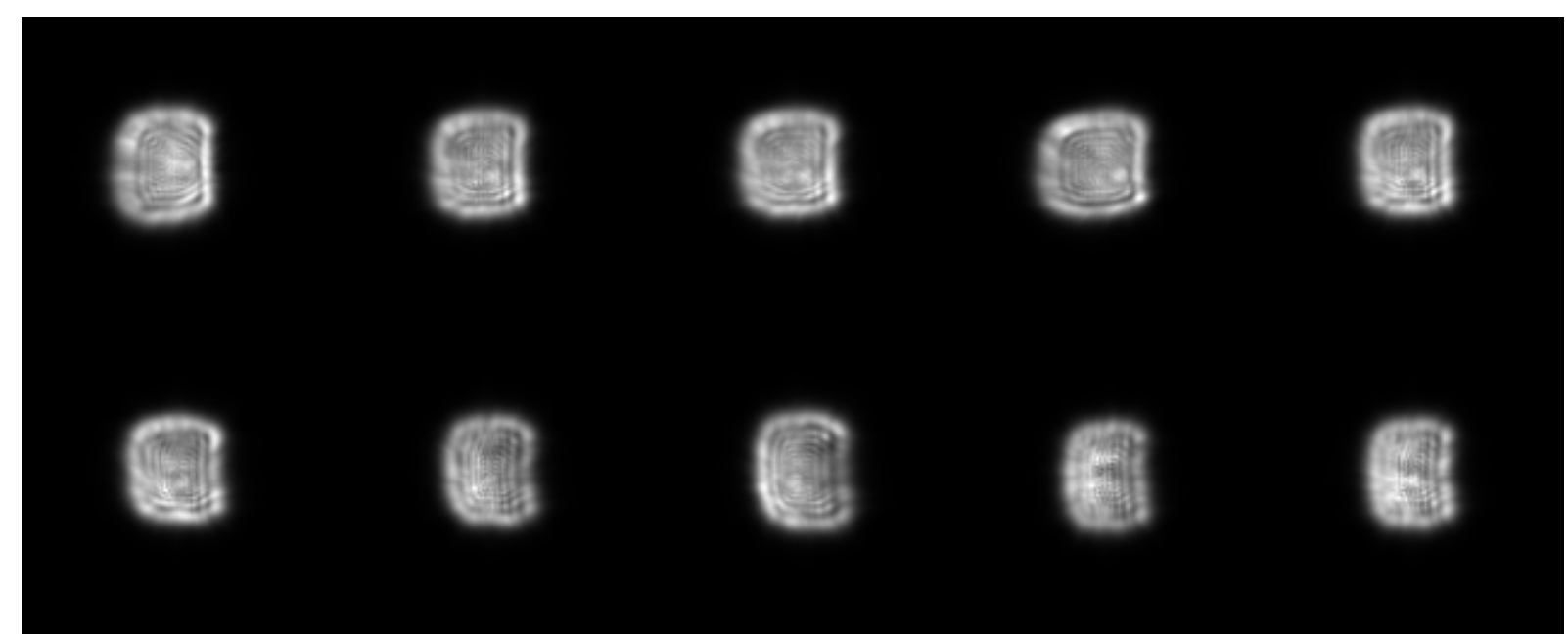

Figura 34. Dez PSFs do campo Astrossismologia. Cada PSF apresenta uma aparência geométrica correspondente a uma posição no CCD e a uma temperatura estelar.

\subsection{DESENVOLVIMENTO DO ALGORITMO}

A partir dos dados simulados, pôde-se iniciar o desenvolvimento do algoritmo híbrido de fotometria estelar a partir de imagens do espaço. $O$ algoritmo consiste das etapas abaixo descritas.

\subsubsection{Simulação de Seqüência de Imagens Capturadas}

A primeira etapa consiste em simular uma seqüência de imagens capturadas pelo CoRoT, a partir das PSFs obtidas com o programa Zemax, acima identificadas. Para tal, foi desenvolvida uma função que gerasse, a partir destas PSFs, imagens degradadas pelos seguintes efeitos:

- Sub-amostragem pela "grade" de píxels do CCD; 
- Jitter de atitude;

- Ruído de fundo de céu;

- Ruído de eletrônica de leitura;

- Ruído de Poisson;

- Impactos de partículas carregadas eletricamente.

Esta seqüência de imagens degradadas foi denominada seqJNI (jitter + noise + impacts). As figuras abaixo ilustram esta etapa.

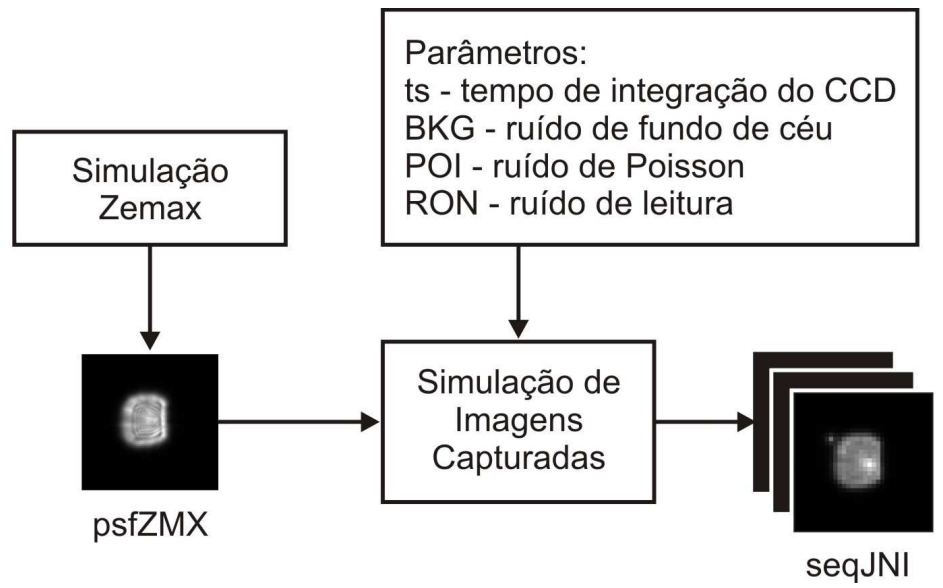

Figura 35. Simulação de Imagens Capturadas pelo CoRoT a partir de PSFs Zemax.

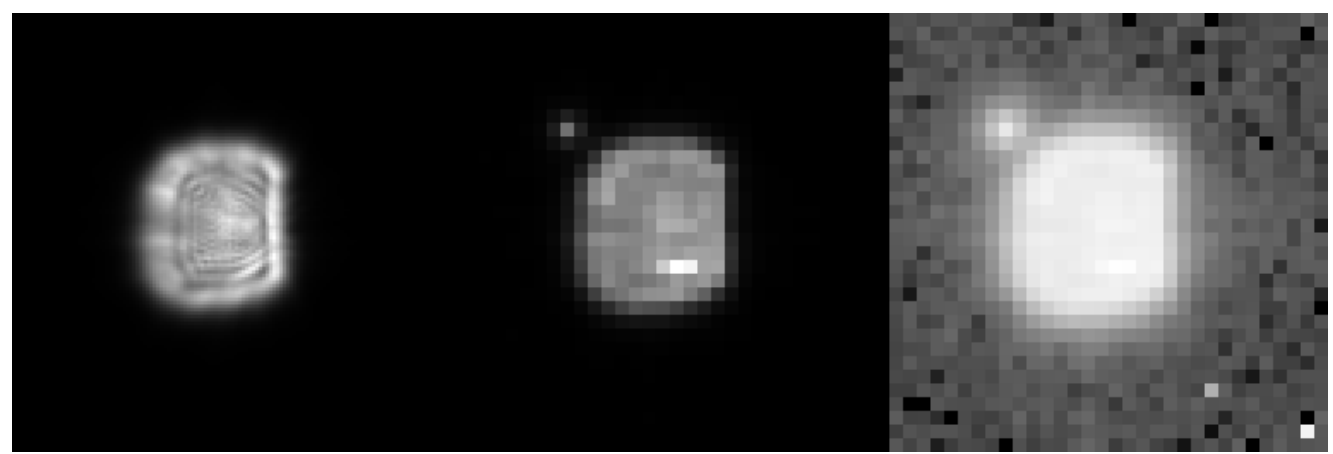

Figura 36. Simulação de Imagens Capturadas pelo CoRoT. À esq.: a PSF Zemax representa a função espalhamento de fonte pontual, contínua, projetada sobre o CCD do telescópio. Ao centro: a PSF é degradada por sub-amostragem do CCD, impactos de partículas ionizadas e ruídos associados. À dir.: função logarítmica aplicada à imagem central, apenas com caráter ilustrativo do efeito da degradação da PSF.

O modelo de degradação de PSF segue a teoria de caracterizações ópticas e eletrônicas do telescópio, além de simular o ambiente orbital do satélite (ver seções 4 a 7$)$. 


\subsubsection{Redução de Dados Fotométricos por Abertura}

A partir da seqüência de imagens degradadas seqJNI, foi utilizada uma função que realiza a redução de dados fotométricos por abertura, ou seja, através de uma máscara ótima obtida pela computação de bordo, realiza-se a extração da curva de luz da estrela sendo estudada (ver seção 9.1 - Fotometria por máscara).

Inicialmente, define-se a máscara que apresenta a melhor relação SNR para a estrela observada, que será utilizada ao longo de toda a observação, que pode durar até 150 dias ininterruptos. A estratégia é análoga à apresentada por Howell (1989) em [19].

Para cada estrela observada no Programa Astrossismologia (e para cada conjunto de estrelas pré-definido no Programa Exoplanetas), foi estimada uma máscara ótima que maximizasse a SNR da estrela (ou conjunto de estrelas), seguindo o seguinte algoritimo:

- Estimação de uma PSF;

- Ordenação decrescente dos píxels da PSF por intensidade luminosa coletada individualmente, em um vetor $N_{*}^{s}$, ao qual é associado um conjunto de máscaras $A p(k)$, compostas dos $k$ píxels mais brilhantes na imagem da PSF (os $k$ primeiros elementos de $N_{*}^{s}$ );

- A SNR fotométrica é então calculada como função de $A p(k)$, usando-se a equação do CCD na seguinte forma:

$$
S N R(k)=\frac{\sum_{i=1}^{k} N_{*}^{s}(i)}{\sqrt{\sum_{i=1}^{k}\left(N_{*}^{s}(i)+\sigma_{i}^{2}\right)}}
$$

onde $\sigma_{i}$ é o ruído de leitura por píxel. A equação acima fornece uma curva de crescimento de SNR característica, em função de $k$, que apresenta um máximo para uma dada máscara de abertura $A p\left(k_{0}\right)$ : máscaras com um número menor de 
píxels $\left(k<k_{0}\right)$ não utilizarão todos os píxels úteis da estrela-alvo, enquanto que máscaras com um número maior de píxels $\left(k>k_{0}\right)$ incluirão píxels com SNR individuais muito baixas. Desta forma, à medida que se afasta deste ponto de maxima $A p\left(k_{0}\right)$, a SNR característica é degradada, ou seja, apresenta valores mais baixos.

A fotometria estelar por máscara fixa é a estratégia de redução de dados utilizada a bordo do CoRoT por apresentar a melhor relação entre completude dos dados obtidos (performance fotométrica) e eletrônica necessária para implementar seu cálculo. A figura que se segue ilustra esta etapa do algoritmo desenvolvido.
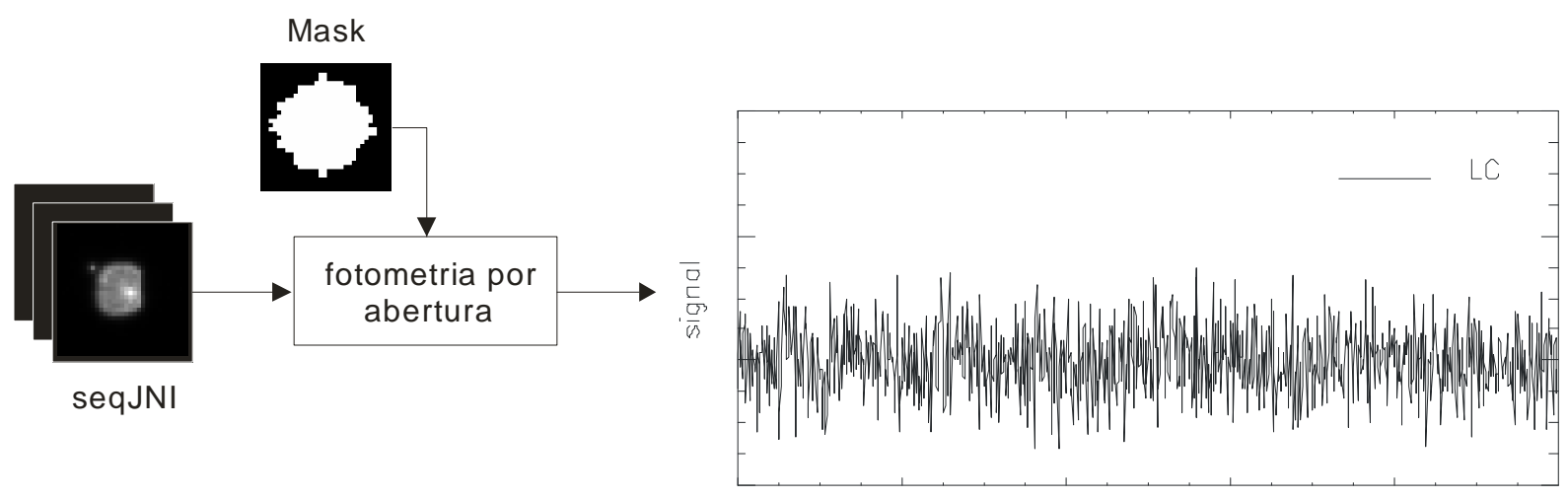

$\operatorname{time}(s)$

Figura 37. Redução de dados por fotometria por abertura. A partir das imagens simuladas, extrai-se a curva de luz pela somatória dos valores dos píxels internos à mascara ótima previamente calculada. É a metodologia adotada a bordo do CoRoT.

O resultado desta função é uma curva de luz, chamada mskLC, extraída de uma seqüência de imagens capturadas, através da fotometria por abertura.

\subsubsection{Redução de Dados Fotométricos por Ajuste de PSF}

Também a partir da seqüência de imagens degradadas seqJNI, foi utilizada uma função que realiza a redução de dados fotométricos por ajuste de PSF, ou seja, através do ajuste de uma imagem a um modelo empírico daquilo que se espera de uma aquisição "limpa" de uma estrela: sem ruídos (de leitura, fundo de céu, 
poissoniano) nem impactos, nem borramento por jitter. Realiza-se então a extração da curva de luz da estrela sendo estudada (ver seção 9.3 - Fotometria por ajuste de resposta impulsiva).

Neste caso, a PSF empírica é calculada a partir das próprias imagens degradadas e sub-amostradas da estrela-alvo, seguindo-se a metodologia apresentada por Pinheiro da Silva (2006) em [24], abaixo resumida:

- Reconstrução de uma PSF empírica a partir de uma seqüência de imagens degradadas e sub-amostradas;

- Extração de informações de jitter de atitude do satélite, que fornecerão o deslocamento da imagem capturada em relação ao baricentro desta PSF;

- Definição de um fator multiplicativo que ajustará a PSF através do método de mínimos quadrados.

Por demandar mais recursos eletrônicos e maior tempo de processamento, a fotometria por ajuste de PSF não é feita a bordo do satélite. No entanto, apresenta grande robustez em relação ao jitter e aos ruídos e impactos aos quais o processo de aquisição de imagem está submetido, e por isso esta estratégia de redução de dados é utilizada na Missão CoRoT pela equipe de solo. Ela foi viabilizada devido à participação brasileira na recepção de dados do satélite. A figura que se segue ilustra esta etapa do algoritmo desenvolvido.
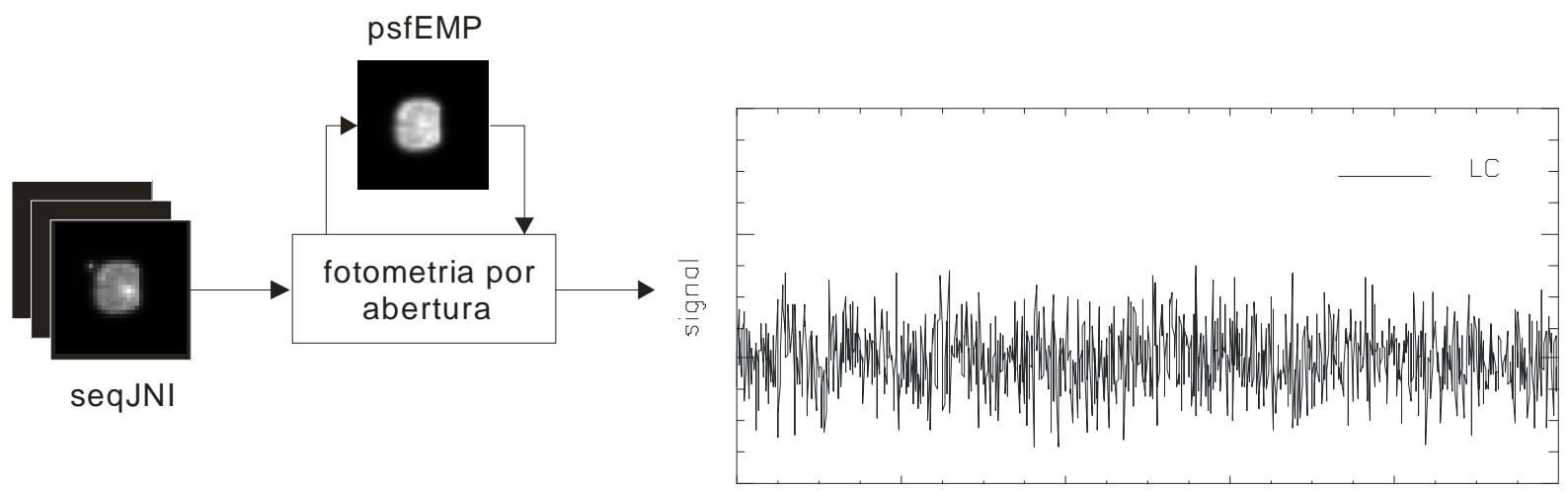

Figura 38. Redução de dados por fotometria por ajuste de PSF. A partir das imagens simuladas, extrai-se a curva de luz por ajuste de uma PSF empírica determinada pelo método de superresolução [24]. É a metodologia adotada pela equipe de solo do CoRoT para aumentar o ciclo de trabalho do satélite. 
O resultado desta função é uma curva de luz, chamada fitLC, extraída de uma seqüência de imagens capturadas, através da fotometria por ajuste de PSF.

\subsubsection{Redução de Dados Fotométricos pelo Método Híbrido}

Finalmente, apresenta-se o algoritmo híbrido de fotometria estelar a partir de imagens do espaço. O algoritmo une as vantagens da alta SNR da fotometria por abertura à robustez da fotometria por ajuste de PSF, objetivando aumentar não só a relação sinal/ruído global da curva de luz, mas também o ciclo de trabalho total do telescópio, utilizando as informações contidas nos dados degradados obtidos durante as passagens pela zona SAA

A fotometria híbrida trabalha com o conceito de máscara ótima da mesma forma que a fotometria por abertura, selecionando somente os píxels que contribuam para a alta SNR nas imagens capturadas ao longo do trajeto orbital do satélite, mas fora da zona de alta probabilidade de impactos ionizantes (SAA).

A fotometria híbrida ainda descarta píxels espúrios decorrentes de impactos de partículas ionizadas, ao mesmo tempo em que leva em consideração os píxels com baixa incerteza estatística (que portanto diminuem o erro de medição), ou seja, as "asas" da PSF (ver seções 8.5 e 9.3).

O algoritmo, portanto, a partir de uma seqüência de imagens capturadas seqJNI, calcula a máscara ótima e a PSF empírica, compõe uma seqüência de imagens híbridas, seqHYB, contendo os píxels de alto SNR individual, baixa incerteza estatística e sem impactos, da qual posteriormente extrairá a curva de luz, seguindose o seguinte algoritmo:

- Reconstrução da PSF empírica a partir de uma seqüência de imagens degradadas e sub-amostradas, seqJNI;

- Geração de uma nova seqüência de imagens ajustadas por PSF, seqFIT, a partir de seqJNI e da PSF empírica definida; 
- Para cada píxel $i$ de cada imagem de seqJNI:

- Se sua intensidade luminosa estiver dentro de limites aceitáveis de ruído (Poissoniano e de leitura), então usar o "píxel original" de seqJNI;

- Se não, significa que se trata de um píxel cujo ruído ultrapassa o limite parametrizado, sendo este portanto fonte de degradação da SNR global fotométrica. Neste caso, usa-se então o píxel correspondente em seqFIT, cujo valor foi ajustado por PSF e fornece uma estimativa do valor esperado para aquele píxel, naquele instante.

As figuras abaixo ilustram como o algoritmo híbrido considera todas estas informações, de modo a produzir uma curva de luz de forma robusta, e com alta SNR.
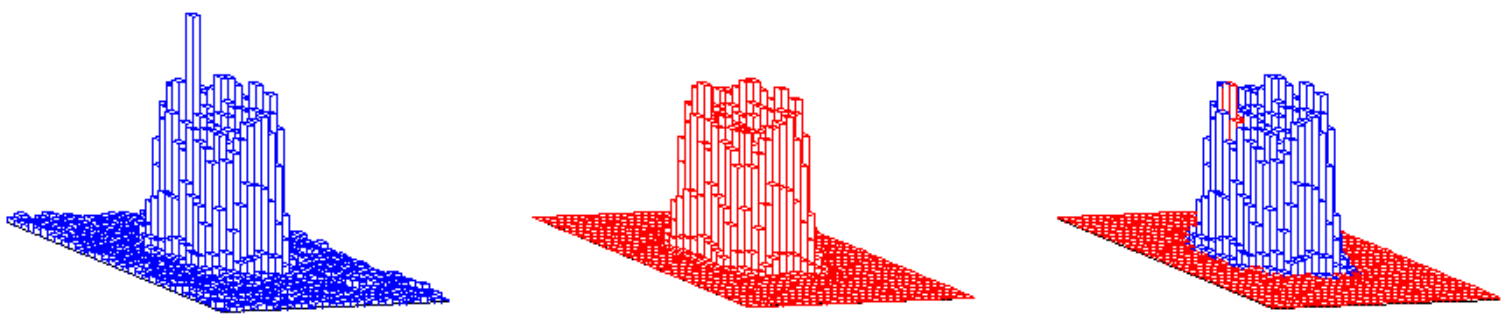

Figura 39. A fotometria híbrida leva em consideração a SNR, a incerteza estatística e os impactos por partículas carregadas. À esq.: imagem original de uma estrela capturada (simulada) pelo CoRoT. Ao centro: PSF empírica relativa a esta estrela. À dir.: imagem composta (híbrida) a partir da qual é extraída a curva de luz.

No detalhe abaixo, identifica-se cada componente da imagem híbrida

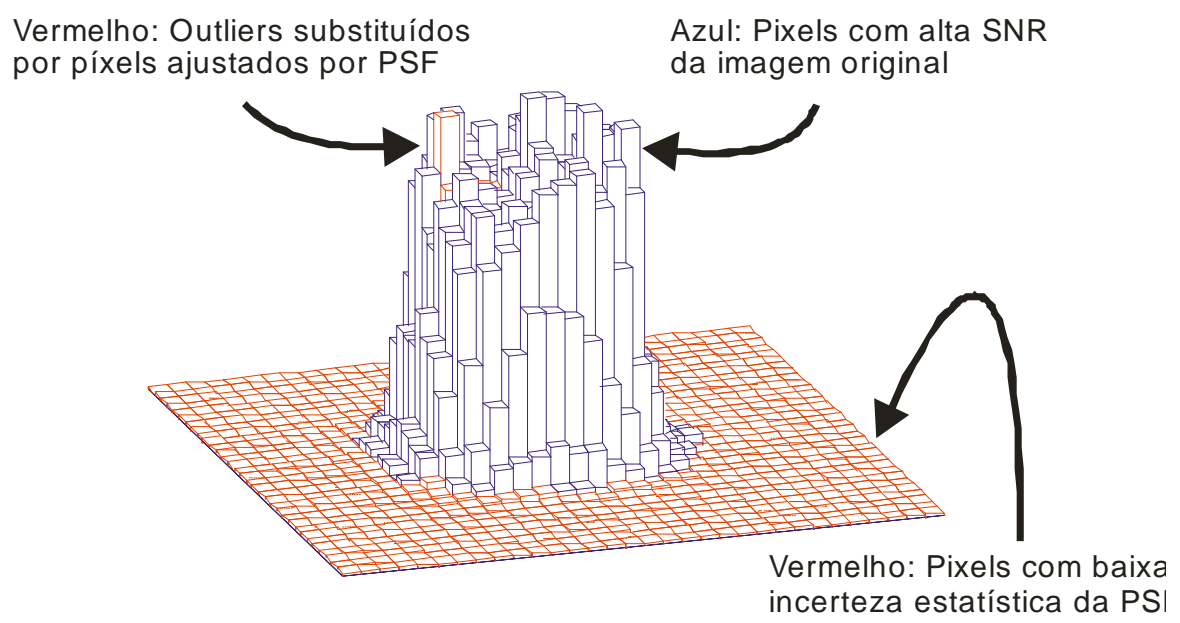

Figura 40. O algoritmo compõe uma seqüência de imagens híbridas, seqHYB, contendo os píxels de alto SNR (azul), baixa incerteza estatística e sem impactos (vermelhos), da qual posteriormente extrairá a curva de luz. 
A figura que se segue ilustra esta etapa do algoritmo desenvolvido.
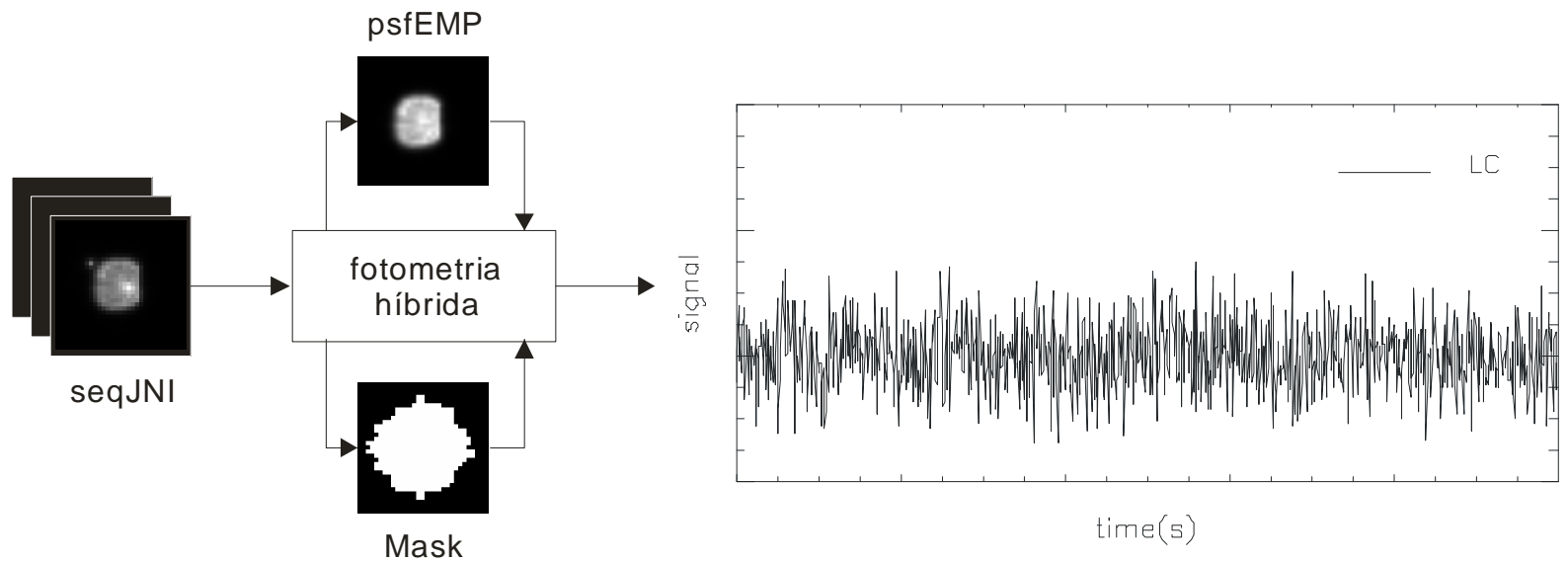

Figura 41. Redução de dados por fotometria híbrida. A partir das imagens simuladas, extrai-se a curva de luz, unindo-se a precisão da abertura para imagens com alta SNR e a robustez do ajuste de PSF par imagens degradadas.

O resultado desta função é uma curva de luz, chamada hybLC, extraída de uma seqüência de imagens capturadas, através da fotometria híbrida.

Os resultados são apresentados e discutidos na seção que se segue. 


\section{RESULTADOS}

Neste capítulo são apresentados os resultados obtidos com cada metodologia estudada (fotometria por abertura, por ajuste de PSF e híbrida), que guiarão as discussões e conclusões das seções seguintes.

\subsection{RESULTADOS DAS SIMULAÇÕES COMPUTACIONAIS}

Para a avaliação do algoritmo híbrido desenvolvido, foram simuladas seqüências de imagens capturadas a partir de um modelo de PSF originado com o software Zemax (Seção 8). Seguindo-se a metodologia descrita na Seção 10, foi gerada uma PSF empírica de alta resolução, a partir da qual se definiu uma máscara ótima. A figura que se segue ilustra estas etapas.
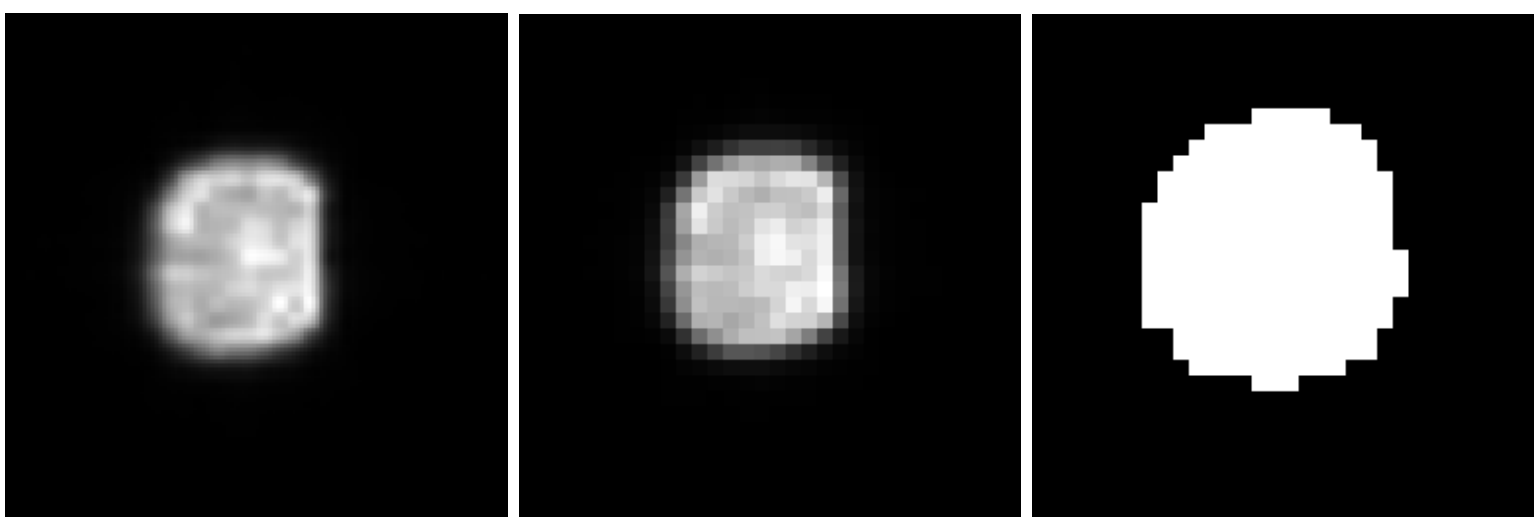

Figura 42. Definição da máscara de abertura ótima: a PSF empírica (esq.) de alta resolução (1/4 de píxel) é reamostrada (centro) para aplicação do algoritmo de extração da máscara ótima (dir.).

O algoritmo de extração da máscara ótima indica quais píxels devem fazer parte da máscara, e quais devem ser deixados de fora dela (ver Seção 10.2.2). Os gráficos abaixo ilustram como o algoritmo opera, ao selecionar os píxels que maximizam a SNR da PSF empírica. 

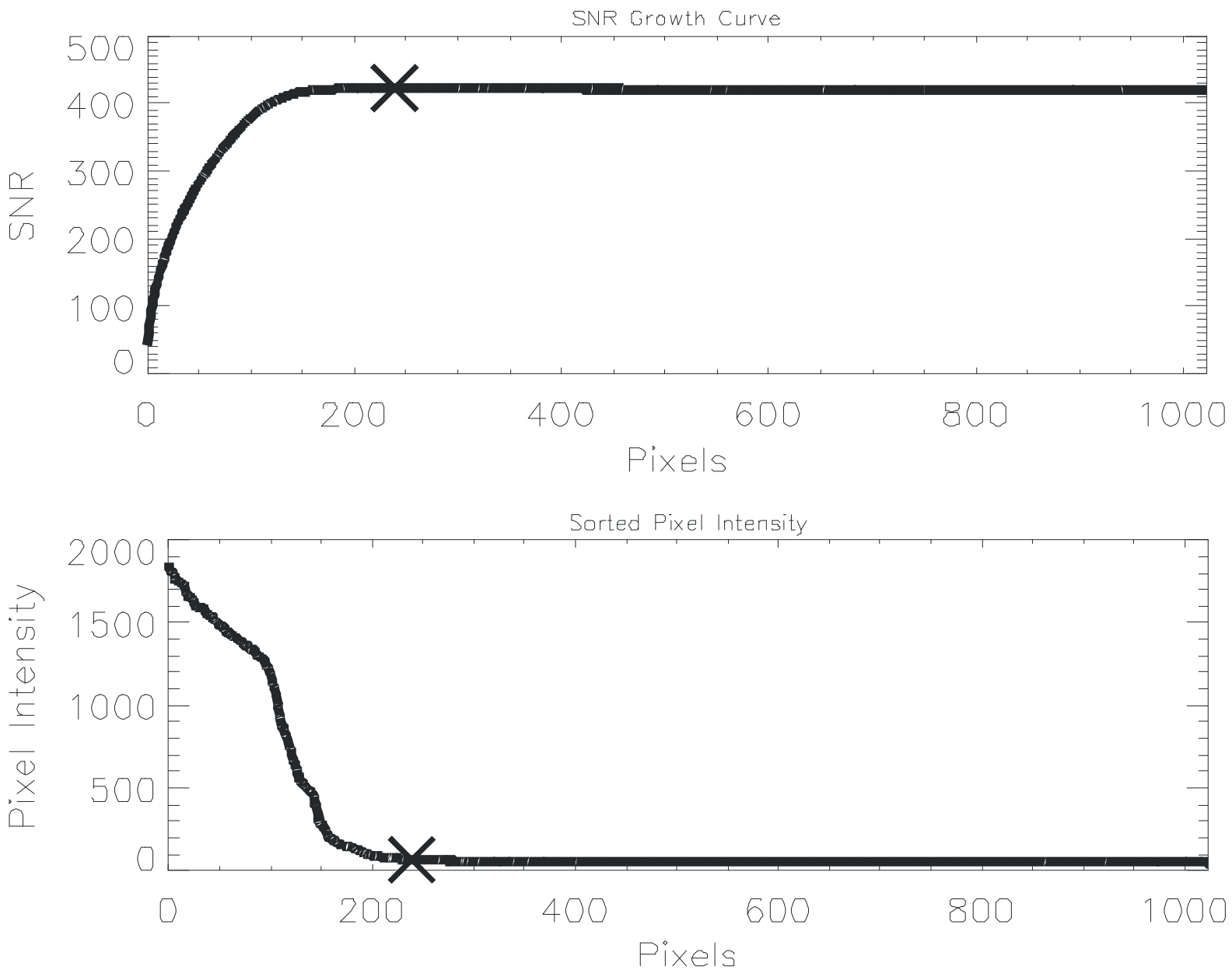

Figura 43. Topo: Curva de crescimento de SNR em função dos píxels incluídos na máscara. Em baixo: Ordem decrescente de intensidade (ADU) de luz em cada pixel da imagem capturada pelo CCD. Neste exemplo, são incluídos na máscara os 239 píxels com maior intensidade luminosa.

Uma vez definidas a PSF empírica e a máscara ótima (ver Figura 42), pode-se proceder à execução de cada técnica de fotometria estudada: por abertura, por ajuste de PSF e por fotometria híbrida, seguindo os passos descritos na Seção 10. As figuras que se seguem ilustram a aplicação das mesmas para dois casos distintos: o primeiro simula somente efeitos na curva de luz provenientes do instrumento (jitter de atitude do satélite, ruídos de Poisson e de leitura, e impactos de partículas carregadas eletricamente na zona da SAA). O segundo simula também o efeito da fonte de luz (estrela-alvo) na fotometria, ou seja, o objeto de estudo científico da Missão. As figuras a seguir ilustram os resultados. 

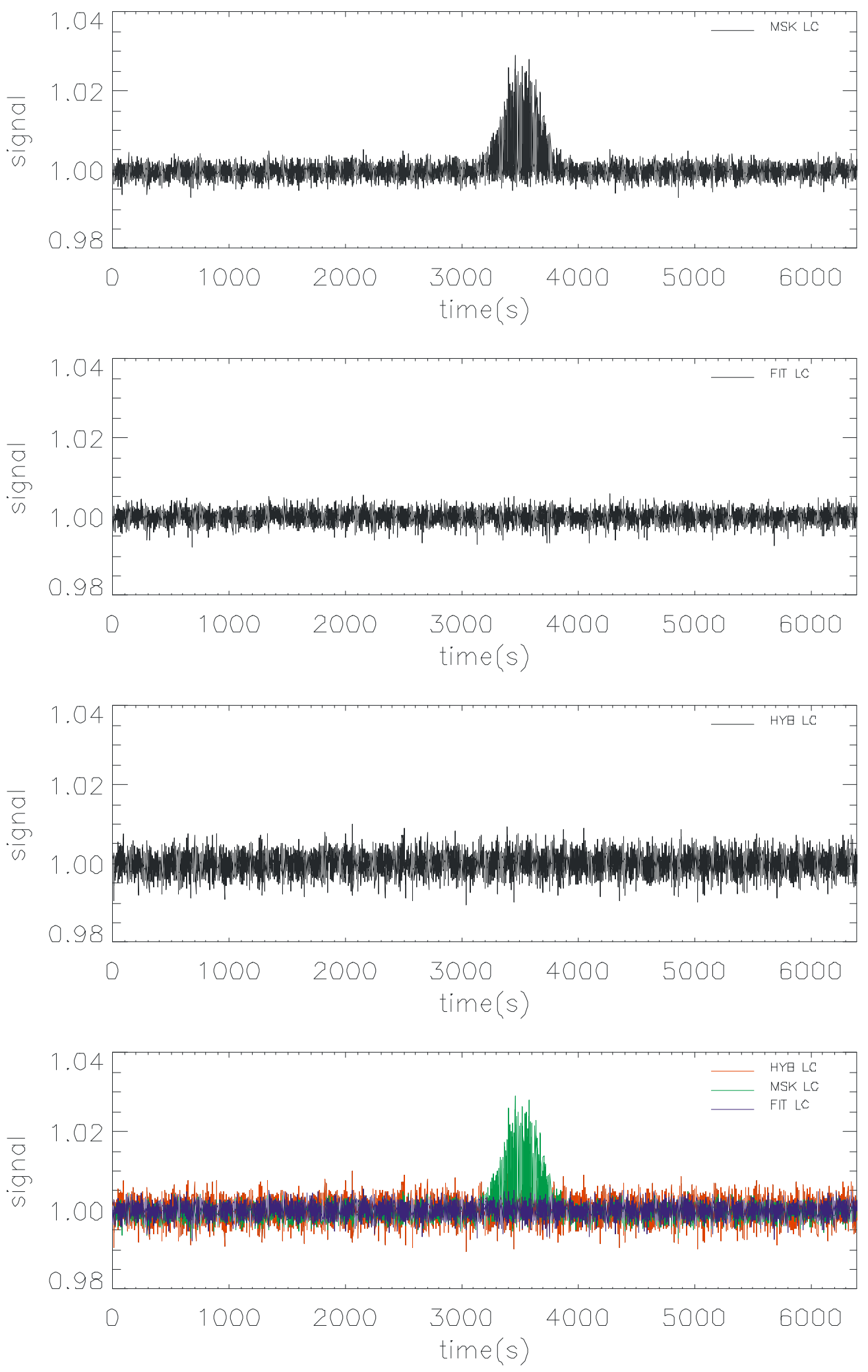

Figura 44. Simulação de uma fonte de luz pontual "estática", onde predominam efeitos de jitter de atitude, ruídos de Poisson e de leitura e impactos na zona da SAA. De cima para baixo: curvas de luz extraídas por fotometria por abertura, por ajuste de PSF e pelo algoritmo híbrido. O último painel mostra a comparação visual entre os métodos. 
llustra-se no primeiro painel da Figura 44 o resultado da fotometria por abertura. $\mathrm{O}$ sinal fotométrico é ruidoso devido aos efeitos instrumentais acima mencionados. Nota-se ainda que a técnica não é capaz de excluir píxels espúrios ocasionados por impactos de partículas carregadas quando estas atingem o CCD dentro da região definida pela máscara ótima.

O segundo painel ilustra a curva de luz extraída através do método de ajuste de PSF. Nota-se que o ruído do sinal fotométrico é visivelmente menor. Isso se deve a uma suavização do mesmo inerente à técnica que, ao ajustar um modelo de PSF a todas as imagens capturadas, acaba por atenuar eventuais discrepâncias individuais nos valores da imagem original (Seção 8.4). Observa-se também que os píxels espúrios são completamente removidos.

Pode-se observar o mesmo efeito no algoritmo híbrido, ilustrado no terceiro painel. Nota-se a ausência de píxels espúrios, e um tênue aumento no desvio padrão do sinal em relação ao sinal fotométrico obtido pelo ajuste de PSF. A tabela abaixo relaciona os desvios padrão para cada caso, no exemplo ilustrado.

Tabela 2. Comparação Estatística entre os três métodos de fotometria. $\boldsymbol{N}^{\star}$ é o fluxo luminoso normalizado, capturado da estrela em uma unidade de tempo, com desvios padrão "fora" e "dentro" da SAA, $\boldsymbol{\sigma}\left(\boldsymbol{N}^{*}\right)$ e $\boldsymbol{\sigma}\left(\boldsymbol{N}^{\star}\right)_{S A A}$, respectivamente. $\boldsymbol{\sigma}_{0}$ é o desvio padrão médio fora da SAA para fotometria, $1.603 \times 10^{-3}$.

\begin{tabular}{cccc} 
Método & Média $\left(N^{*}\right)$ & $\sigma\left(N^{*}\right) / \sigma_{0}$ & $\sigma\left(N^{*}\right)_{S A A} / \sigma_{0}$ \\
\hline \hline Abertura & 1.0 & 1.000 & 3.457 \\
PSF-Fitting & 1.0 & 1.027 & 1.061 \\
Híbrido & 1.0 & 1.654 & 1.750
\end{tabular}

Nota-se que o desvio padrão das fotometrias por abertura e por ajuste de PSF são similares quando se considera uma seqüência de imagens sem efeitos de impactos. No entanto, quando o satélite cruza a zona da SAA, os fluxos que deveriam se manter "estáveis" são perturbados pelos impactos de prótons. Neste caso, a fotometria por abertura apresenta o maior aumento no desvio padrão $\left(\sigma\left(N^{*}\right)_{S A A}\right.$ $>3 . \sigma\left(N^{*}\right)$ ) entre as metodologias utilizadas, enquanto que os algoritmos de ajuste de PSF e híbrido se mantém praticamente constantes. Finalmente, o quarto painel da Figura 44 compara visualmente as curvas de luz obtidas com cada uma das técnicas estudadas.

A seqüência de painéis abaixo, por sua vez, apresenta dados simulados de uma estrela-alvo com atividade fotométrica detectável, seja no campo Exoplanetas, ou no 
campo Astrossismologia. A curva de luz apresenta, neste exemplo, uma característica puramente senoidal, que sofre perturbações devido ao jitter de atitude, a ruídos de leitura e de Poisson e a impactos na zona SAA. A mesma análise estatística realizada anteriormente é válida neste caso.
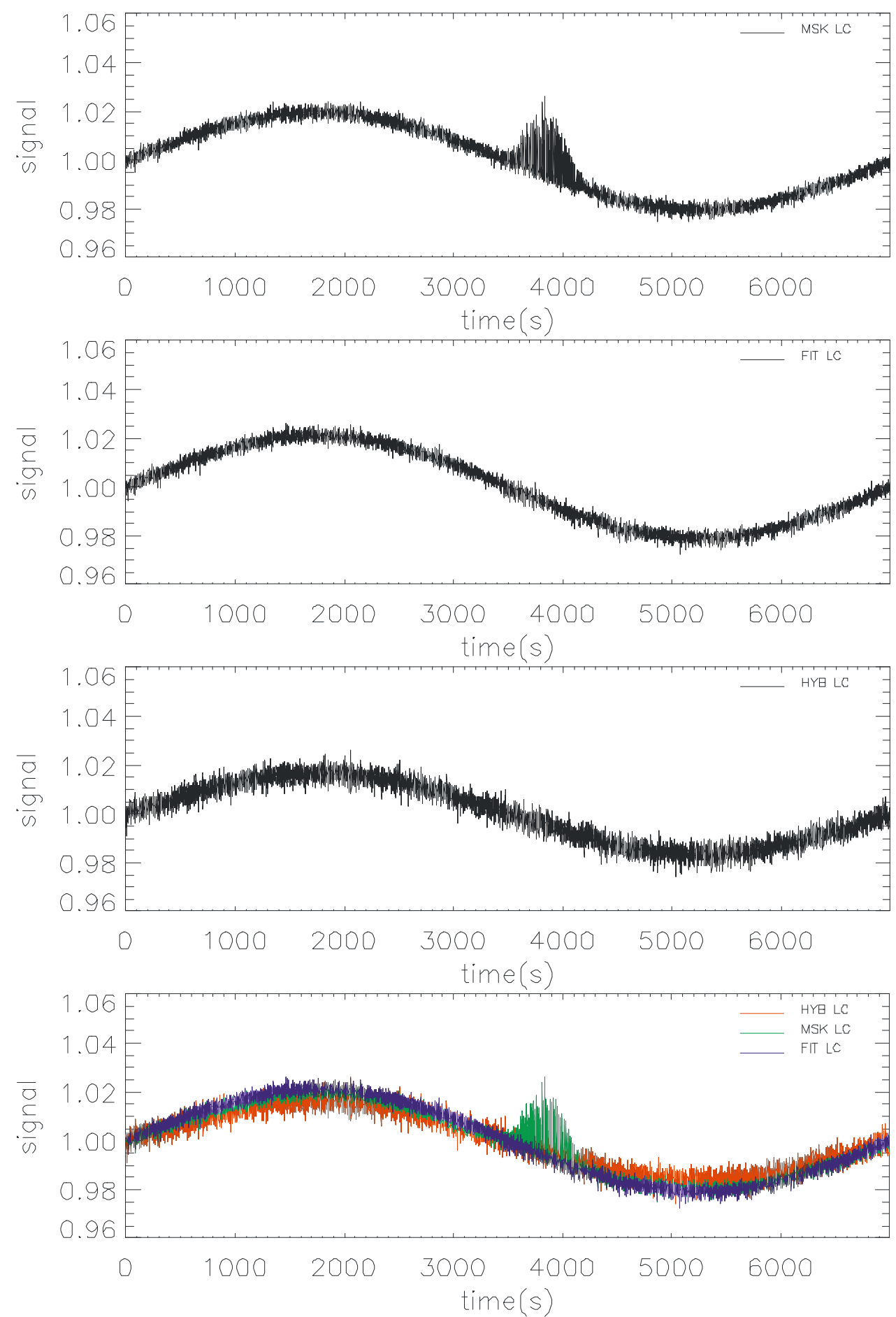

Figura 45. Simulação de uma estrela-alvo com atividade fotométrica, em que efeitos de jitter de atitude, ruídos de Poisson e de leitura e impactos na zona da SAA podem comprometer a qualidade da análise científica dos dados. De cima para baixo: curvas de luz extraídas por fotometria por abertura, por ajuste de PSF e pelo algoritmo híbrido. O último painel mostra a comparação visual entre os métodos. 


\section{DISCUSSÃO}

Em uma ambiente orbital de baixa altitude, todo equipamento espacial está sujeito a efeitos da Anomalia Magnética do Atlântico Sul. No caso do satélite CoRoT, tanto o uso de componentes eletrônicos blindados, quanto o emprego de algoritmos fotométricos eficazes são necessários e fundamentais para se obter uma exploração robusta e precisa dos dados coletados.

A fotometria por abertura realizada a bordo do satélite é recomendada em cenários onde o controle de atitude seja altamente eficiente e o ambiente orbital seja "livre" de impactos de partículas ionizadas. Tal algoritmo não é computacionalmente complexo, e apresenta bom desempenho fotométrico na maior parte do tempo (duty cycle operacional de aproximadamente 93\% [32]).

A fotometria por ajuste de PSFs apresenta melhor desempenho na presença de jitter de atitude, radiação luminosa dispersa proveniente da atmosfera terrestre, e para estrelas-alvo tênues. Seu custo computacional é maior, o que impede seu uso a bordo do satélite, sendo por isso realizada no segmento solo da Missão. Com isso, aumenta-se a quantidade de imagens aproveitáveis para análise, o que proporciona ganho no ciclo de trabalho operacional aumenta em aproximadamente $3 \%$ [32].

O algoritmo híbrido combina os benefícios de ambas as técnicas anteriores, associando a vantagem de uma PSF instrumental de alta resolução à alta SNR obtida pela técnica de fotometria por abertura realizada a bordo.

As simulações computacionais desenvolvidas e apresentadas nas Seções 10 e 11 (Metodologia e Resultados) demonstraram que é possível aumentar aproveitamento de imagens degradadas capturadas durante a passagem do satélite pela zona de alta probabilidade de impactos de partículas carregadas (SAA). Com isso, o ciclo de trabalho útil do telescópio CoRoT também aumenta em aproximadamente $3 \% \mathrm{em}$ relação à técnica por abertura, levando-o ao um patamar similar de $97 \%$. A complexidade computacional do algoritmo híbrido é similar à da técnica por ajuste de PSF, e por isso sua aplicação é também limitada ao segmento solo da Missão. 
A pesquisa aqui apresentada mostra que apesar de um incremento significante no ciclo operacional do telescópio não ser alcançado (em comparação com a fotometria por ajuste de PSF), as curvas de luz extraídas com o algoritmo híbrido apresentam, para as imagens impactadas na zona SAA, um desvio padrão menor que o da técnica de fotometria por abertura, como conseqüência do uso de píxels com alta SNR individual e píxels de baixa incerteza estatística das "asas" da PSF empírica obtida para cada estrela. Além disso, valores espúrios ocasionados pela radiação da SAA são substituídos por valores esperados empiricamente da própria PSF, eliminando também os píxels impactados que agregariam ruído à curva de luz e permitindo ganhos na precisão fotométrica.

Com relação ao algoritmo de fotometria por ajuste de PSF, o algoritmo híbrido apresenta maior desvio padrão ao longo de toda a órbita, mas isso se deve ao fato de 0 ajuste de PSF se utilizar de suavizações em seu processo, enquanto que 0 algoritmo híbrido tende a manter a grande maioria dos píxels originalmente capturados.

\subsection{TRABALHOS FUTUROS}

Através do algoritmo híbrido de fotometria estelar a partir de imagens do espaço desenvolvido neste trabalho, viabiliza-se o uso de imagens capturadas durante a passagem do satélite pela região SAA. Com isso, o sinal fotométrico - ou curva de luz - proveniente de uma dada estrela passa a ser complementado com esta informação, o que aumenta o ciclo de trabalho do sistema para aproximadamente $97 \%$. Desta forma, um trabalho importante referente ao controle de atitude do satélite deve ser realizado: o desenvolvimento de um algoritmo mais preciso de apontamento do satélite.

Atualmente, a estabilidade do CoRoT é dada pelo sistema de controle de atitude (Attitude Control System - ACS) da plataforma PROTEUS, cujo desempenho (estabilidade de 16 arcsec rms ) é melhorado em 100 vezes com o uso do próprio 
telescópio para guiar o apontamento do satélite [32]. $O$ atual algoritmo de estabilidade do satélite calcula o erro de apontamento através da posição de duas estrelas brilhantes em um CCD do campo Astrossismologia. Para obter uma maior precisão no baricentro destas estrelas, realiza-se inicialmente a subtração dos valores de fundo de céu e offset medidos para estas estrelas. Então, selecionam-se os píxels com valores acima de um dado limiar (tipicamente 400 ADU) para o cálculo do baricentro destas estrelas. Nota-se que se trata de um simples algoritmo de threshold que auxilia o ACS da PROTEUS no controle de atitude do satélite.

Este algoritmo, no entanto, é obviamente sensível ao impacto de partículas ionizadas durante a passagem do CoRoT pela zona de SAA. Este problema, até o momento, não é levado em conta para a redução de dados fotométricos do satélite, pois a própria redução sofre o efeito dos impactos de prótons durante o cruzamento da SAA, e as informações coletadas (imagens e curva de luz resultante) neste período são descartadas, independente da precisão do apontamento do satélite neste intervalo.

Com o algoritmo híbrido de fotometria estelar desenvolvido neste projeto, estas informações poderão ser utilizadas, aumentando-se o ciclo de trabalho do satélite, mas para isso é necessário uma evolução do algoritmo de controle de apontamento do mesmo. Seria interessante, como trabalho complementar, poder estudar o desempenho do ACS durante a passagem do satélite pela SAA usando-se esta melhoria no controle de atitude, e o seu efeito nas curvas de luz obtidas pelo telescópio.

Sugere-se, além da melhoria acima citada, a complementação do trabalho aqui desenvolvido, estendendo-se sua aplicação ao campo Exoplanetas e discutindo-se sua validade para esses dados. 


\section{CONCLUSÃO}

O Projeto aqui exposto foi desenvolvido atendendo os objetivos iniciais em sua totalidade: o estudo aprofundado das variáveis que regem a aquisição de imagens do satélite CoRoT, bem como das metodologias mais praticadas de redução de dados proporcionaram a conseqüente proposição de um algoritmo híbrido de fotometria estelar.

O algoritmo proposto procurou unir as principais vantagens dos métodos já consolidados de fotometria estelar por abertura fixa e por ajuste de PSF, aliando a alta relação sinal/ruído da primeira técnica à robustez da PSF empírica perante imagens degradadas proporcionada pela segunda técnica de redução de dados. Desta forma, viabiliza-se uma melhor exploração dos dados disponibilizados pelo satélite, principalmente no tocante aos dados degradados enviados durante as passagens do mesmo pela região da SAA, onde a freqüência de impactos de partículas ionizantes impede, atualmente, o aproveitamento científico destes dados.

As simulações comparativas desenvolvidas e apresentadas mostraram que é possível levar o ciclo de trabalho útil do telescópio CoRoT a um patamar de aproximadamente $97 \%$.

Deve-se ressaltar no entanto, que a pesquisa não se esgota no Projeto aqui apresentado, e tanto a extensão de sua aplicação ao campo de Exoplanetas, quanto um algoritmo melhorado de controle de atitude do satélite são linhas de pesquisa que poderão complementar o estudo aqui desenvolvido.

Os resultados desta pesquisa foram apresentados no I CoRoT International Symposium [33].

O satélite CoRoT foi lançada ao espaço em 27 de dezembro de 2006, e teve recentemente sua vida útil estendida de 2,5 anos para 6,5 anos, o que permitirá a aplicação da técnica aqui proposta aos dados ainda a serem capturados e processados pela Missão. 


\section{REFERÊNCIAS}

[1] WOLSZCZAN, A. Confirmation of Earth mass planets orbiting the millisecond Pulsar PSR-B125. Science, 264, p. 538, 2006.

[2] MAYOR, M., QUELOZ, D. A Jupiter-mass companion to a solar-type star, Nature, 378, p. 355, 1995.

[3] FIALHO, F. ET AL. Jitter Correction Algorithms for the CoRoT Satellite Mission: Validation with Test-Bench Data and MOST On-Orbit Photometry. PASP, vol. 119, pp. 337-346, 2006.

[4] DOLEZ, N., ET AL. HD 51106 and HD 50747: an ellipsoidal binary and a triple system observed with CoRoT. A\&A, vol. 506, pp. 159-165, 2009.

[5] CoRoT. In http://en.wikipedia.org/wiki/, acessado em janeiro de 2010.

[6] MICHEL, ERIC. ET AL. CoRoT measures solar-like oscillations and granulation in stars hotter than the Sun. Science, vol 322, issue 5901, pp. 558560, 2008.

[7] APPOURCHAUX, T ET AL. On posterior probability and significance level : application to the power spectrum of HD 49933 observed by CoRoT. A\&A, vol 506, pp. 1-5, 2009.

[8] DEGROOTE, P. ET AL. Evidence for nonlinear resonant mode coupling in the Beta Cephei star HD 180642 (V1449 Aquilae) from CoRoT photometry. A\&A, vol 506, pp. 111-123, 2009.

[9] DUPRET, M.A., ET AL. Theoretical amplitudes and lifetimes of non-radial solar-like oscillations in red giants. A\&A, vol. 506, pp. 57-67, 2009.

[10] LAPEYRERE V. Étalonnage des Détecteurs de CoRot, PhD Thesis, Université de Paris VI, France, 151p., 2006.

[11] PINHEIRO DA SILVA. L. Caractérisation Instrumentale appliquée à la Photométrie de Très Haute Précision dans le cadre de la Mission Spatiale CoRoT, PhD Thesis, Université de Toulouse III, France, 123p., 2006. 
[12] JAMES, B. F. et al. The Natural Space Environment: Effects on Spacecraft, NASA RP-1350, NASA. Marshall Space Flight Center, AL 35812, 1994.

[13] BOISNARD, L., AUVERGNE, M. CoRoT Mission Engineering: CostEffective Solutions for Stellar Photometry in Low Earth Orbit, 55th Congress of the International Astronautical Federation (IAF), IAC-04-IAF-Q.1.01, 2004.

[14] GRUNEISEN, R. Calibration des CCDs CoRoT: Adaptation aux besoins scientifiques de la mission, PhD Thesis, Université de Paris VI, France, 2006.

[15] LAPEYRERE V. et al. Calibration of flight model CCDs for CoRoT mission, Monthly Notices of the Royal Astronomy Society (MNRAS), vol. 365, pp. 1171-1179, 2006.

[16] JANESICK, J. Scientific Charge Coupled Devices, SPIE Press, Bellingham, 2006.

[17] KJELDSEN, H., FRANDSEN, S. High-Precision Time-Resolved CCD Photometry. Publications of the Astronomical Society of the Pacific PASP, vol. 104, pp. 413-434, 1992.

[18] Adda, M. Photométrie CCD de très haute précision dans l'espace. Application au programme de sismologie COROT, Thèse : Université de Paris VI; 2000.

[19] HOWELL, S.B. Two-dimensional aperture photometry: signal-to-noise ratio of poiont-source observations and optimal data-extraction techniques. PASP, vol. 101, pp.616-622, 1989.

[20] BEN-EZRA, M., NAYAR, S. K. Motion-Based Motion Deblurring, IEEE Transactions on Pattern Analysis and Machine Intelligence, vol. 26, pp. 689-698, 2004.

[21] PARK, S. C., PARK, M., KANG, M. Super-resolution image reconstruction: A technical overview, IEEE Signal Processing Magazine, pp. 21-35, 2003.

[22] ELAD, M., FEUER, A. Restoration of a Single Superresolution Image from Several Blurred, Noisy, and Undersampled Measured Images, IEEE Trans. on Image Processing, vol. 6, pp. 1646-58, 1997. 
[23] BERTERO \& BOCACCI. Introduction to Inverse Problems in Imaging, Insitute of Physics Publishing, 1998.

[24] PINHEIRO DA SILVA. L. et al. Estimation of a super-resolved PSF for the data reduction of undersampled stellar observations, Astronomy \& Astrophysics, vol. 452, pp. 363-369, 2006.

[25] PINHEIRO DA SILVA, L. PSF reconstruction for fitting photometry with CoRoT, Proceedings of the CoRoT-Brazil Workshop (abstract), Ubatuba, Brazil, 2005.

[26] KJELDSEN, H., FRANDSEN, S. High-Precision Time-Resolved CCD Photometry, PASP, vol. 104, pp. 413-434, 1992.

[27] MIGHELL, K. J. Algorithms for CCD Stellar Photometry, Astronomical Data Analysis Software and Systems VIII, ASP Conference Series, vol. 172, 1999.

[28] MIGHELL, K. J. Parameter Estimation in Astronomy with Poissondistributed Data - The Chi-Square Gamma Statistic, Astrophysical Journal, vol. 518, pp. 380-393, 1999.

[29] WALKER, G., MATTHEWS, J., KUSCHNIG, R., et al., The MOST Astroseismology Mission: Ultraprecise Photometry from Space, Publications of the Astronomical Society of the Pacific (PASP), vol. 115, 2003.

[30] GUMLEY, L. Practical IDL Programming, Morgan Kaufmann, $1^{\text {st }}$ Ed, 2001.

[31] CoRoT N2 Public Archive, http://idc-corotn2-public.ias.u-psud.fr/ , acessado em janeiro de 2010.

[32] AUVERGNE, M. ET AL. The CoRoT satellite in flight: description and performance. A\&A, vol. 506, pp. 411-424, 2009.

[33] I CoRoT International Symposium, 02 a 05/fev/2009, Paris, França, http://www.symposiumcorot2009.fr, acessado em janeiro de 2010. 


\section{APÊNDICE A}

Os algoritmos desenvolvidos e utilizados neste Projeto, bem como a versão eletrônica deste Trabalho estão disponibilizados em um CD-ROM anexado aos volumes desta dissertação presentes na Biblioteca da Escola Politécnica da Universidade de São Paulo. 


\section{APÊNDICE B}

1. Apresentação de Pôster em Congresso Internacional: "1st CoRoT International Symposium", de 02/02/2009 a 05/02/2009, abaixo reproduzido.

2. Artigo a ser submetido para aceitação no XXIX Simpósio Brasileiro de Telecomunicações (SBrT'11), de 05/10/2011 a 08/10/2011, abaixo reproduzido. 